\title{
MAPPING NEFARIOUS SOCIAL MEDIA ACTORS TO SPEED-UP COVID-19 FACT-CHECKING
}

\section{- FULL REPORT -}

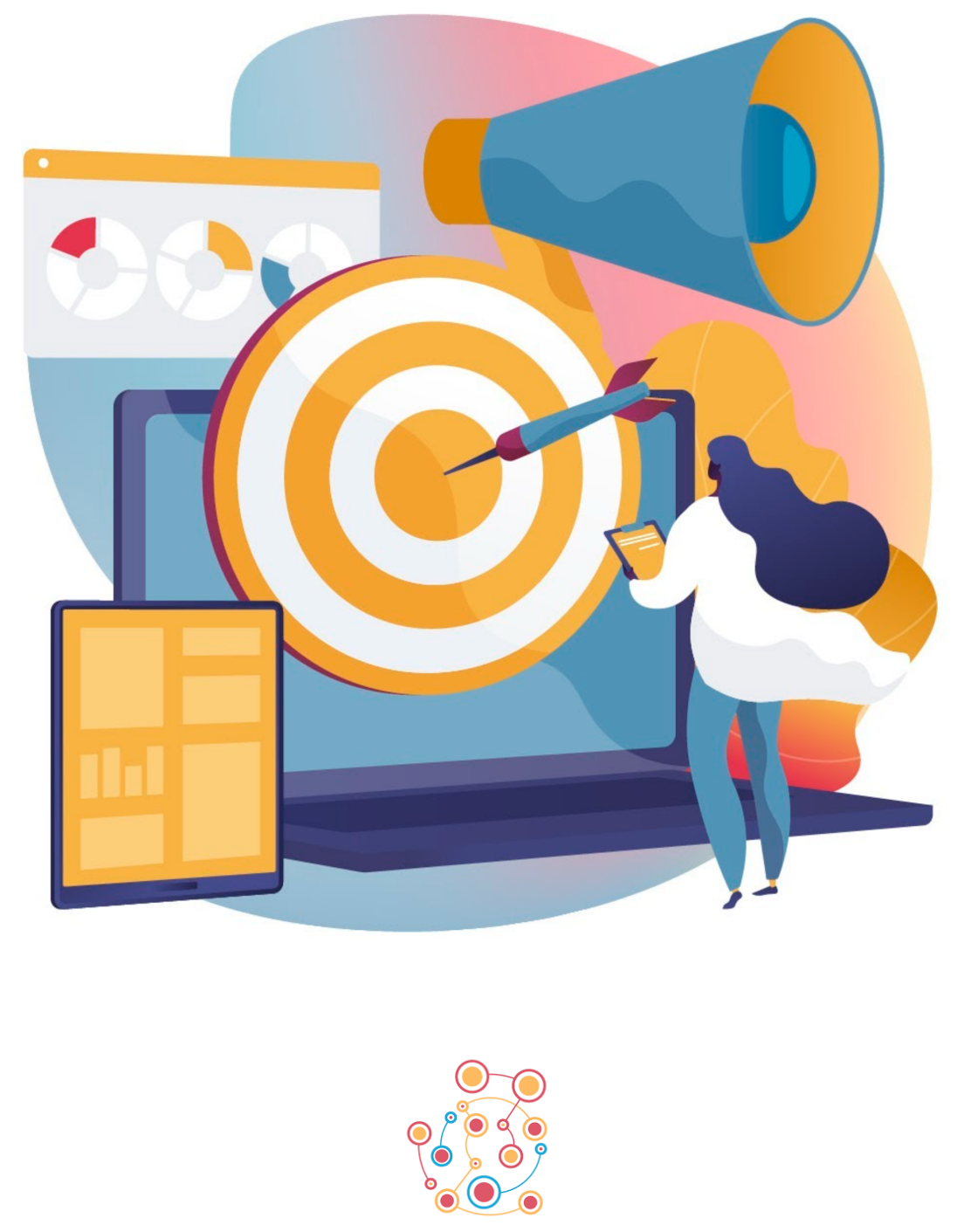

Mapping Italian News Research Program LaRiCA - University of Urbino Carlo Bo January 10, 2022 


\title{
Acknowledgment
}

The study was supported by a grant issued by the Italian Ministry of Education and Research (MUR), FONDO INTEGRATIVO SPECIALE PER LA RICERCA (FISR) DECRETO DIRETTORIALE N. 562 DEL 05/05/2020 "Progetti di ricerca di particolare rilevanza strategica, finalizzati ad affrontare le nuove esigenze e questioni sollevate dalla diffusione del virus SARS-Cov-2 e dell'infezione Covid-19". Project code: FISR2020IP_00327e.

\section{In collaboration with}

\section{Authors}

Fabio Giglietto (University of Urbino), Manolo Farci (University of Urbino), Giada Marino (University of Sassari), Serena Mottola (University of Urbino), Tommaso Radicioni (University of Urbino), Massimo Terenzi (University of Urbino)

\author{
Università di Urbino Carlo Bo - LaRiCA - Mapping Italian News Research Program \\ Via Saffi 15 - 61029 - URBINO (PU) - ITALY \\ fabio.giglietto+mine@uniurb.it \\ Permanent link https://osf.io/preprints/socarxiv/6umqs/
}

V 1.01 updated January 10, 2022

Keywords: covid-19, fact-checking, coordinated behaviour, Italy, CrowdTangle, Facebook, CooRnet

This work is licensed under the Creative Commons Attribution-ShareAlike 4.0 International License. To view a copy of this license, visit http://creativecommons.org/licenses/by-sa/4.0/ or send a letter to Creative Commons, PO Box 1866, Mountain View, CA 94042, USA. 


\section{Table of Contents}

1. Executive Summary 5

1.1. Overview of methods 5

1.2. Key takeaways 5

2. Introduction 8

3. The first wave of infodemic in Italy: what circulated most on Facebook and who contributed to spread it

3.1. Widely viewed and interacted Italian links during the first wave (February/June 2020)

3.2. The rise of the Covid-skeptic cluster 14

4. MINE-FACTS coordinated networks at macro, meso and micro level 18

4.1. Macro 18

4.2. Meso 22

4.2.1. Case \#1: The Blogs Strikes Back 23

4.2.1.1. Actors 23

4.2.1.2. Behavior $\quad 27$

4.2.1.3. Content 28

4.2.2. Case \#2: The "Amen" Awakens 31

4.2.2.1. Actors 31

4.2.2.2. Behavior 33

4.2.2.3. Content 34

4.2.3. Case \#3: Return of the "GEDI" 36

4.2.3.1. Actors 36

4.2.3.2. Behavior $\quad 40$

4.2.3.4. Content 41

4.2.4. Case \#4: Attack of the clones 43

4.2.4.1. Actors 43

4.2.4.2. Behavior 46

4.2.4.4. Content 47

4.3. Micro 51

4.3.1. Third dose 51

4.3.2. Shocking declaration of a doctor 53

4.3.3. Thrombosis due to inoculation 56

5. Design and test of the MINE-FACTS prototype 59

5.1. Design and development $\quad 59$

5.1.1. Posts 60

5.1.2. Links $\quad 60$

5.2. Outcomes of the testing phase 61 
Appendix II: Categories of the coding protocol adopted by Facta.news

Appendix III: IFCN lists of coordinated account and links shared

IFCN list

Top coordinated URLs

Appendix VI: Lists of coordinated accounts in the networks analyzed $\quad 74$

Meso Level: Case \#1 74

Meso Level: Case \#2 74

Meso Level: Case \#3 76

Meso Level: Case \#4 78

Appendix V: Most popular Italian news stories on Facebook (Feb/June 2020) 79

$\begin{array}{ll}\text { Views } & 79\end{array}$

$\begin{array}{ll}\text { Clicks } & 79\end{array}$

$\begin{array}{ll}\text { Shares } & 80\end{array}$

Shares without clicks $\quad 81$

$\begin{array}{ll}\text { Comments } & 81\end{array}$ 


\section{Executive Summary}

This report presents the outcomes of a project aimed at developing and testing a prototype tool that supports and speeds up the work of fact-checkers and debunkers by surfacing and ranking potentially problematic information circulated on social media with a content-agnostic approach.

The tool itself is the result of a multi-year research activity carried on within the Mapping Italian News Research Program of the University of Urbino Carlo Bo to study the strategies, tactics, and goals of influence operations aimed at manipulating the Italian public opinion by exploiting the vulnerabilities of the contemporary media ecosystem. This research activity led to developing original studies, public reports, new methods, maps, and tools employed to study the activity of Italian nefarious social media actors aimed at amplifying the reach and impact of problematic information by coordinating their efforts. Tracking these actors proved instrumental to observe the "infodemic" unraveling during the early days of the COVID-19 outbreak in Italy.

Combining this existing knowledge with a range of original tools and data sources provided by Meta's Facebook Open Research Initiative (Fort) and by The International Fact-Checking Network (IFCN) at Poynter, the report:

- documents those early days by highlighting a list of widely viewed and interacted links circulated on Facebook;

- traces the establishment, growth, and evolution of Italian covid-skeptic coordinated networks on Facebook;

- presents a comprehensive and updated map of the activities performed by these networks of nefarious social media actors;

- unveils a set of original tactics and strategies employed by these actors to adjust their operations to the mitigation efforts adopted by social media platforms to reduce the spread of problematic information;

- describes the circulation of three specific pieces of problematic information;

- provides an overview of the outcomes of the testing phase of the prototype tool (carried out in collaboration with Facta.news).

\subsection{Overview of methods}

While the report leverages a wide range of methods spanning from social network and qualitative content analysis to open source intelligence assisted investigations, the core approach is informed by CooRnet, a CrowdTangle based library that detects coordinated link sharing behaviour (CLSB) on Facebook/Instagram.

Given a set of links, CooRnet outputs a list of Facebook/Instagram accounts (Pages, public groups, or verified profiles) that performed CLSB on one or more of these links. For this report, we ran multiple iterations of CooRnet. A CooRnet iteration is the process of using the links posted by a set of accounts that performed CLSB to initiate a new cycle of detection.

\subsection{Key takeaways}

1. Besides pointing out several cases of high performing problematic information, the analysis of widely viewed and interacted links circulated on Facebook during the first 
wave of the COVID-19 outbreak illustrates how, in response to a context characterized by a widespread uncertainty, partisan content advancing oversimplified explanations (blaming China or advocating stricter lockdowns) outperformed more balanced views;

2. Both this list of widely circulated links and the collections of problematic information surfaced during the different stages of the analysis and by the tool we developed highlighted the role played by partisan communities and "celebrities" (Montagnier, Monsignor Viganò, Robert Kennedy, etc.). Communities of covid-skeptics systematically amplify their content creating strong incentives for these celebrities to intervene in the public debate to benefit from this form of amplification.

Unprincipled celebrities can exploit these communities creating a mutually beneficial symbiotic relationship. Furthermore, content that simply reports the views (even when blatantly false) of these celebrities tend to be rated as true by fact-checkers insofar the sentence was pronounced by the individual at stake;

3. Our maps all point out various forms of contiguity (link co-sharing) between a core covid-skeptic cluster and clusters of official and unofficial accounts affiliated to the League and Five Stars Movement political parties. The covid-skeptic cluster grew up during the first months of 2020 as an offshoot of the giant political component of coordinated accounts;

4. At the periphery of the covid-skeptic cluster, large public groups such as "MOVIMENTO DEI DISOCCUPATI E DEI PRECARI - LAVORO DI CITTADINANZA", "VENETI : IERI - OGGI - DOMANI ( by B. Dilan )" or "La Cruna dell'Ago" act as a bridge between the core of covid skepticism and other communities;

5. Besides political communities, this is the case for a coordinated network of public groups eminently devoted to circulating religious content (case \#2 in paragraph 4.2.2). Large and unaware audiences may be exposed to covid-skeptic ideas through the rapid and repeated co-sharing activity performed by certain users;

6. Also linked to "La Cruna dell'Ago" is one network that performed particularly well during the test phase of the tool in November 2021 employed coordinated link sharing behavior to drive traffic off-platform to a network of conspiracy theories driven blogs hosted on the Google-owned blogging platform Blogger (case \#1 paragraph 4.2.1). These blogs, all sharing the same basic layout, host Google Ads calling into question the role played by Google in monetizing and providing revenues to creators that spread questionable content;

7. Another network that frequently emerged during our test phase for the good performances of their posts drives traffic to an online magazine of questionable reputation (NewsGuard mentioned this website in a list of top 2021 disinformation influencers in their end-of-the-year report) called Mag24 (case \#4 in paragraph 4.4.1). While it is not the only coordinated network we observed using this technique, Mag24 coordinated Pages uses the first comment under a post to host the link. The double benefit is that the post itself can't be automatically recognized as a post with a link and comments are rarely fact-checked. This network has a long and paradigmatic history that we dissect and reconstruct to show how certain operations can resist platforms' enforcement efforts by adjusting their strategies and shifting their shape; 
8. And speaking of shape-shifting, our tool also surfaced a large coordinated network of Pages (mostly well-known for having spread disinformation in the past) that currently all share, at about the same time, click-bait image-macros pointing to news articles published by reputable outlets all belonging to the same publisher (case \#3 in paragraph 4.3.1). While gaining little traction in terms of interactions, this is either a way for the publisher (or its advertising agency) to attempt to increase the circulation of their content or a deliberate attempt by these Pages to clean their Facebook "criminal records" by posting links to reputable sources for a certain period;

9. False, misleading, and out-of-context information tends to be recirculated at the right time. While not new, this strategy is confirmed by our analysis of the circulation of two cases of information surfaced by our tool and rated as problematic by Facta.news during our test month;

10. During the one-month testing phase of the prototype (November 2021), the tool surfaced 70 links and 360 potentially problematic pieces of information circulated on social media by the monitored nefarious actors;

11. Comparing the share of news rated as true (72\%) by Pagella Politica and Facta.news in their role as Facebook's third-party fact-checkers, our tool surfaced a significantly higher share of problematic information ( $40 \%$ of links and posts deemed as true);

12. According to our analysis, the distribution of a metric that takes into account the ratio between comments and shares gathered by a post or link (as the aggregation of interactions gathered by posts pointing to such a link) turned out to be significantly different for problematic and non-problematic information. The latter appears to be characterized by a number of social media shares that vastly outnumber those of comments. 


\section{Introduction}

In their classic essay "An Analysis of Rumor", Gordon Allport and Leo Postman postulated their basic law of rumor (1946). The law, expressed as a mathematical formula, states that "the amount of rumor in circulation will vary with the importance of the subject to the individuals concerned times the ambiguity of the evidence pertaining to the topic at issue" (1946, p. 502).

The COVID-19 outbreaks, across the different waves and especially during its first phases, maximized both these metrics. The perceived importance of the topic (measured by the unprecedented saturation of the media agendas Fig. 1), its level of ambiguity (e.g. the origin of contagion, ...), and the lack of compelling scientific evidence (e.g. brand new unknown virus, no vaccine or effective drugs, ...) led the novel coronavirus to forge ideal conditions for the information overload and the perfect mis/disinformation storm that the WHO referred to as the infodemic (Zarocostas, 2020).

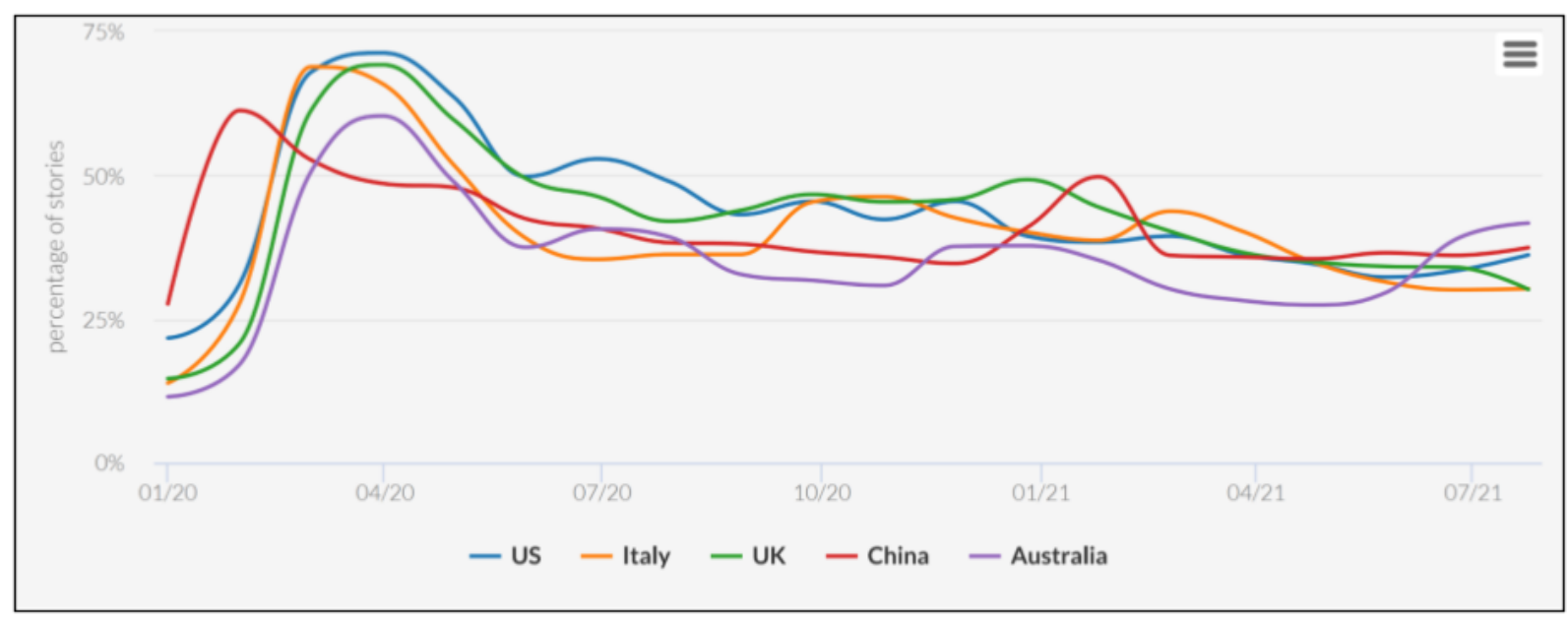

Figure 1: Media Attention to COVID-19 Over Time (data source: Media Cloud)

But beyond the information scarcity and its corresponding attempts to feel the void (Golebiewski \& Boyd, 2018) that exists in any acute crisis, the circulation of rumor, misinformation, and disinformation about COVID-19 is also directly affected by the activities of problematic actors and networks that exploit legitimate anxieties and existing uncertainties for political, commercial, or personal gain (European Commission, 2020). As the Allport-Postman law postulates, increased interest in an ambiguous topic multiplies the amount of rumor in circulation (1946). We thus expected a corresponding increase in the amount of activities by these nefarious actors during such times.

The research design of the present work turns the worrying peculiarities of the coronavirus news cycles into a unique opportunity to study the behavior of these malicious actors. The leading research questions aim to elucidate different types of problematic actors, their interactions, and strategies. In doing so, we will provide a tool that surfaces problematic information that is gaining traction to fact-checkers, investigative journalists, and researchers. 
Building on the rapidly growing literature that increasingly points out the challenges of detecting false news and/or bad actors (e.g. bots) (Cresci, 2020), this project relies on an innovative content-agnostic detection method and leverages the peculiarities of the coronavirus news cycle to identify, map and track actors and networks of actors that spread problematic information in Italy. The main aim is to provide a content-agnostic tool to support and speed-up the work of fact-checkers and debunkers by surfacing and ranking problematic content and narratives in real-time.

In order to do so, we leveraged our previous work on "Coordinated Link Sharing Behavior" (CLSB). CLSB is a strategy for boosting the reach and distribution of links by using coordinated activities performed by Facebook Pages, groups, and verified public profiles (Facebook public entities/accounts ${ }^{1}$ ) that repeatedly share the same news articles in a very short period of time from each other (Giglietto, Righetti, Rossi, et al., 2020a).
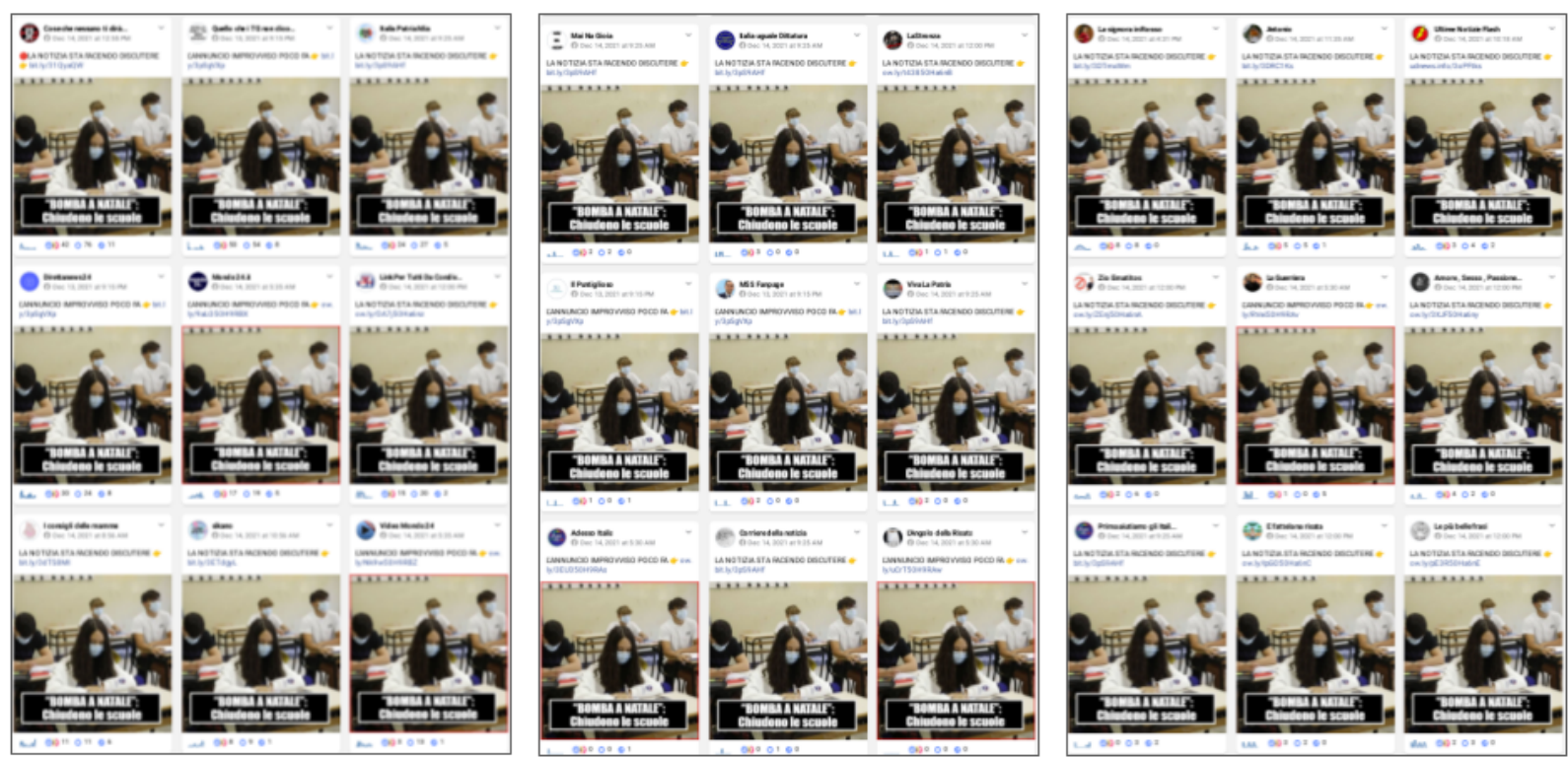

Figure 2: An example of a post shared by a network of coordinated accounts (data source: CrowdTangle)

To identify such networks, we designed, implemented and tested an algorithm - now publicly available in the open source CooRnet R package (Giglietto, Righetti, \& Rossi, 2020) - that detects sets of Facebook public entities which performed CLSB by (1) estimating a time threshold that identifies URLs shares performed by multiple distinct entities within an unusually short period of time (as compared to the entire dataset), and (2) grouping the entities that repeatedly shared the same news story within this coordination interval.

Thanks to the experience gained and the results achieved by this ongoing work, the team behind the project developed and tested a prototype of a tool in the form of a digital dashboard tailored to the needs of Italian fact-checkers. The dashboard leverages the extraordinary efforts of the Italian fact-checking organizations that contributed hundreds of false COVID-19 claims to the CoronaVirusFacts Alliance Database (an initiative led by the International Fact-Checking Network - IFCN at the Poynter Institute). Using this list of

\footnotetext{
${ }^{1}$ The limitation to public accounts is due to the restrictions in data provided by Facebook.
} 
knowingly false news stories that emerged during the Italian novel coronavirus outbreak, the project employs the aforementioned method to identify Facebook Pages, public groups, and accounts that contributed to spread these stories on social media. The tool then tracks the activities of these social media actors highlighting trending stories at risk of rapidly spreading misinformation to a large audience. The prototype of this tool has been designed and developed in strict collaboration with Facta.news (one of the aforementioned Italian fact-checking organizations, a signatory member of IFCN, and Facebook's partner for their third-party-fact-checkers program²).

In this report we describe the results of this project by presenting a comprehensive map of the Italian social media actors that performed coordinated links sharing behavior from early 2020 on, the prototype and the outcomes of the collaboration with Facta.news.

The map is presented in chapter 2 at three different levels of detail. The bird view perspective provided by the macro level chapter highlights the relationships between all these actors within respective coordinated networks.

At the meso level, the report provides an in-depth description of four different exemplary coordinated networks. Similarly to other previous analysis (Giglietto et al., 2021), this in-depth description grounds the Camille François ABC framework (François, 2020) and is threefold, i.e. the cases under analysis are presented from Actors involved, Behaviors performed and Content shared perspectives.

Finally, at the micro level we analyse three cases of problematic content and how this content was spread by its network. We present two Facebook posts and one link labeled by Facta.news as totally or partially false or misleading. The descriptions include quantitative information about the Facebook Pages that circulated the story, content analysis and references to the sources - if there were any - indicated in the articles.

The prototype is described in detail in chapter 3. The chapter describes the design and development of the prototype created to support the work of fact-checkers/debunkers and the outcomes of the testing phase held during the month of November 2021. During this test, a team from Facta.news used the tools to detect, rate and categorize 360 posts and 71 links using a typology of content veracity that ranges from true to false news (see Appendix II for the full description of each category).

The report opens with a summary of what we observed during the first months of the outbreak in terms of Italian news stories that circulated the most on Facebook (based on a dataset provided by Meta), Italian false claims about COVID (based on a dataset provided by the International Fact-Checking Network - IFCN), and the emergence and growth of the Italian covid-skeptic coordinated network on Facebook.

\footnotetext{
${ }^{2}$ See https://www.facebook.com/journalismproject/programs/third-party-fact-checking.
} 


\section{The first wave of infodemic in Italy: what circulated most on Facebook and who contributed to spread it}

Italy has been the first western country to experience a COVID-19 outbreak. Following days of constant coverage of the coronavirus outbreak in China, on Friday February 21, 2020 Italian citizens woke up with the news of the first native infected patient, lacking any apparent link with China, who was hospitalized in serious conditions.

The national media ecosystem went rapidly under stress (lannelli et al., 2020). Journalists and traditional media (both at the local and national level) struggled to provide evidence-based coverage of a rapid flow of circulating claims and health related data. Traditional gatekeepers often disown their mediation role by amplifying novel scientific claims and bringing scientists and experts at the forefront of media attention. In this phase, politicians and policy makers, often deeply divided over partisan lines, failed to provide a consistent message on crucial matters such as the use of protective equipment and the need for containment policies (llardi, 2020).

Pervasiveness and uncertainty created the perfect context for rumors and conspiracy theories to proliferate. Foreing and indigenous nefarious actors scrambled to exploit this remarkable time. US based social media companies were caught unguard by the breadth and depth of information operations capitalizing the spotlight of COVID attention for their partisan gain. To face the mounting infodemic, both Facebook and Twitter started to proactively redirect traffic toward reliable official sources such as the World Health Organization and the Italian Ministry of Health (Lovari, 2020). Both at the local and national level the volume of interactions on social media posts created by different bodies of the Italian public administration skyrocketed (Lovari \& Righetti, 2020).

At that time, our ongoing studies on coordinated behaviour during two Italian elections (Giglietto, Righetti, et al., 2019) had placed us in a privileged position to observe the infodemic unfolding under our own eyes through the posts of the problematic actors we were already tracking. In this chapter we reconstruct our efforts to document and describe that tumultuous time by employing exclusive tools and data provided directly by Meta through their partnership program with external researchers.

\subsection{Widely viewed and interacted Italian links during the first wave (February/June 2020)}

To give readers an overview of what popular content circulated on the platforms between February and June 2020 we employed Meta's URL Shares dataset. Unlike other social media data sources available, this dataset includes individual level counts of the number of people who viewed, clicked and interacted with URLs ${ }^{3}$ circulated on Facebook. In this list of contents that have circulated the most (see Figure 3 and Appendix $V$ for the tables with detailed figures and links), there is no shortage of problematic information that have contributed to polluting a public debate already made difficult by the emergency situation and by the lack of scientific certainty on which to rely.

\footnotetext{
${ }^{3}$ Any URL with at least 100 public shares. Each user is counted only once even if they viewed/interacted multiple times with the same URL.
} 


\begin{tabular}{|c|c|c|c|c|c|}
\hline & VIEWS & CLICKS & SHARES & SHARES WITHOUT CLICKS & COMMENTS \\
\hline 1 & $\begin{array}{l}\text { Coronavirus, l'esperto americano di } \\
\text { bioterrorismo: "Creato in laboratorio, } \\
\text { un'arma da guerra biologica" (Tgcom 24) }\end{array}$ & $\begin{array}{c}\text { Coronavinus, dentro il reparto di terapia } \\
\text { intensiva (Piazza Pulita) }\end{array}$ & $\begin{array}{l}\text { II rianimatore: "Se stessimo tutti a casa il } \\
\text { Coronavirus si fermerebbe in } 15 \text { giorni" } \\
\text { (Globalist) }\end{array}$ & \begin{tabular}{|c|}
11 rianimatore: "Se stessimo tutti a casa it \\
Coronavirus si fermerebbe in 15 giorni" \\
(Globalist)
\end{tabular} & $\begin{array}{l}\text { Voi andreste in piazza per protestare contro } \\
\text { Giuseppe Conte? (Libero) }\end{array}$ \\
\hline 2 & $\begin{array}{l}\text { Patente, revisione, multe, RC auto: il } \\
\text { decreto Cura Italia e le altre novità per } \\
\text { l'auto - SCHEDE (Quattroruote) }\end{array}$ & $\begin{array}{c}\text { Coronavirus, l'esperto americano di } \\
\text { bioterrorismo: "Creato in laboratorio, è } \\
\text { un'arma da guerra biologica" (Tgcom } \\
\text { 24) }\end{array}$ & $\begin{array}{l}\text { Coronavirus, dentro il reparto di terapia } \\
\text { intensiva (Piazza Pulita) }\end{array}$ & $\begin{array}{l}\text { "Condividete l'appello per ritrovare il } \\
\text { mio cane Otto" (Rieti Life) }\end{array}$ & $\begin{array}{l}\text { IL COVID-19 SCOMPARIRA DA SOLO A } \\
\text { BREVE! (Luc Montagnier - premio Nobel e } \\
\text { scopritore dell'HIV) (rouTube) }\end{array}$ \\
\hline 3 & $\begin{array}{c}\text { Togliere le scarpe in casa tiene fuori } 400 \text { mila } \\
\text { bstteri (meningite, polmonite) (Oltre TV) }\end{array}$ & \begin{tabular}{|c|} 
CORONAVIRUS, L'ULTIMO SALUTO DI \\
UNA MAMMA AI SUOI 4 FIGLI: LA \\
DRAMMATICA TESTIMONIANZA DI \\
UN'INFERMIERA (Pinerolo News) \\
\end{tabular} & $\begin{array}{l}\text { IL COVID-19 SCOMPARIRA DA SOLO A } \\
\text { BREVE! (Luc Montagnier - premio Nobel e } \\
\text { scopritore dell'HIV) (YouTube) }\end{array}$ & $\begin{array}{l}\text { Reti } 5 G \text { e salute, la paura ferma lo } \\
\text { sviluppo in Svizzera (Techradar) }\end{array}$ & $\begin{array}{l}\text { Coronavirus, "Una scusa per gli italiani per } \\
\text { non fare niente": il commento infelice di un } \\
\text { presentatore britannico (La Repubblica) }\end{array}$ \\
\hline 4 & $\begin{array}{l}\text { Coronavinus, dentro il reparto di terapia } \\
\text { intensiva (Piazza Pulita) }\end{array}$ & $\begin{array}{l}\text { IL CORONAVIRUS SMASCHERATO } \\
\text { (YouTube) }\end{array}$ & $\begin{array}{l}\text { "Condividete l'appello per ritrovare il mio } \\
\text { cane Otto" (Rieti Life) }\end{array}$ & $\begin{array}{c}\text { Roby Facchinetti - Rinascerò, Rinascerai } \\
\text { (1'll be reborn, you'll be reborn) } \\
\text { (YouTube) }\end{array}$ & $\begin{array}{l}\text { SONDAGGIO: FAVOREVOLE O } \\
\text { CONTRARIO A USCIRE DALL'EURO? } \\
\text { (Rassegna Stampa 2.0) }\end{array}$ \\
\hline 5 & $\begin{array}{l}\text { Il rianimatore: "Se stessimo tutti a casa il } \\
\text { Coronavirus si fermerebbe in } 15 \text { giomi" } \\
\text { (Globalist) }\end{array}$ & $\begin{array}{c}\text { Coronavirus, bollette sospese per } 2 \\
\text { mesi. Stop anche al canone Rai (ll Sole } \\
24 \text { Ore) }\end{array}$ & $\begin{array}{l}\text { Roby Facchinetti - Rinascerò, Rinascerai (l'll } \\
\text { be reborn, you'll be reborn) (YouTube) }\end{array}$ & $\begin{array}{c}\text { Referendum, rimandato il voto sul taglio } \\
\text { dei parlamentari (Torino Today) }\end{array}$ & $\begin{array}{l}\text { Don Bucci, il vescovo: "Pedofilia e aborto } \\
\text { sono azioni immorali" (Notizie) }\end{array}$ \\
\hline 6 & $\begin{array}{c}\text { Reti 5G e salute, la paura ferma lo sviluppo } \\
\text { in Svizzera (Techradar) }\end{array}$ & $\begin{array}{c}\text { La bozza del nuovo decreto: misure } \\
\text { restrittive prorogabili fino al } 31 \text { luglio } \\
\text { (Fanpage) }\end{array}$ & $\begin{array}{c}\text { Reti 5G e salute, la paura ferma lo sviluppo } \\
\text { in Svizzera (Techradar) }\end{array}$ & $\begin{array}{l}\text { Diodato - Fai Rumore (Nideo Ufficiale) } \\
\text { [Sanremo 2020] (YouTube) }\end{array}$ & $\begin{array}{l}\text { Coronavirus, Zingaretti: "Senza Europa non } \\
\text { ce l'avremmo mai fatta" (Adnkronos) }\end{array}$ \\
\hline 7 & $\begin{array}{l}\text { Sull'ambulanza a Bergamo con Marcoe } \\
\text { Roberto: "Dopo } 8 \text { notti la paura del buio" } \\
\text { (Huffingtonpost') }\end{array}$ & $\begin{array}{l}\text { I sintomi? Per il virologo Francesco } \\
\text { Broccolo "attenzione a mal di gola, mal } \\
\text { di testa, diarrea e difficoltả respiratorie. } \\
\text { Poi febbre e polmonite" (Tgcom 24) }\end{array}$ & $\begin{array}{l}\text { Diodato - Fai Rumore (Video Ufficiale) } \\
\text { [Sanremo 2020] (YouTube) }\end{array}$ & $\begin{array}{c}\text { "Bambini e anziani non devono uscire, } \\
\text { stiamo vedendo i primi risultati. Rischio } \\
\text { di vanificare gli sforzi" (Liberta) }\end{array}$ & $\begin{array}{c}\text { Serie A, Cellino: "Lo Stato aiuti a pagare i } \\
\text { calciatori. Si potrebbe giocare a maggio" (II } \\
\text { Romanista) }\end{array}$ \\
\hline 8 & $\begin{array}{l}\text { Diodato - Fai Rumore (Video Ufficiale) } \\
\text { [Sanremo 2020] (YouTube] }\end{array}$ & \begin{tabular}{|c|} 
L'ultimo messaggio del $18 \mathrm{enne}$ Mattia \\
prima di essere intubato: "Non ti lascio, \\
lotteró per te" (III Giomale) \\
\end{tabular} & $\begin{array}{l}\text { "Bambini e anziani non devono uscire, } \\
\text { stiamo vedendo i primi risultati. Rischio di } \\
\text { vanificare gli sforzi" (Libertà) }\end{array}$ & $\begin{array}{c}\text { Arrivano in Italia medici cinesi esperti } \\
\text { nella lotta al Coronavirus: "Vi aiuteremo } \\
\text { a combatterlo" (Fanpage) }\end{array}$ & $\begin{array}{l}\text { Coronavirus, i milanesi affollano i navigli: } \\
\text { "Non possono imporci di stare a casa" } \\
\text { (Ansa) }\end{array}$ \\
\hline 9 & $\begin{array}{l}\text { CORONAVIRUS, L'ULTIMO SALUTO DI UNA } \\
\text { MAMMA AI SUOI } 4 \text { FIGLI: LA } \\
\text { DRAMMATICA TESTIMONIANZA DI } \\
\text { UN'INFERMIERA (Pinerolo News) }\end{array}$ & \begin{tabular}{|c|} 
Coronavinus, direttrice laboratorio \\
Sacco: "Stiamo scambiando un' influenza \\
per una pandemia globale" (Fanpage)
\end{tabular} & $\begin{array}{l}\text { Coronavirus, l'esperto americano di } \\
\text { bioterrorismo: "Creato in laboratorio, è } \\
\text { un'arma da guerra biologica" (Tgcom 24) }\end{array}$ & $\begin{array}{l}\text { Francesco Gabbani - Viceversa (Official } \\
\text { Music Video) - Sanremo } 2020 \text { (YouTube) }\end{array}$ & $\begin{array}{c}\text { È morto Ezio Bosso, il maestro che sapeva } \\
\text { commuovere. Aveva } 48 \text { anni (Corriere della } \\
\text { Sera) }\end{array}$ \\
\hline 10 & $\begin{array}{l}\text { Francesco Gabbani - Viceversa (Official } \\
\text { Music Video) - Sanremo } 2020 \text { (YouTube) }\end{array}$ & $\begin{array}{c}\text { Coronavirus: "Sappiamo guarirlo", } \\
\text { annuncio del virologo francese (Virgilio } \\
\text { Notizie) }\end{array}$ & $\begin{array}{l}\text { Referendum, rimandato il voto sul taglio dei } \\
\text { parlamentari (Torino Today) }\end{array}$ & $\begin{array}{c}\text { Togliere le scarpe in casa tiene fuori } \\
400 \text { mila batteri (meningite, polmonite) } \\
\text { (Oltre TV) }\end{array}$ & $\begin{array}{l}\text { Coronavirus, Milano: folla ai Navigli all'ora } \\
\text { dell'aperitivo e poche mascherine (La } \\
\text { Repubblica) }\end{array}$ \\
\hline
\end{tabular}

Figure 3: Italian links circulated on Facebook between February and June 2020 ranked per views, clicks, shares, shares without click and comments (source: URL Shares Data by Facebook) 
In spite of this radical uncertainty, many of the articles in these rankings tend to present simple and polarized solutions as absolute certainties. Sometimes these certainties are delegated to expert interventions and presented in the form of statements. This is an element to reflect on, because this type of content can pollute the public debate by escaping fact-checking since they report sentences actually spoken by the interested parties.

The news that has obtained more views (appeared in the news feed of over 15 million Italian users), was published by Tgcom 24 and reports the statements of an "American expert" who claimed that the virus was created in the laboratory as a biological weapon. The same article is also the second for the number of users who have clicked on it, almost 3 million. The article was fact-checked by Facebook third-party fact-checkers and classified as "opinion". Throughout the entire report, we highlight different cases of news stories and posts reporting patently false claims actually pronounced by experts or noteworthy persons. This type of content is rarely labeled as false insofar the statement itself was actually pronounced and faithfully reported.

Among the links with the most views, over 13 million unique users, there is also a video from Oltre Tv entitled "Taking off your shoes at home keeps out 400 thousand bacteria (meningitis, pneumonia)". News Guard (a team of independent journalists specialized in rating the reliability of online news sources), considers Oltre TV to be a source of information that fails to respect several fundamental journalistic standards.

Among the links commented by a greater number of users (over 200,000) we find first a political article by Libero asking readers if they want to protest against Giuseppe Conte, while second, with over 130,000 (and third among those with a greater number of users who shared it), there is a YouTube video (now removed) which reports the very optimistic statements of Luc Montagnier on the imminent disappearance of Covid-19.

Another removed video occupies the fourth position among the most clicked. In the video, a well-known blogger in the circles of Italian Covid skepticism associates Coronavirus and $5 \mathrm{G}$ technology. The arguments presented are disputed by Facta.news's analysis ${ }^{4}$ which concludes categorizing the content as pseudo-scientific.

Still on the subject of $5 \mathrm{G}$, it is interesting to note that, both among the most viewed links (about 12 million unique views) and among those with a greater number of users who have shared (over 100,000), a Techradar news item entitled " 5 G networks and health, fear stops development in Switzerland ".

Finally, the "share without click" category collects links that have been shared by users without having clicked and therefore read them first. The 10 URLs that are placed in this category are the same ones that appear in the other lists, except for the Fanpage news entitled "Chinese doctors are coming to Italy, experts in the fight against Coronavirus: We will help you to fight it", which collects the shares of nearly 100,000 users. Also in this case a reflection is needed in the light of the reports in which the European Commission has warned against the proliferation of propaganda operations orchestrated by foreign states in reference to the aid offered and given during the health emergency.

\footnotetext{
${ }^{4}$ See

https://Facta.news.news/notizia-falsa/2020/04/15/il-video-il-corona-virus-smascherato-ora-sappiamocosa-lo-attiva-e-pseudoscienza/.
} 


\subsection{The rise of the Covid-skeptic cluster}

During this tumultuous time, Italian fact-checkers scrambled to debunk the rumors that started circulating via social media and instant messaging apps such as WhatsApp. The CoronaVirus Alliance Dataset compiled by the International Fact Checking Network, lists 212 false and misleading claims identified by three Italian fact-checking organizations (PagellaPolitica, Facta.news, and Open), and published between January 22, 2020 and August 26, 2020. Starting from this list, we used the CrowdTangle (CrowdTangle Team, 2019) 'Search' feature to identify a dataset of related news stories, finding a total of 1,258 corresponding URLs.

Using CooRnet (Giglietto, Righetti, \& Rossi, 2020) on these links, we identified, back in December 2020, 30 Facebook Pages (2.1M Followers) and 308 public Groups (2.73M members) that coordinately shared two or more of these links (full list in Appendix III, from now on IFCN lists).

For both Pages (+24.3K Followers) and Groups (+1.23M members) in these lists, the monthly growth rate of respectively Likes and members skyrocketed during the period February/April 2020 (source CrowdTangle). At the time of writing, 5 Pages and 20 Groups are not anymore available and 13 changed their form from public to private Groups.

Among the links most frequently circulated by these coordinated accounts, the large majority are deeply problematic content that are not anymore available at the time of writing (see Appendix III).

During the second half of 2020 we started observing the emergence and consolidation of an Italian Facebook network of coordinated accounts devoted to spreading various forms of misleading content related to the novel coronavirus. The same network of accounts adapted the argumentations employed and the targets of their skepticism during the different phases of the pandemic. Echoing narratives often emerged abroad and adapting them to the local context, these accounts operated to support unproven claims on the origin of the virus, blame the EU for the lack of help provided to Italy during the first phases of the pandemic, underestimate the real danger posed to health by the virus, opposed, often in the name of freedom, any policy aimed at reducing the spread of the virus (lockdown, social isolation, use of masks), promoted the idea of the virus exploited (or even invented) by deviated elites to control citizens through restrictive laws and vaccination, and spread fears on the efficacy and safety of COVID-19 vaccines.

To investigate and trace the origin of this network we used CrowdTangle on the IFCN lists of coordinated accounts to collect all the links posted by these accounts during October 2020. The idea was to see the evolution of these coordinated networks outside the time frame provided by the CoronaVirus Alliance dataset (January/August 2020). For these lists, we then gathered all the posts with links shared by these accounts over a period of one month (we used the month of October 2020 due to the resurgence of the coronavirus outbreak in Italy). We call this process of using links posted by knowingly coordinated accounts to identify a wider and updated list of coordinated accounts that co-shared links with the original list a CooRnet iteration.

The resulting dataset of 59,346 URLs has been used as the input of the second iteration of the CooRnet that detected 364,400 Facebook shares for these links and identified 344 coordinated accounts. 


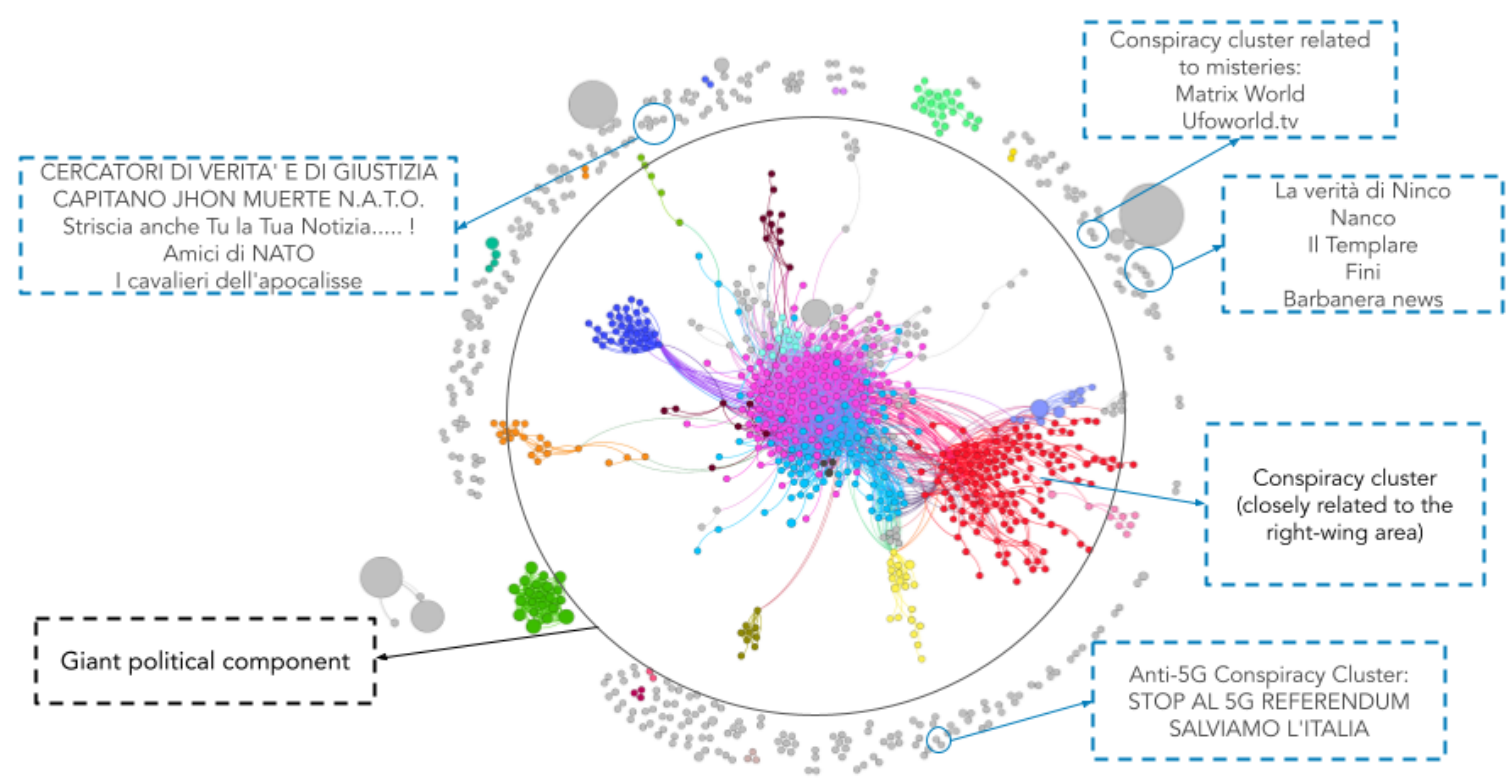

Figure 4: Map of the coordinated networks activity and relationships during October 2020

The core of this graph represents a giant political component mostly composed of Five Star Movement, League and Brothers of Italy unofficial groups. An inspection of the account names and content shared led to identify 5 conspiracy clusters, the wider, in red, share its space with right-wing entities ${ }^{5}$, while the others are related to specific conspiracy theories, such as the $5 G$, or supposed cabals.

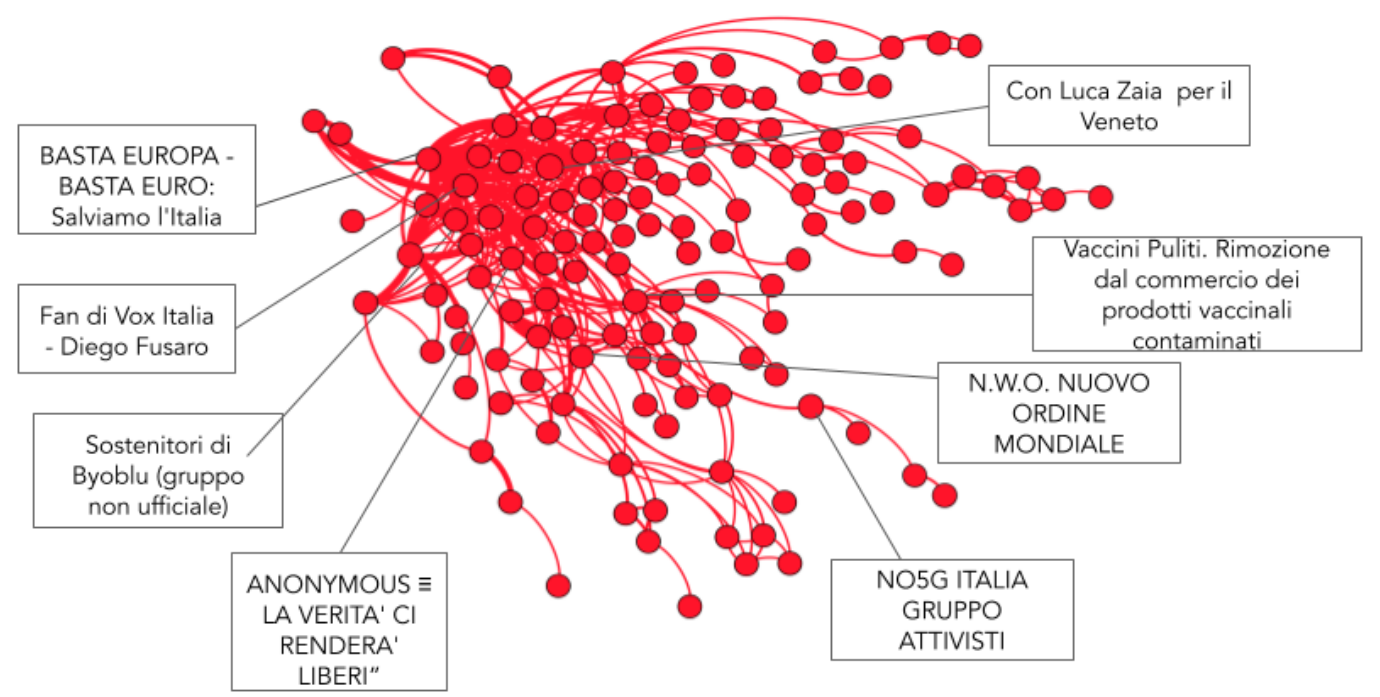

Figure 5: A closer view on the conspiracy cluster that formed the early backbone of the covid-skeptic Italian network

This filtered graph highlights major entities (ranked by number of coordinated shares) in the main conspiracy cluster, from anti-vaxxers to anti-Europe to New World Order conspiracies. There are also some fans of international conspiracy groups/networks, such as

\footnotetext{
${ }^{5}$ The positioning algorithm employed by this visualization (Force Atlas 2 ) places accounts that co-shared the same links closer.
} 
Anonymous and Vox, as well as Facebook entities related to right-wing parties. For instance, the membership of "Sostenitori di Byoblu (gruppo non ufficiale)", (a group devoted to sharing conspiracy theories now removed by Facebook) increased by more than six times during the lockdown period (Figure 5).
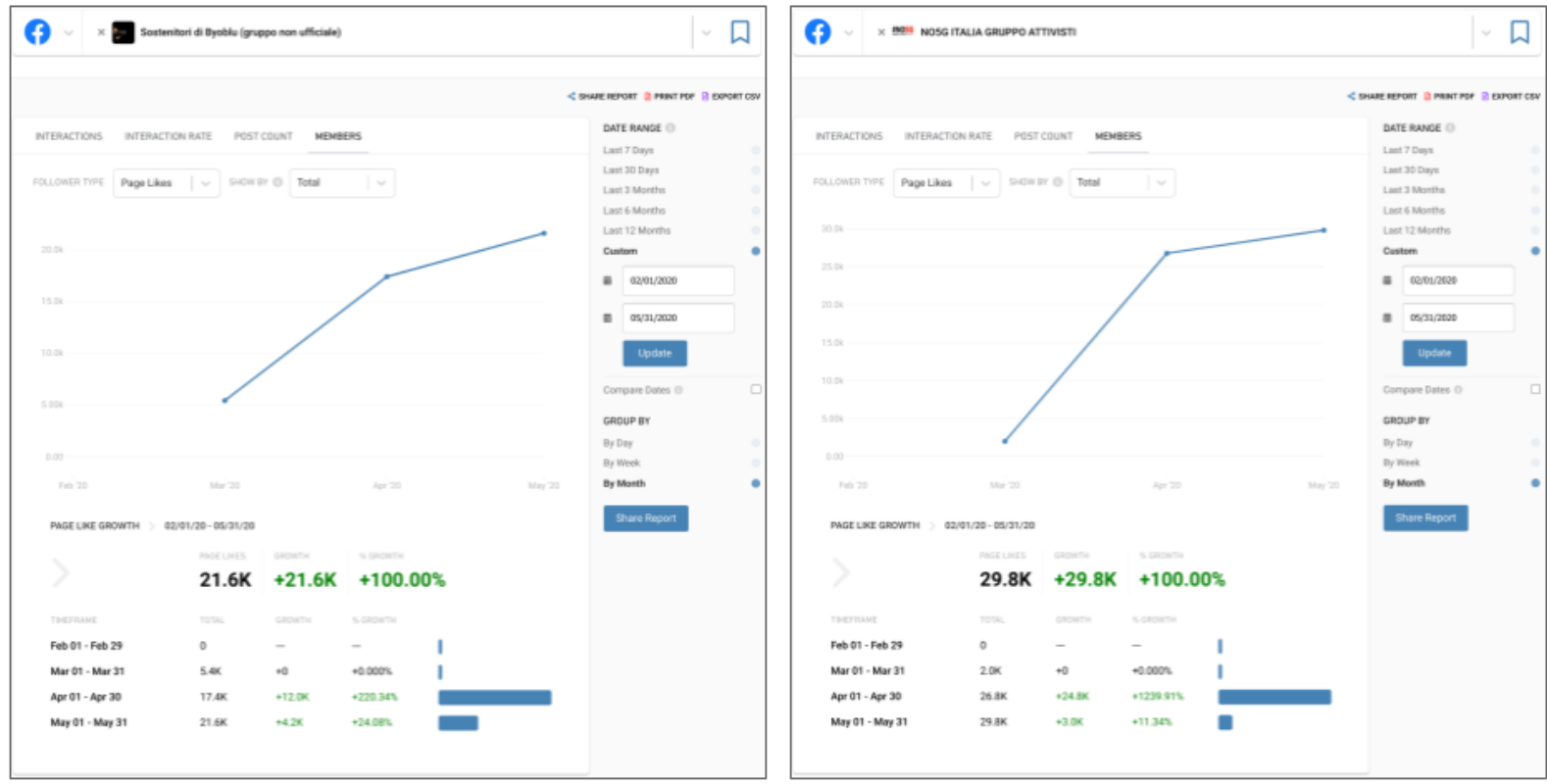

Figure 6: Two examples showing the membership increase of two Groups belonging to the conspiracy theory cluster (source CrowdTangle)

We then compared the volume of interactions on all the posts created by the accounts in the conspiracy clusters with the remaining entities (Figure 6). Using the average volume of total interactions obtained by the two groups during the pre-lockdown period as a baseline, the interactions on conspiracy groups ${ }^{6}$ during the lockdown increased by about three times. Non-conspiracy groups increased their interactions too, but only to a lesser extent.

\footnotetext{
${ }^{6}$ Due to the fact that CrowdTangle started taking some new Pages in our lists during the period between February and June 2020, we focused our analysis on groups only.
} 


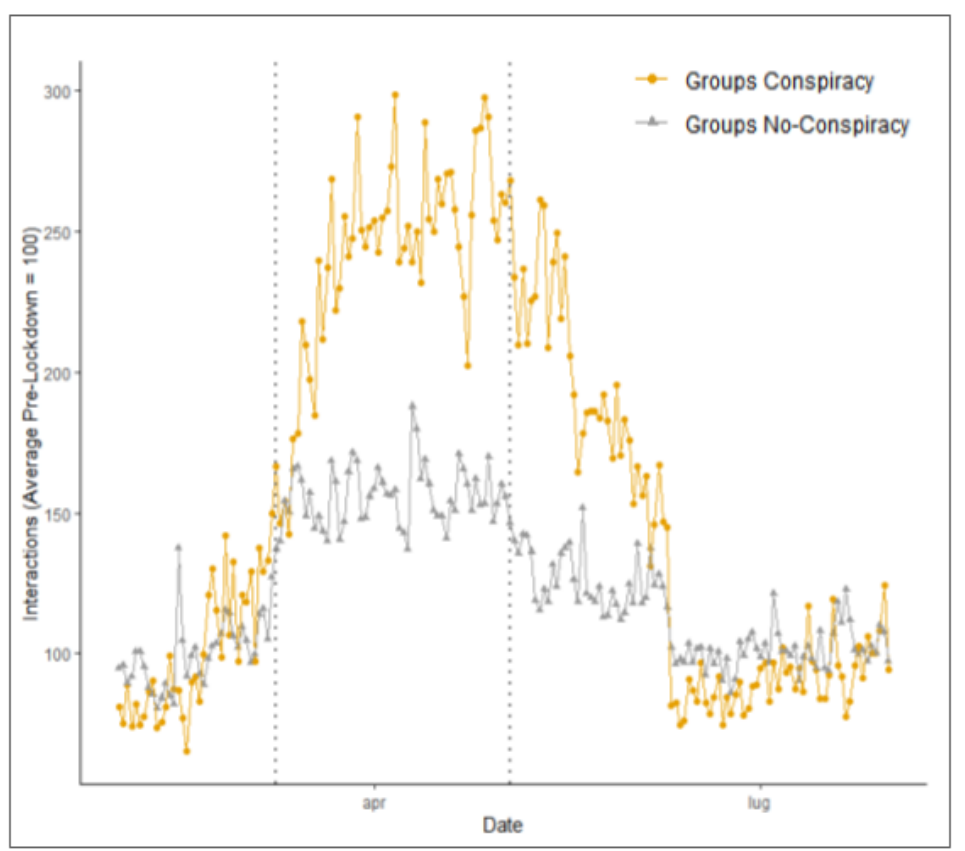

Figure 7: Increase in the volume of interactions on posts published in the conspiracy related groups vs other groups (data source: CrowdTangle)

Based on this work, we additionally identified and described in depth three coordinated networks. This work resulted in the publication of three working papers (Giglietto et al., 2021; Giglietto, Terenzi, Marino, et al., 2020a, 2020b) in which we reconstruct the history and behind-the-scenes of some of these coordinated actors, and point out novel link sharing strategies and forms of adaptations aimed at overcoming the mitigation efforts put in place by Facebook to contain the spread of content that violates their platform policies.

One year later, far from being completely disrupted, most of the accounts belonging to these networks are still active under disguised forms and the practices that we early observed in one network have been adopted by others.

In the following section we provide an up to date description of these networks and their strategies based on the content they shared between January and October 2021. The iteration performed on these links generated the final network and corresponding list of entities tracked by the tool developed to support the work of fact-checkers. 


\section{MINE-FACTS coordinated networks at macro, meso and micro level}

The tool we designed to support the work of fact-checkers tracks the posting activities of coordinated accounts identified as a result of a CooRnet iteration. The idea is that, given that links spread by coordinated networks tend to be more frequently associated with problematic information (Giglietto, Righetti, Rossi, et al., 2020b), tracking the best performing content posted by these accounts may lead to early-detect worth-investigating content.

To develop and test the prototype we used two lists of coordinated accounts identified by running a CooRnet iteration on links posted by coordinated accounts that shared false news on COVID. The process is thus similar to what led to identifying the networks discussed in the previous paragraph with the exception of the timeframe. In the case of the prototype we used CooRnet on 403,071 links posted by the accounts in IFCN lists ${ }^{7}$ between January 1, 2021 and October 31, 2021 and detected 89 components consisting of 2,151 accounts (242 Pages and 1,900 public Facebook groups). All these accounts performed at least eight coordinated shares (shared the same link within 25 seconds for this case).

Besides surfacing a list of potentially problematic content every six hours (see paragraph 4.1. for a description of the method), the tool also keeps track of new accounts that share this content via coordinated links sharing but were not included in our original lists. The inventory of accounts is thus dynamic with new coordinated accounts constantly added to the original lists.

In the following paragraphs we describe the original networks detected (Macro level), and provide an in-depth analysis of three different examples of clusters of Pages/groups originally detected plus one example of a cluster that was discovered by the tool itself during its operations (Meso level). Finally, we described and reconstructed the circulation of three content ( 2 posts and one link) surfaced by the tool and categorized as false or out of context by Facta.news during the testing phase held during the month of November 2021 (Micro level).

\subsection{Macro}

The relationship between the coordinated accounts detected can be visualized using tools for social network analysis. In these visualizations, a node represents a social media account. Each coordinated share of the same link by two nodes is instead represented by an edge. A standard layout algorithm (in our case we used Force Atlas 2) will then position the nodes according to the number of times the accounts performed the coordinated link sharing. The higher the number, the closer are the nodes. Nodes are thus grouped together based on this co-sharing behavior and clusters of coordinated Pages and Groups emerge.

We thus used this technique to visualize the coordinated accounts detected by the iteration of CooRnet described above. In the resulting visualization (Fig. 8), it is possible to

\footnotetext{
${ }^{7}$ The iteration was run on October 25 2021. At that time the IFCN lists included 27 Pages and 281 public Facebook groups.
} 
identify some noteworthy cases among the 106 total different clusters detected by the algorithm.

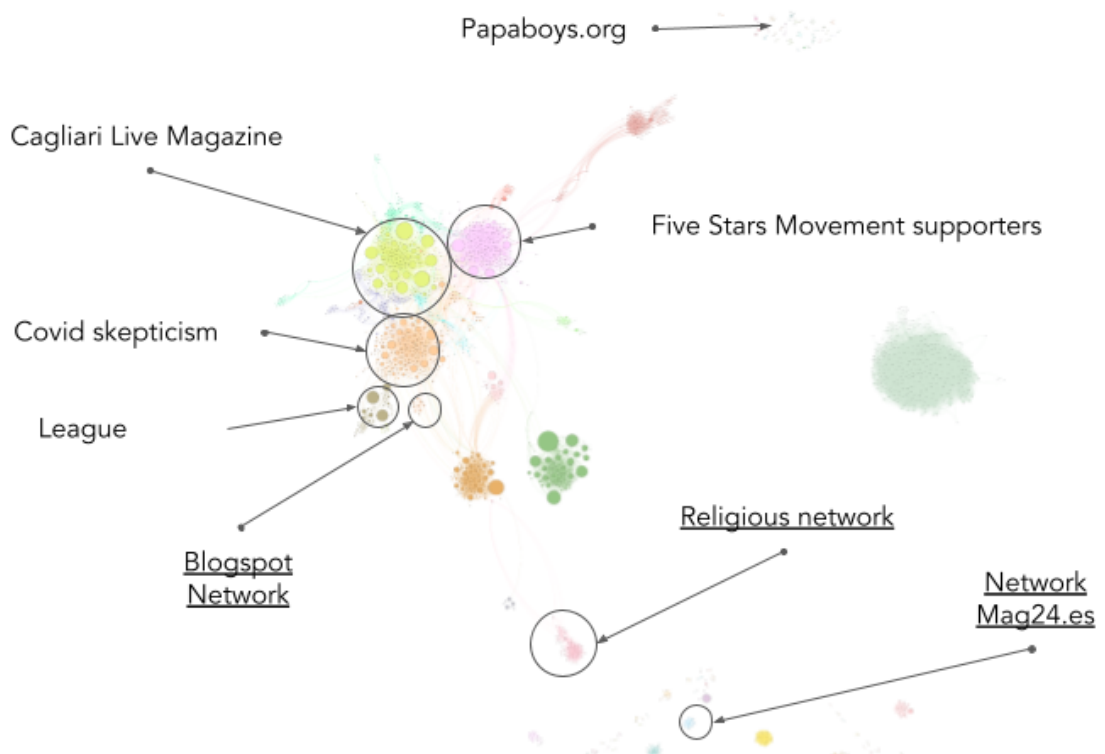

Figure 8: MINE-FACTS coordinated networks (based on 403,071 links shared by IFCN list of account between January and October 2021

The giant component in the network includes 18 clusters (Fig. 9). The largest cluster in this component includes 246 accounts (14 Pages and 232 groups) mostly devoted to sharing misleading and false information that supports various forms of covid skepticism. This cluster is the current incarnation of what we observed emerging during the Italian first wave of the pandemic.

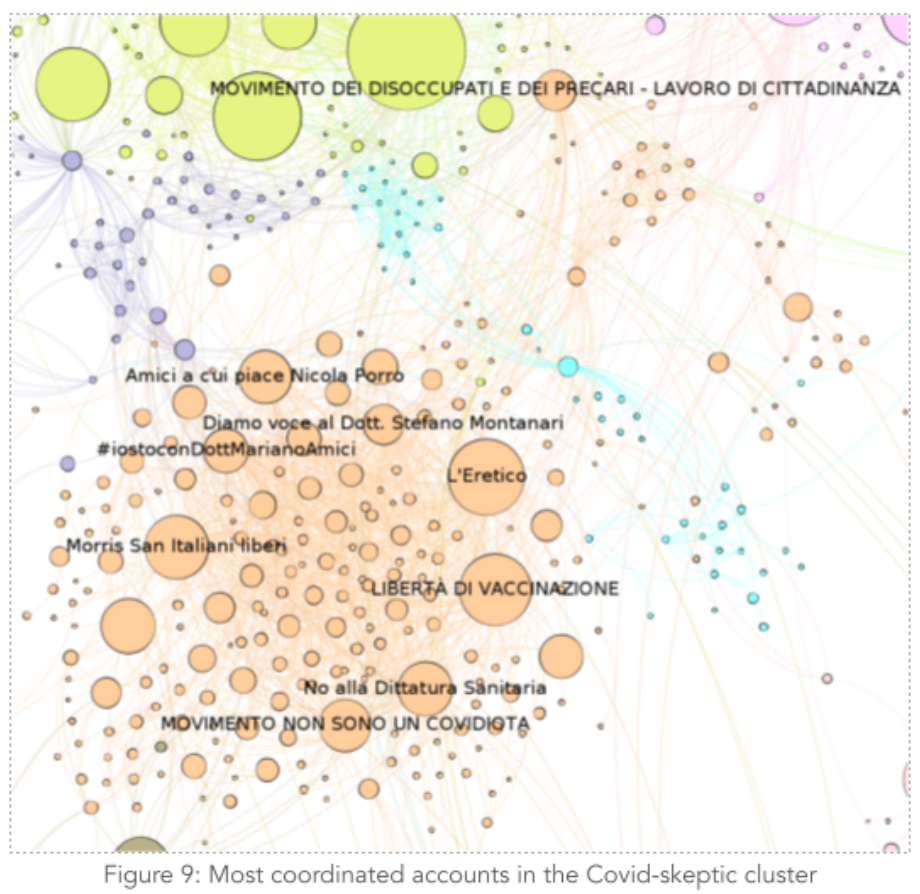


While the group "L'Eretico", 35K members at the time of the analysis, is the central node in this cluster with 886 coordinated shares, a crucial role in the entire component is played by the group "MOVIMENTO DEI DISOCCUPATI E DEI PRECARI - LAVORO DI

CITTADINANZA" (46K members and 587 coordinated shares). This group acts as a bridge between the covid-skeptic cluster and, at least, two other significant groups of actors.

The largest of these two clusters includes 216 accounts (8 Pages and 208 groups) that circulate pro Five Star Movement content (Fig. 10).

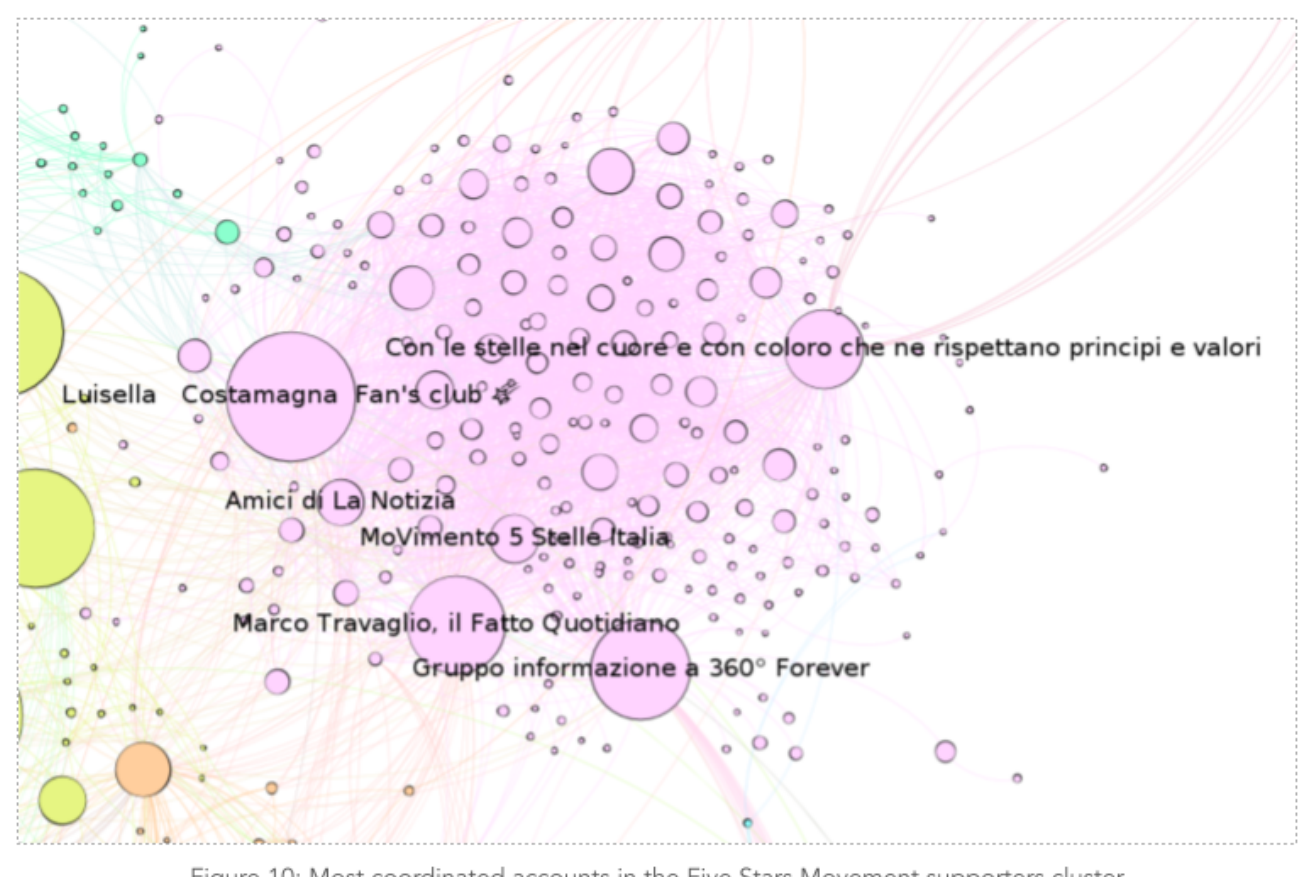

Figure 10: Most coordinated accounts in the Five Stars Movement supporters cluster

The other consists of 190 accounts (6 Pages and 184 groups). A common threat of these accounts are names that resemble those of news outlets (see Figure 11) and posts often pointing to news stories published by $\underline{\text { Cagliari Live Magazine (a registered online news }}$ outlet). 


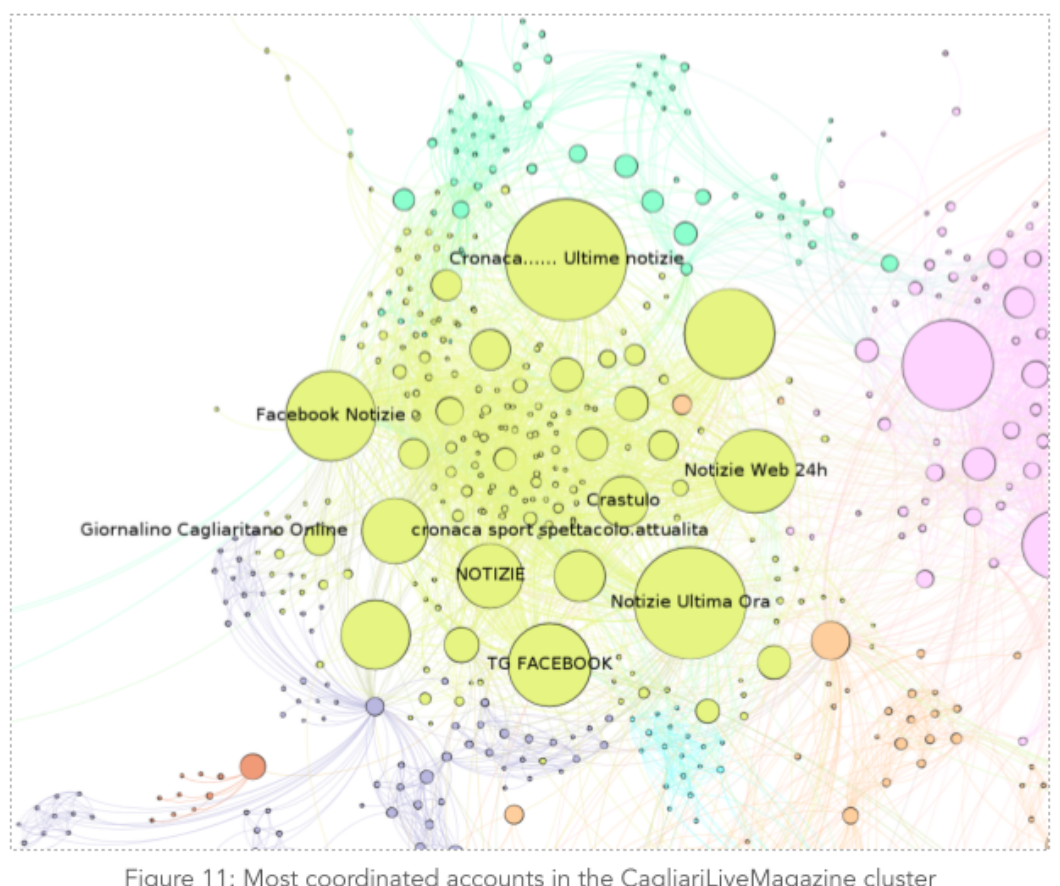

Another political network (League cluster, Figure 12) has been positioned by the algorithm below the covid-skeptic cluster with some overlap in terms of content shared. The bridge between these two clusters is represented by the group "VENETI : IERI - OGGI - DOMANI ( by B. Dilan )" (5,149K members and 397 coordinated shares).

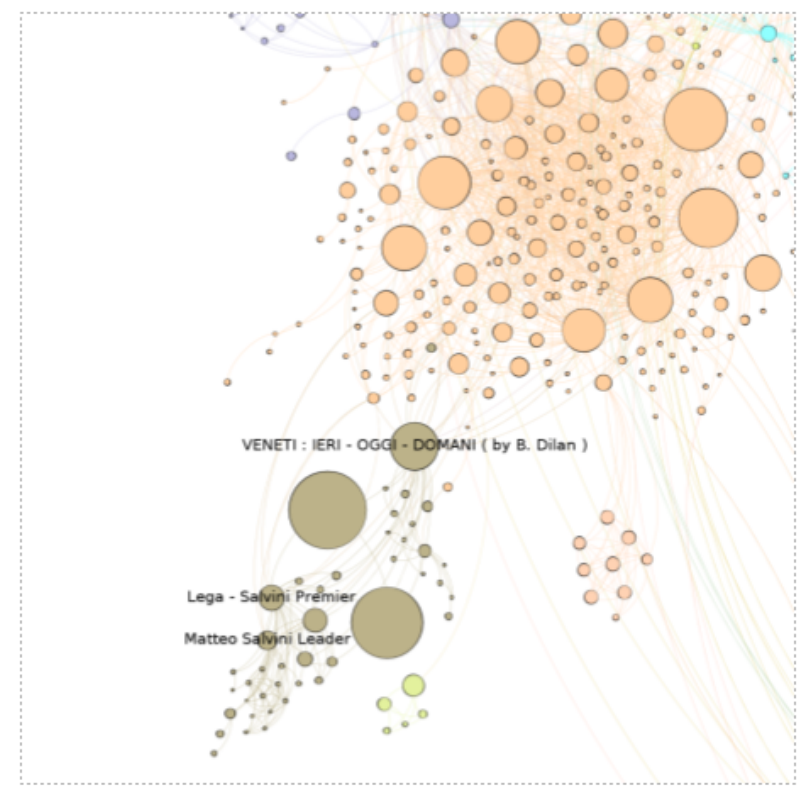

Figure 12: Most coordinated accounts in the League cluster

Groups and Pages often play different roles within a coordinated network and their relationship with the other accounts is shaped by the different affordances of the two types of Facebook venues. Networks eminently or uniquely composed by Pages are often centrally controlled by some forms of automation that cross-post the exact same post at about the same time. Most of the time the main aim of these networks is to drive traffic off 
the platform to specific domains owned or affiliated with the Pages' administrators. During our previous studies we often observed editorial brands employing the same strategy for cross-posting news stories published by a national outlet to a set of local Pages openly affiliated with the same editional brand. As long as the identity of the brand is disclosed by the Pages (either in the ownership section or as a Page website), this strategy may be deemed as non problematic. Some other times, the Pages where the content is simultaneously cross-posted do not disclose any affiliation with the website they point the traffic to. This is the case of the Mag24 network described in paragraph 3.2.4. A similar case of lack-of or misleading affiliation (both forms of inauthenticity) is exemplified by the "Gedi" Network (paragraph 3.2.3.). Unlike these two networks, Pages in the Blogspot network (3.2.1.) openly share the same name of the blogs where they direct the traffic to.

Groups based networks are instead often taken together by the activism of certain personal profiles. CooRnet often detects groups as coordinated when multiple personal profiles repeatedly share the same links in multiple groups during a very short period of time. Inspecting the profiles of these super-spreaders is often instructive. We rarely found evidence of fully automated accounts but a thorough analysis is hindered by the privacy related limitations of tools available when it comes to automatically retrieve information on personal profiles. The religious network described in 3.2.2. in an example of such group based networks.

In the following paragraph we report on in-depth analysis centered around these four networks. Starting from the clusters initially mapped, the analysis of a single network is often the result of additional CooRnet iterations where the links used are those posted by all the accounts in the cluster at stake for a recent period of time. By doing so we progressively isolate a single network getting a better sense of its boundaries. The analysis underlines the peculiarity and novelty of the strategies adopted by these coordinated networks and reports on our investigations aimed at identifying the individuals and organizations behind these operations.

\subsection{Meso}

As part of the process of developing the MINE-FACTS tool we came across several networks of Facebook coordinated entities that, in various ways, are involved in spreading problematic information. Whether present among the clusters of Pages and Groups performing coordinated link sharing behavior or surfaced by the use of the tool among the best performing posts/links (both in terms of total interactions or comments/shares ratio), we decided to delve into the most interesting cases by describing them under the A-B-C framework perspective (François, 2020). The A-B-C framework advocates a multi-perspective approach in describing information operations. Such a multi-perspective approach takes into account harmful content, manipulative actors and deceptive behaviour.

The first case is a network of 13 Facebook entities that coordinately shares links to at least 8 conspiracy theories blogs all hosted on Blogger.com.

Then, we are going to describe a network of 62 Facebook groups whose main topic is Catholicism and content related to prayers, celebration of saints, etc. but where, sometimes, are shared political oriented or conspiracy content. 
Identified by the tool and not previously available in the original list of coordinated accounts, the third network under analysis includes 31 Facebook pages which share links to articles by authoritative publications such as Repubblica.it and other sites referable to the GEDI publishing group.

Lastly, we will describe a long lasting network of Facebook Pages that share news stories published by the domain Meg24.es.

\subsubsection{Case \#1: The Blogs Strikes Back}

\subsubsection{Actors}

During the phase of content detection we noticed that several URLs to blogs hosted on Blogger.com emerged as information pieces with a higher comments/shares ratio (see paragraph 4.1). These links (all pointing at the domains ilsapereepotere2.blogspot.com, terrarealtime.blogspot.com, terrarealtime3.blogspot.com, ilgiornaledellasera.blogspot.com, thedayafter2012.blogspot.com, video-reporter.blogspot.com, centro-lavoro.blogspot.com, and la-voce-della-coscienza.blogspot.com) are all pieces of conspiracy theories news debating topics such as the New World Order ${ }^{8}$, Covid-19 denials, anti-vaccine issues, etc.

The network of Facebook entities spreading these domains is composed of a core of 6 pages and 7 more loosely affiliated groups (see Fig. 13). While link posting on groups seem to follow a known pattern of single users that rapidly share content on multiple groups, pages show a separate system of news sharing that will be described in depth in the behavior section.

\footnotetext{
${ }^{8}$ A conspiracy theory which hypothesizes a secretly emerging totalitarian world government run by a power elite with a globalist agenda.
} 


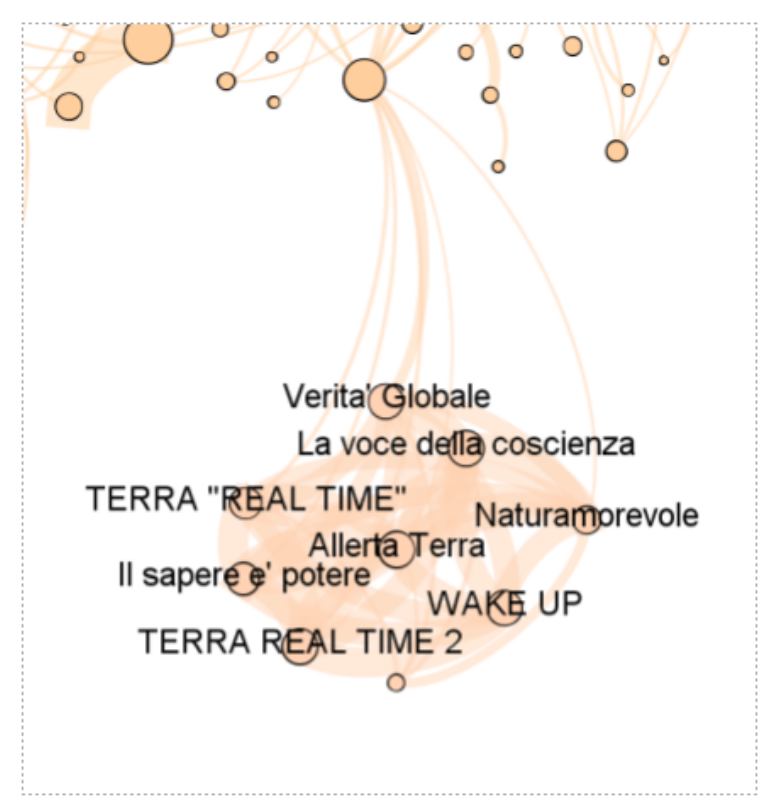

Figure 13: Main accounts in the network sharing blogspot URLs. The full list of accounts is available in Appendix VI

Figure 14 shows multiple examples of the - almost identical - homepages layout used by the blogs/domains boosted by this network. At the top of the page is displayed the name of the website and a menu list of news topics. In this case, topics range from exceptional natural phenomena, such as storms or earthquakes, to popular conspiracy theories, such as New World Order, to political or pseudo scientific issues.

What attracted our attention on this network is also the "old-fashioned" look of these news websites that have the basic aspect of 2000 first blogs. 


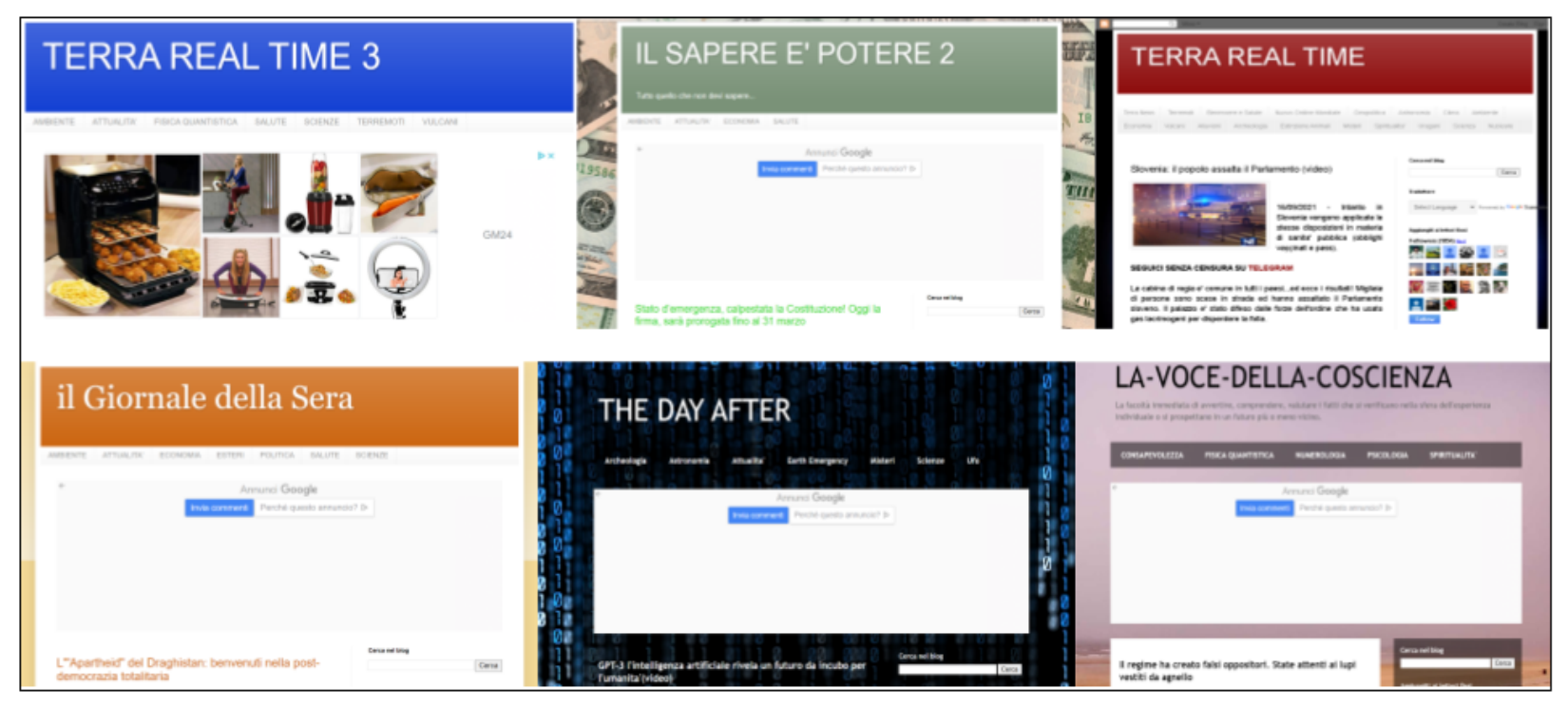

Figure 14: Collage of Blogspot domains homepages

As part of the features made available by Bloggers to their content creators, blogs shared by this network all host ads provided by Google. By analysing the Google AdSense advertising account of some of those, we discovered that 12 domains hosted on Blogger.com used the same advertising account ${ }^{9}$. Some of these domains are also the most frequently shared by our network of Facebook pages: ilsapereepotere2.blogspot.com, terrarealtime.blogspot.com, thedayafter2012.blogspot.com and centro-lavoro.blogspot.com. Two of these domains, instead, are not anymore available: video-corriere.blogspot.com and terrarealtime2.blogspot.com. Interestingly, there are 3 domains that point to blogs that look very similar to the others both in terms of aspect and topics but they are in English (Fig. 15).

\footnotetext{
${ }^{9}$ Blogs belonging to the same Google AdSense (ID pub-6170766994335201) account are the following: centro-lavoro.blogspot.com, dailymain.blogspot.com, earth-emergency.blogspot.com, ilsapereepotere.blogspot.com, ilsapereepotere2.blogspot.com, naturamorevole.blogspot.com, tecnologico2000.blogspot.com, terrarealtime.blogspot.com, terrarealtime2.blogspot.com, thedayafter2012.blogspot.com, thelastsigns.blogspot.com, video-corriere.blogspot.com
} 


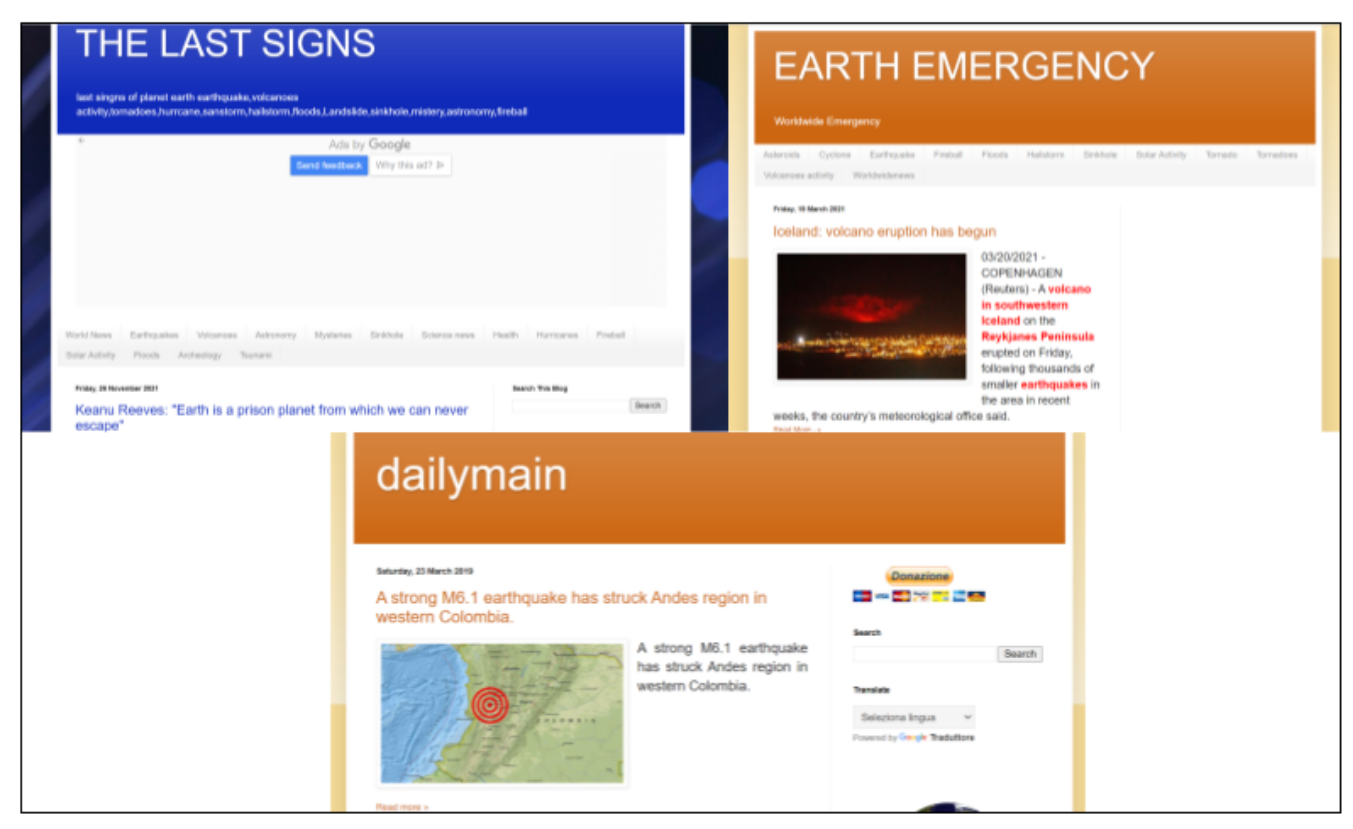

Figure 15: Network sharing blogspot URLs

Looking at CrowdTangle Intelligence data summary, we notice that the Facebook page belonging to this network with the highest number of followers and total interactions is clearly "Il sapere e' potere"10 (almost 57,000 followers). Despite this, the Facebook page with the highest interactions rate, i.e. a percentage calculated by accounting the number of interactions for weights and dividing by the account size (CrowdTangle Team, 2019), is Live Web.

Created on October 2019, "Live Web", which was not initially tracked by CrowdTangle due to its relatively small number of followers, was observed during the analysis of the network - and then manually added to our lists - because it was frequently shared by more popular pages in the network, such as the aforementioned "Il sapere e' potere". This page has few likes and followers (less than 2k), but a significantly higher value of interaction rate if compared to the other pages (Fig. 16). In other terms, the network is attempting to grow the popularity of this new Page leveraging the existing audience of the other accounts. At the same time, despite its size, instances of links posted on "Live Web" often generate the same engagement (mostly shares) than what is observed on other accounts of the network.

\footnotetext{
10 Knowledge is power in English.
} 


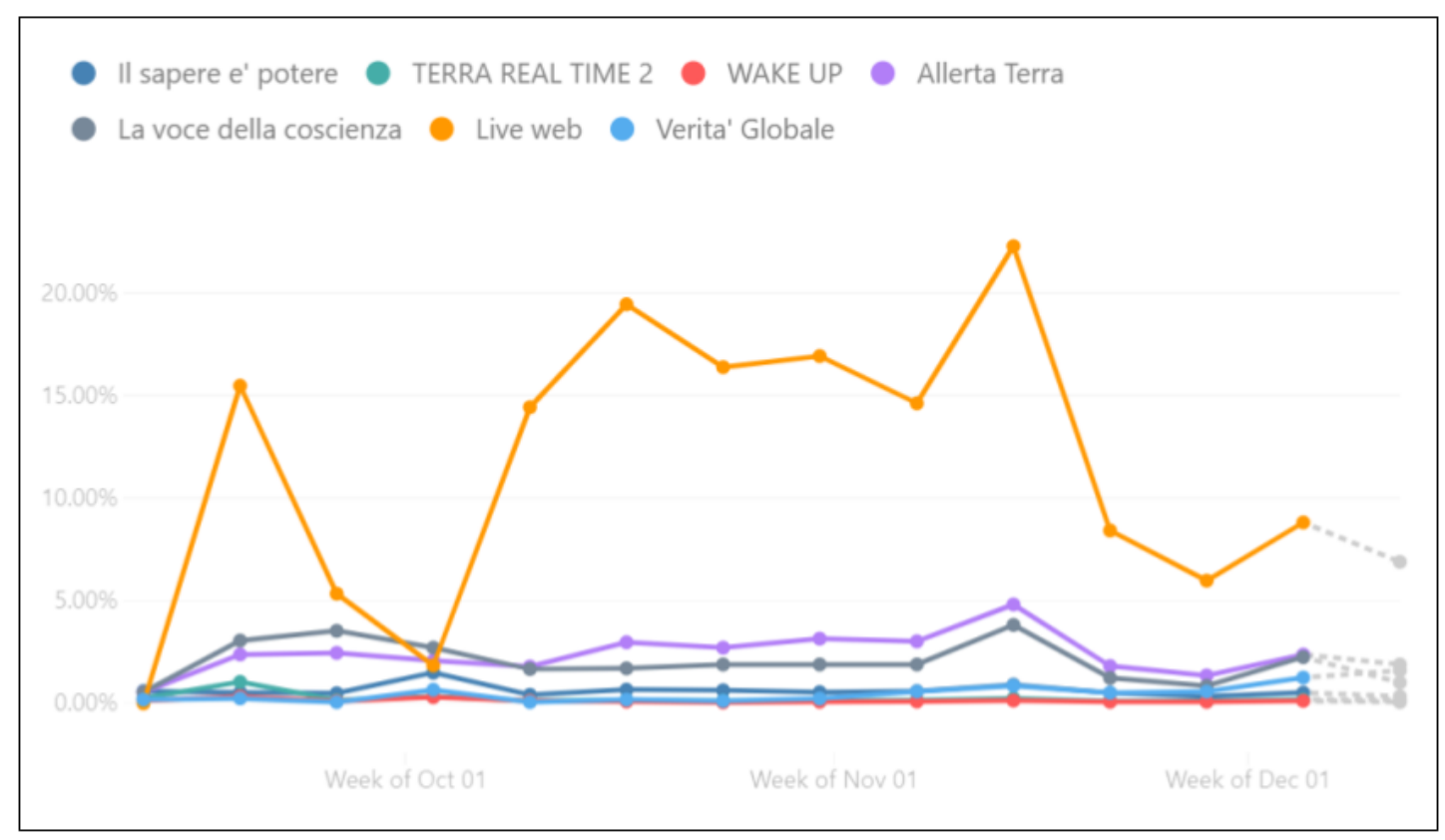

Figure 16: Interaction rate by followers of Blogspot network pages (source: CrowdTangle)

During the last 12 months, the cumulative number of page's likes for the network increased by $16.62 \%$. If we look at the single page growth, the only one that showed a significant increase is also the biggest one - "Il sapere è potere", which grew by 7,211 likes (+14.5\%).

\subsubsection{Behavior}

This dissimilarity in the interaction rate despite the low number of page likes (Fig. 16) attracted our attention. In particular, we observed a specific content sharing strategy of these Facebook pages that is peculiar of the network under consideration.

As shown in the central image of figure 17, a post could be firstly shared as status by "Live Web" page with the link to the article in the first comment. In the following example, the article of video-reporter.blogspot.com describes talks about the President John F.

Kennedy who denounced the New World Order and consequently was assassinated. Then it is re-shared by bigger pages of the same network, with - again - the URL inserted in the first comment. Lastly, it is shared as a link post or as a status with the link in the description. This strategy is not necessarily performed in this order. 


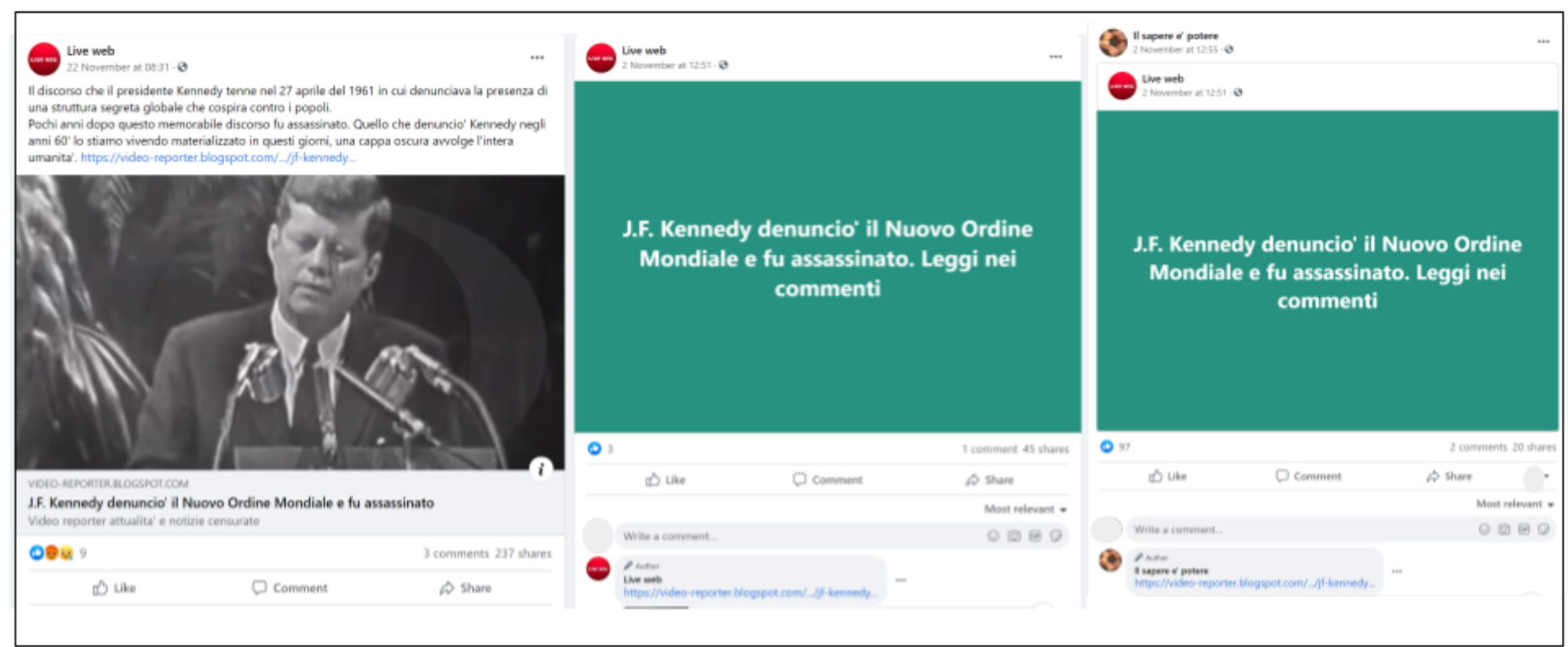

Figure 17: Screenshot carousel of a news entitled "Kennedy denounced the new world order and was assassinated" the network Facebook pages sharing strategies. The post is shared as status by Live web page with the link to the article in the first comment. Then it is re-shared by bigger pages of the same network with, again, the URL inserted in the first comment. Lastly, is shared as a link post or as a status with the link in the description. This strategy is not necessarily performed in this order

\subsubsection{Content}

During the last 12 months, the network of 7 pages under analysis shared a total amount of 21,276 posts, with a monthly average of 1,572. The vast majority of content is represented by link type posts, that are $95.57 \%$ of the total, while a residual percentage are statuses and photos (respectively $3.05 \%$ and $1.25 \%$ ). Link type posts are also those collecting the highest number of interactions (Fig. 18).

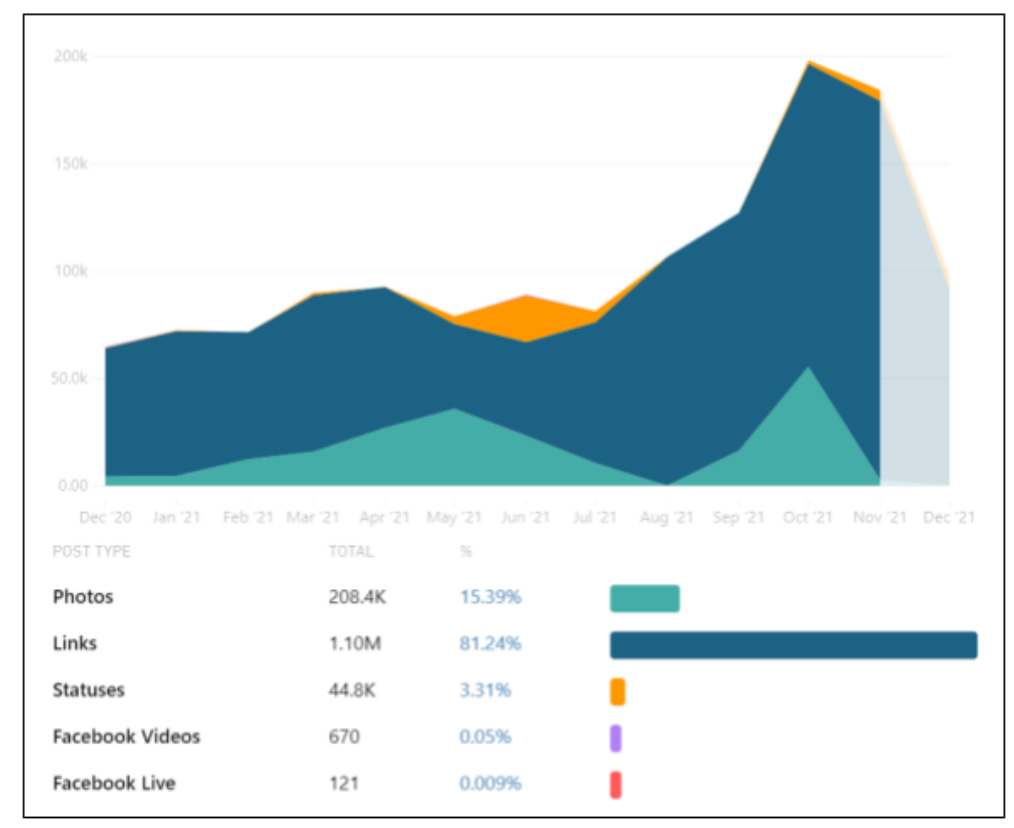

Figure 18: Last 12 months number of interactions per post type (source: CrowdTangle) 
As in the case of page likes growth, we observed a dissimilarity among network pages in types of posts preferably shared: the majority of status posts are shared by "Il sapere e' potere" and "Live web" (respectively, 48.15\% and 46.76\%), while the other pages mainly published link type posts.

\begin{tabular}{|c|c|c|}
\hline $\begin{array}{l}\text { Live web } \\
\text { O Dec 10, } 2021 \text { at 11:12 AM } \\
\text { q) II premio Nobel Montagnier } \\
\text { querela Bassetti per diffamazione } \\
\text { aggravata (Video) }: \text { ilsapereepotere } \\
\text { 2.blogspot.com/2021/12/il-premio-n }\end{array}$ & $\begin{array}{l}\text { Allerta Terra } \\
\oplus \text { Dec 10, } 2021 \text { at 11:12 AM } \\
\text { querela Bassetti per diffamazione } \\
\text { aggravata (Video)(:) }\end{array}$ & $\begin{array}{l}\text { II sapere e' potere } \\
9 \text { Dec 10, } 2021 \text { at 11:13 AM } \\
\text { querela Bassetti per diffamazione } \\
\text { aggravata (Video) }\end{array}$ \\
\hline 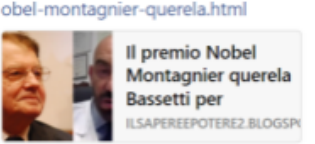 & $\begin{array}{l}\text { II premio Nobel } \\
\text { Montagnier querela } \\
\text { Bassetti per } \\
\text { ILSAPEREEPOTERE2 BLOGSPS }\end{array}$ & $\begin{array}{l}\text { II premio Nobel } \\
\text { Montagnier querela } \\
\text { Bassetti per } \\
\text { ILSAPEREEPOTERE2 BLOGSPI }\end{array}$ \\
\hline Oi) $18 \quad 00 \quad 022 \mathrm{~K}$ & O) $57 \bigcirc 6 \bigcirc 2.2 \mathrm{~K}$ & OB) $1.3 \mathrm{~K} \bigcirc 149 \bigcirc 2.2 \mathrm{~K}$ \\
\hline $\begin{array}{l}\text { La voce della coscienza } \\
9 \text { Dec } 10,2021 \text { at 11:14 AM }\end{array}$ & $\begin{array}{l}\text { Verita' Globale } \\
\text { O Dec 10, } 2021 \text { at 11:15 AM }\end{array}$ & $\begin{array}{l}\text { Rat WAKE UP } \\
O \text { Dec } 10,2021 \text { at } 11: 15 \text { AM }\end{array}$ \\
\hline $\begin{array}{l}\text { (i) II premio Nobel Montagnier } \\
\text { querela Bassetti per diffamazione } \\
\text { aggravata (Video) } \text { ilsapereepotere }^{-} \\
\text {2.blogspot.com/2021/12/il-premio-n } \\
\text { obel-montagnier-querela.html }\end{array}$ & $\begin{array}{l}\text { :) II premio Nobel Montagnier } \\
\text { querela Bassetti per diffamazione } \\
\text { aggravata (Video) } \Theta \text { ilsapereepotere } \\
\text { 2.blogspot.com/2021/12/il-premio-n } \\
\text { obel-montagnier-querela.html }\end{array}$ & 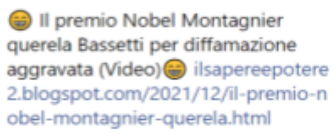 \\
\hline 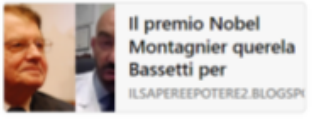 & $\begin{array}{l}\text { II premio Nobel } \\
\text { Montagnier querela } \\
\text { Bassetti per } \\
\text { "LsAperexportuz: BLospr }\end{array}$ & $\begin{array}{l}\text { II premio Nobel } \\
\text { Montagnier querela } \\
\text { Bassetti per } \\
\text { ILSAPEREEPOTERz BLOGSP: }\end{array}$ \\
\hline O) $: 00 \bigcirc 1.5 \mathrm{~K}$ & $O D 10 \bigcirc 2 \quad O_{18}$ & Oi) $34 \quad O_{2} \quad Q_{12}$ \\
\hline
\end{tabular}

Figure 19: Screenshot carousel of a news shared by the pages composing this network. This piece of content is entitled "Nobel laureate Montagnier sues Bassetti for aggravated defamation" and it is referred to a complaint of Montagnier versus the Italian infectious disease specialist Matteo Bassetti

As shown in the example post in figure 19, the pages of this network share a link to the constellation of conspiracy theories supporting blogs hosted in Blogger at approximately the same time. This news, that had a particularly high number of interactions $(N=10,976)$, is entitled "Nobel laureate Montagnier sues Bassetti for aggravated defamation" and reports that Luc Montagnier has taken legal action for defamation against Matteo Bassetti, a popular Italian infectious disease specialist. Bassetti publicly called him a "stupid" when he was hosted in national a tv show.

During the last 12 months, content shared by this network reached 1,336,885 total interactions, with a monthly average of 98,777 interactions. Interestingly, figure 20 shows that most of these interactions are shares (60.11\%), 30.45\% are likes and a few are comments (3.89\%). Furthermore, we often observed that posts created by these Pages obtain the exact same number of shares despite the different base of followers (see Fig. 21). 


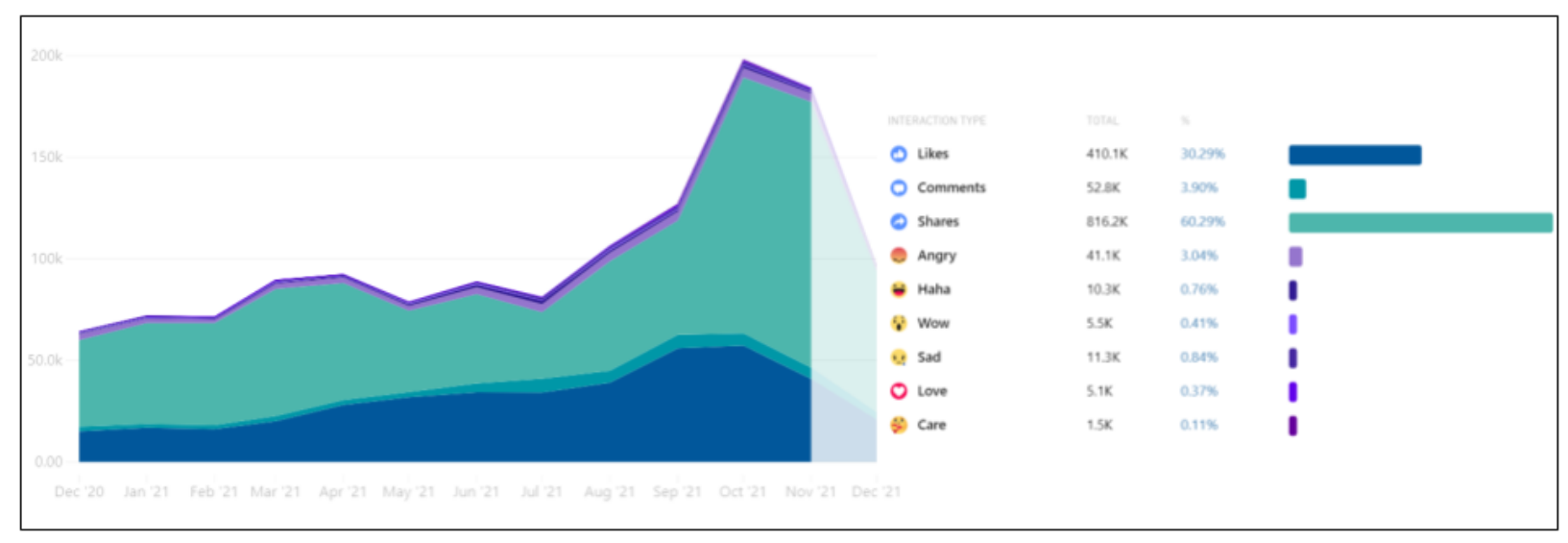

Figure 20: Last 12 months number of interactions per interaction type (source: CrowdTangle)
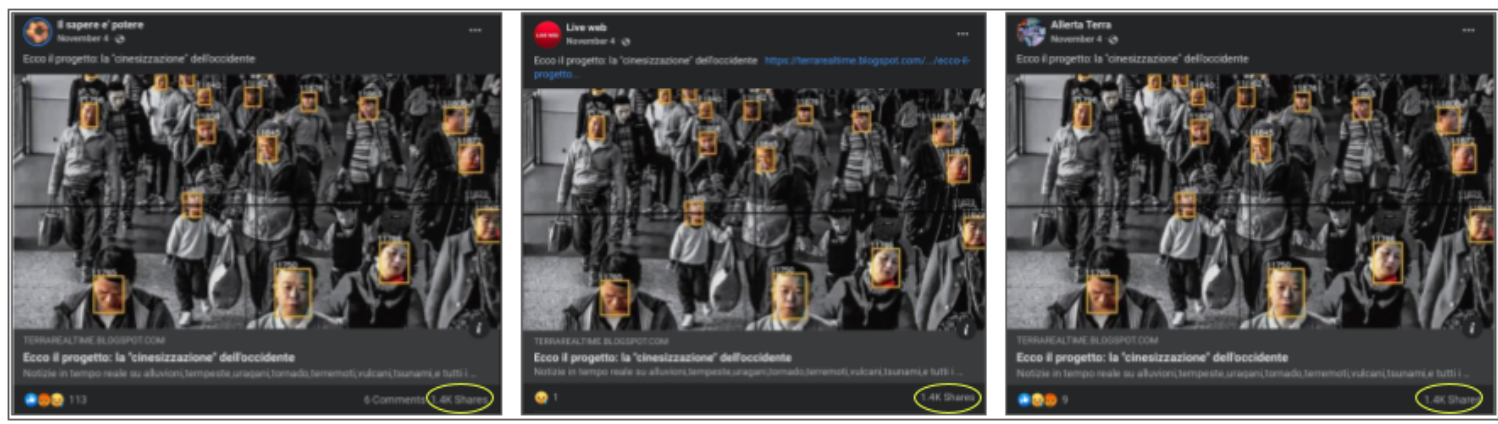

Figure 21: Screenshot carousel of a link type post cross-posted by three Pages and showing the exact number of Shares

Link type posts gathered the majority of interactions $(N=677,473)$, although the content with the higher number of total interactions during the last 12 months is the photo type post in figure 22. This post was shared uniquely by "Il sapere e' potere" and it is an ironique image against the rising popularity of electric vehicles that, the image claims, are only apparently more green. 


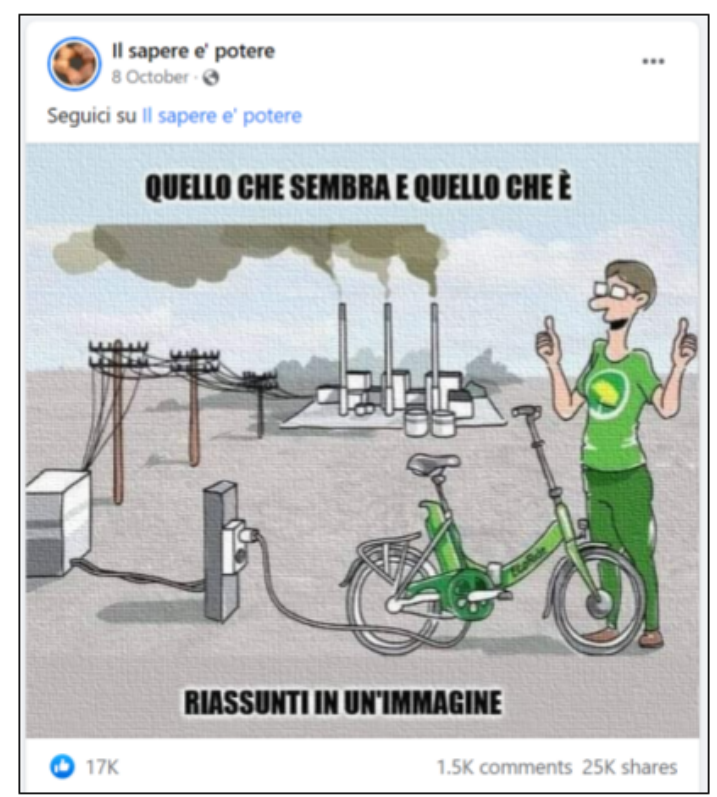

Figure 22: Screenshot of the network most engaging post during the last 12 months. The post says "what it seems and what it is, summarized in an image" and is referred to the "lie" of the electric vehicles

\subsubsection{Case \#2: The "Amen" Awakens}

\subsubsection{Actors}

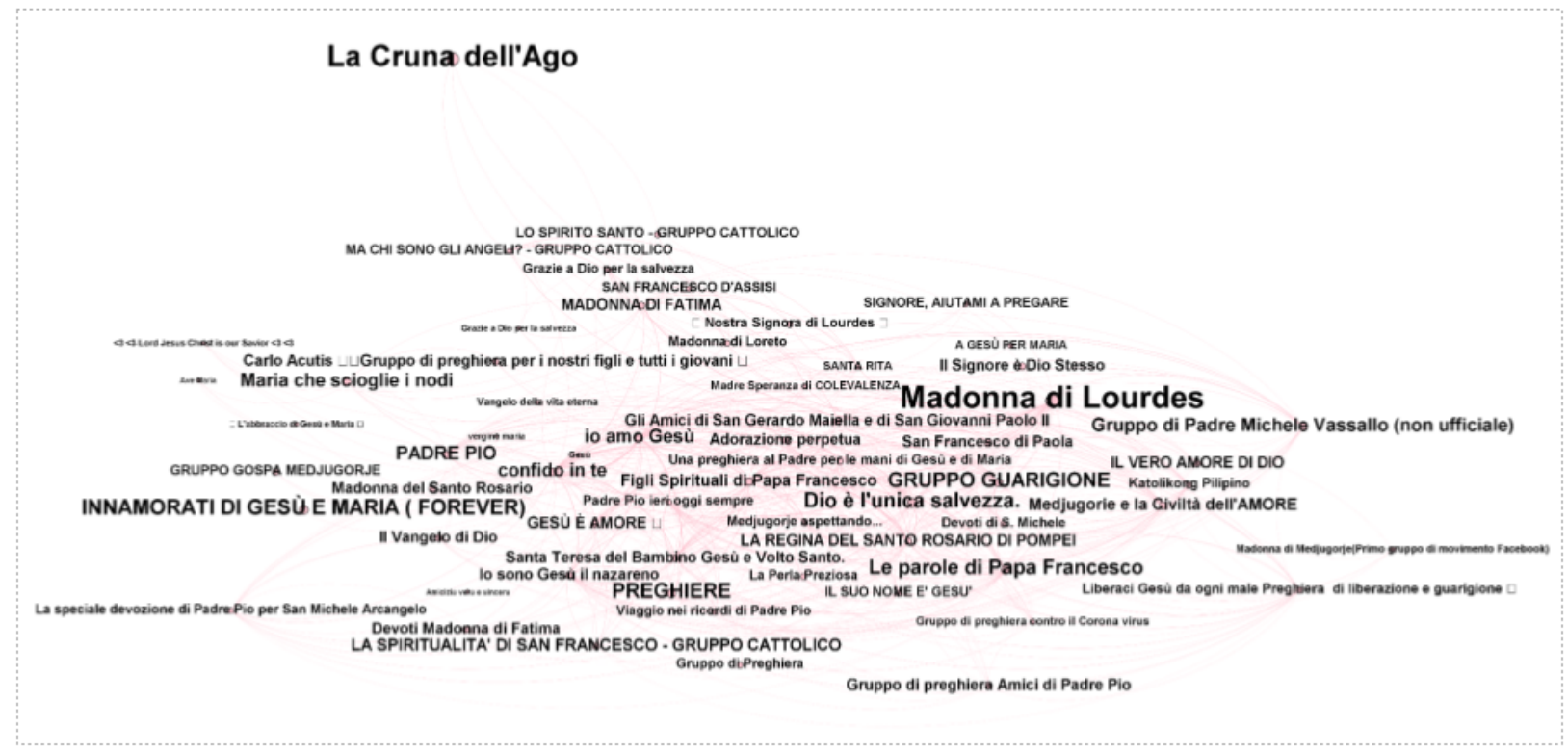

Figure 23: Network related to religious content. The full list of accounts is available in Appendix VI

Among the various networks of Facebook Pages and groups, we noticed two clusters of accounts focused on spreading catholic-oriented content. In particular, two of these attracted our attention. The smaller one is related to the domain papaboys.org. This 
network is composed of 6 Facebook pages: "Papaboys 3.0", "Associazione Nazionale Papaboys", "Santa Rita da Cascia prega per noi", "San Francesco D'Assisi", "Prega Per Noi", "W L'italia", "Il Vangelo del giorno - a cura dei Papaboys". The page "W L'italia", that does not seem to be related to catholic issues, actually posts papaboys.org news (see paragraph 3.3.2. for the analysis of one link circulated by this network).

The larger catholic-oriented network is instead described in this section. It includes 62 religiously inspired groups. The Facebook group "La Cruna dell'Ago" acts as a bridge between this network and the covid-skeptic cluster. This group is well-known for spreading controversial content on COVID-19 and it is listed in the Blogspost network as well as to testify the important role played for the larger community of Italian covid-skeptics.

This network counts 1,397,175 total subscribers and, during the last 12 months, has grown considerably (+820,805 subscribers). This growth was mainly driven by the following accounts: "Madonna di Lourdes", "Maria che scioglie i nodi", "SANTA RITA", "PADRE PIO", "confido in te", "LA SPIRITUALITA' DI SAN FRANCESCO - GRUPPO CATTOLICO", and "Gesù". The subscribers' increment for these entities range from +100 to over +1000 percent.

Interestingly, among the groups with the highest increase of subscribers mentioned above, "Madonna di Lourdes", "SANTA RITA" and "PADRE PIO" have the same admins (Fig. 24).

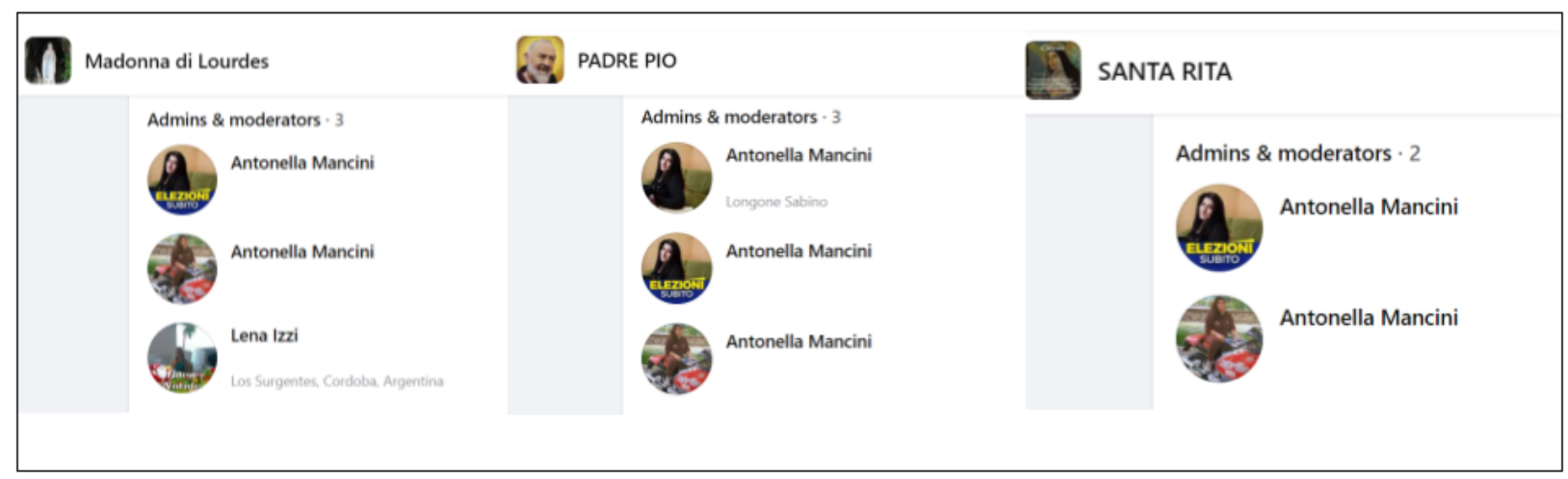

Figure 24: Admins of the groups Madonna di Lourdes, PADRE PIO, and SANTA RITA

All these groups were created in 2016 with another name that is not mentioned in the Facebook transparency feature, and their name was changed in 2019. Three of the admins profiles are referable to the same person, and usually post content related to catholicism as well as politics related to the League.

Another interesting feature that attracted our attention is that some of these Facebook groups (e.g. "Dio è l'unica salvezza", "Grazie a Dio per la salvezza") are administered by several users that, despite their Italian names and surnames, from their profile picture they seem to be Chinese immigrants. Moreover, inspecting their Facebook personal profiles, we can observe that they post exclusively catholic content, while other topics or their private life content are totally missing. Indeed, looking at the links some of these Facebook profiles share, we observed that they frequently publish URLs from kingdomsalvation.org, a Chinese catholic cult considered heterodox from the Catholic 
Church and persecuted up to the repression in China. While these Facebook groups don't seem to spread problematic information, the nature of the admins Facebook profiles is at least opaque. Some elements, such as the lack of personal information and the presence of few personal photos that look like stock pictures, led to the impression of being fake accounts.

\subsubsection{Behavior}

As we usually observe in the networks mainly composed of groups, also these entities are kept together by single users that coordinately share links across different groups. For instance, looking at figure 22 we observe the same news in which the italian pro-life influencer Anna Bonetti claims to have been intimidated by supporters of Fedez (a popular Italian singer and activist pro civil rights) for her criticisms to the DDL Zan ${ }^{11}$. As shown in figure 22, the news was shared multiple times almost simultaneously on July 20 , at 11.26 PM.

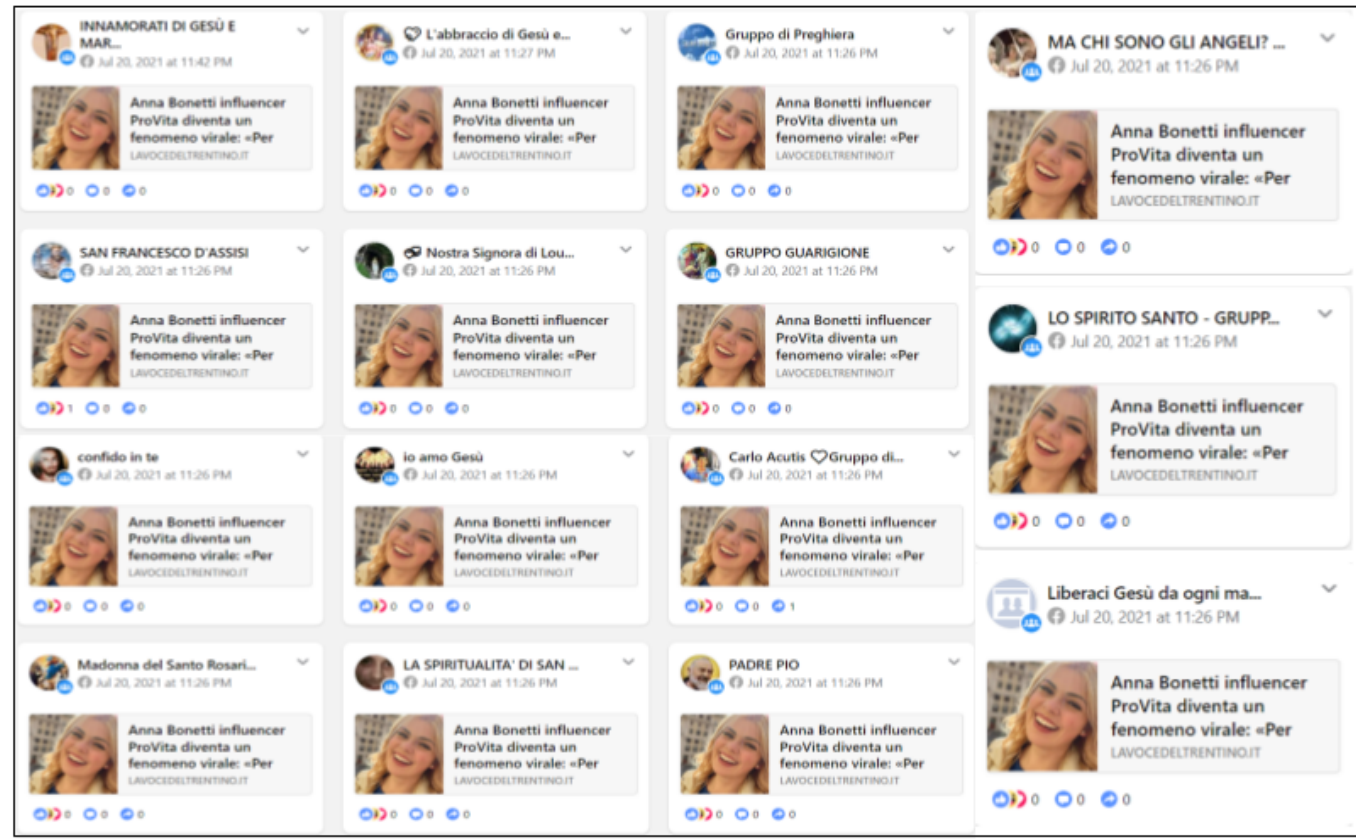

Figure 25: Example of post coordinately shared by religious network. This news is entitled "Anna Bonetti influencer ProVita becomes a viral phenomenon: "I was threatened with death for replying to Fedez"

As shown by the examples in figure 23, this content has been shared by a single user multiple times on different Facebook groups.

\footnotetext{
${ }^{11}$ DDL Zan (Zan's Bill from the name of Senator Alessandro Zan), is a draft law that introduces specific punishments for violent homo-transphobic, misogynist and handicap bias behavior. This bill is strongly opposed by conservatives Members of Parliament.
} 


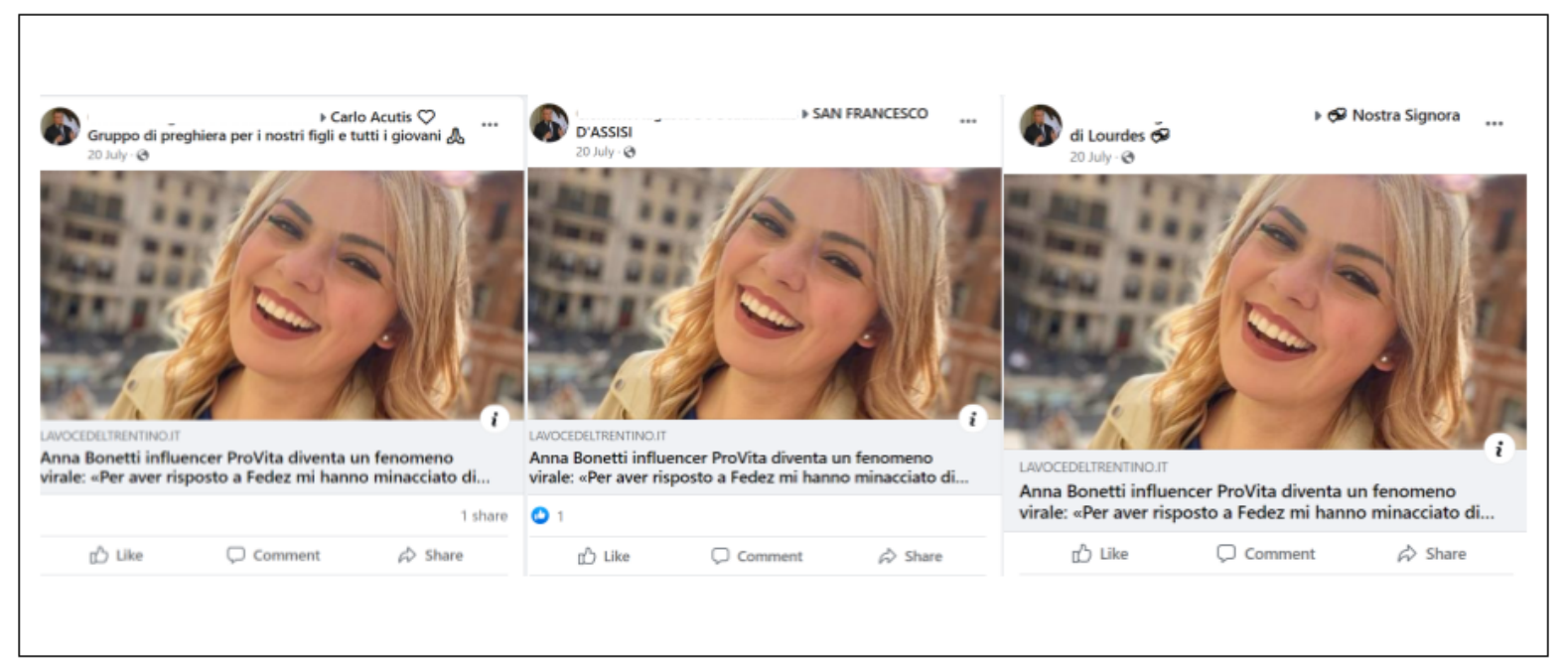

Figure 26: Example of a single user sharing the same link on different Facebook groups

This piece of content is further interesting due to its nature. While this network is centered on the sharing of catholic content among religious users, sporadically some of them publish politically oriented posts. This behavior explains also the fact that all these Facebook groups are linked with "La Cruna dell'Ago", a noteworthy conspiracy theorists group, which in turn directly connects this network to Covid-19 skepticism Facebook entities.

\subsubsection{Content}

During the last 12 months, the network generated an impressive amount of posts (a total of $1,237,447$ content), most of which are photo type posts $(49.42 \%$ of the total). During the same period, these posts gathered many interactions $(N=82,791,486)$ mostly concentrated on photo type posts (as shown in figure 21 , about $85 \%$ of interactions are made by photos).

Differently to other network of entities under analysis, the distribution of interactions per interactions types of this case study follow the main trend of posts on Facebook, where the most popular metric is "like" (in this case, the $45.98 \%$ of the total, as shown in figure 24), that definitely outdistance "comments" (21.04\%) and, in the end, "shares" (7.47\%). 


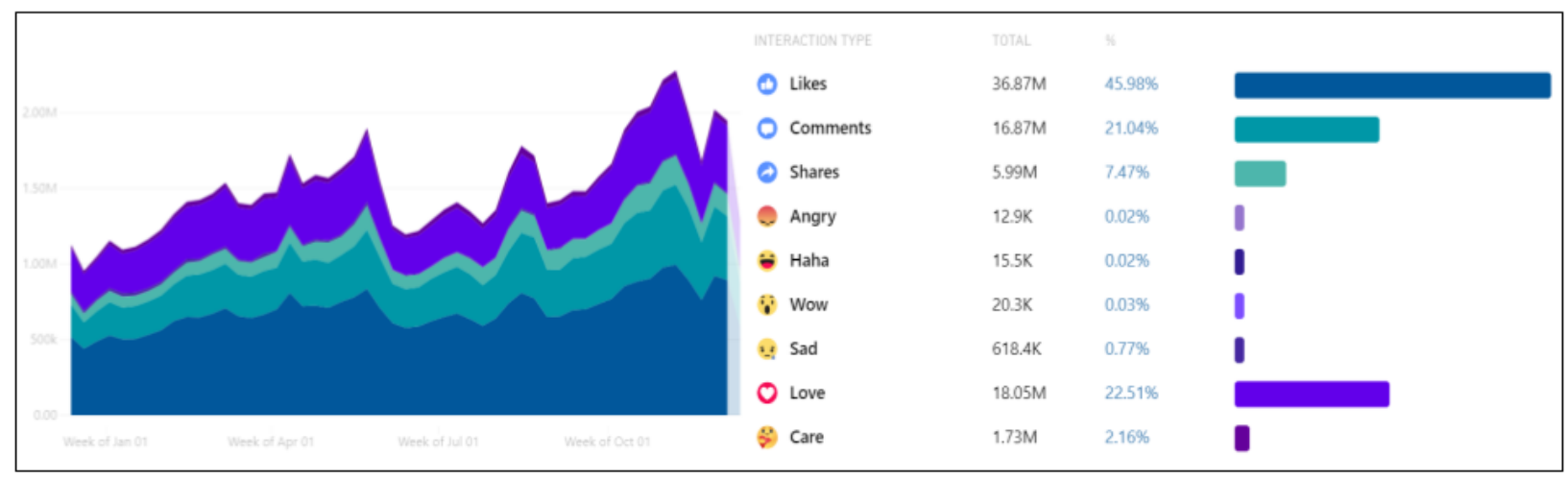

Figure 28: Last 12 months number of interactions per interaction type (source: CrowdTangle)

OGGI E'IL GIORNO PER POTER CHIEDERE UNA GRAZIA....

RECITATELA E IN ALCUNI PUNTI DELLA PREGHIERA CHIEDETE LA GRAZIA.

Gesù Dio mio in te ripongo tutta la mia fiducia, tu sai tutto padre $e$ Signore dell'universo, sei il re dei re, tu che hai fatto al paralizzato camminare, al morto vivere, al lebbroso guarire, tu che vedi le mie angosce e le mie lacrime, ben sai Divino amico mio come ho bisogno di raggiungere questa grazia.

(si chiede la grazia con fede)

La mia conversazione con te mi riempie di animo e allegria per vivere. Solo da te aspetto con fede e fiducia

(Si chiede nuovamente la grazia con fede).

Come ringraziamento pubblicherò questa preghiera in diversi gruppi affinché altre persone che hanno tanto bisogno di te in questo momento imparino ad avere fiducia nella tua divina misericordia e illumina i miei passi cosi come il sole illumina ogni giorno l'alba e testimoniare la nostra conversazione.

(Pregare un padre nostro, Ave Maria, gloria al padre. II mio cuore è il mio cuore

Gesù Cristo la mia fiducia in te ogni volta aumenterà la mia fede. AMEN AMEN

LODATO SEI MIO SIGNORE AMEN

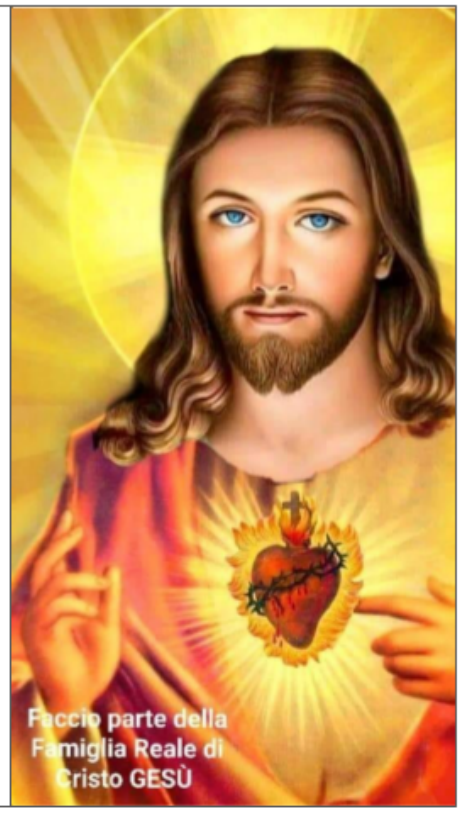

Figure 29: Example of one of the most popular post of this network

This outstanding number of photo type posts and their interactions is illustrated by the example in Figure $25^{12}$, a particularly popular post circulated by this network. Posts generated by these communities in fact are often catholic images of Jesus, Mary or other Saints including prayers, pleas of God intercession, and so on. While posts of this kind represent the majority of the cases, they are not the only type. As described in the behavior section, some users share posts with political domains as shown

${ }^{12}$ The text instructs the reader on how to request a grace from Jesus while praying. However, the last paragraph also suggests sharing the same prayer in "different groups" to thank God and help others. 


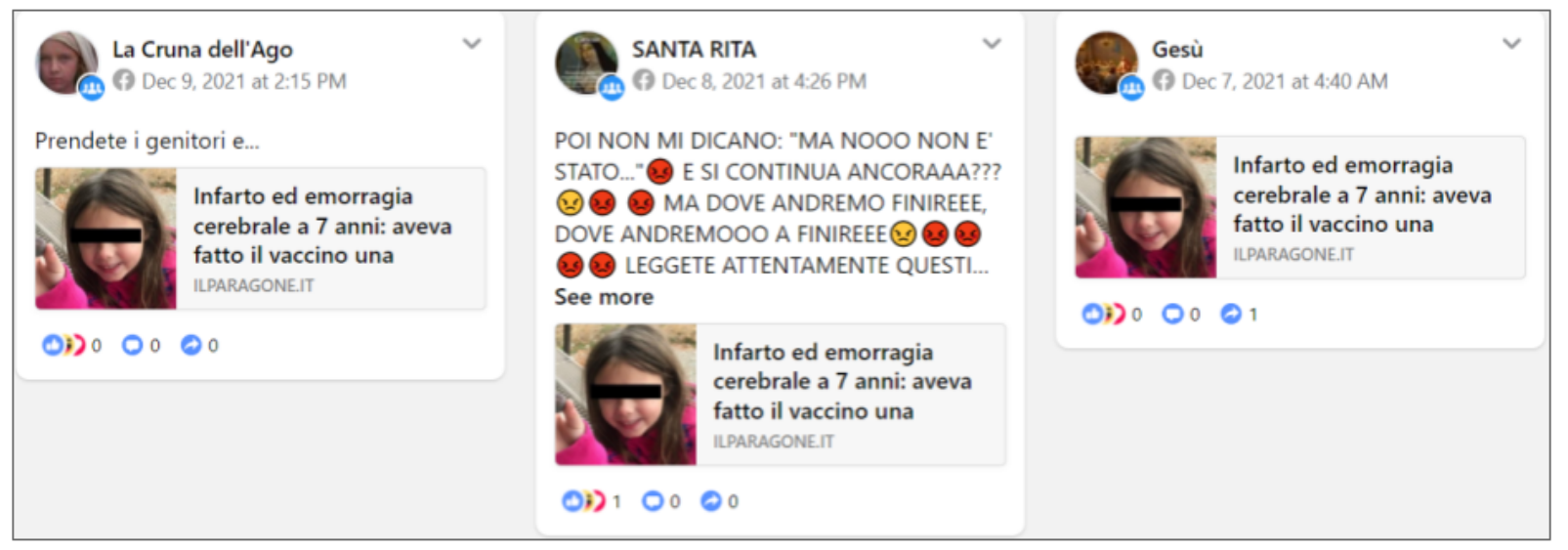

Figure 30: Example of anti-vaxx content spreaded across the religious network

in figure 26. This news published by ilparagone.it, the popular news site of Gianluigi Paragone ${ }^{13}$ which spreads at least controversial information, is entitled "Heart attack and cerebral haemorrhage at age 7: she had the vaccine a week earlier", which would suggest the danger of Covid-19 vaccine. While this kind of content is rare if confronted with religiously inspired posts, it is evidence of a concerning tactique in which large communities of unaware users can be exposed to problematic information posted by infiltrated individuals.

\subsubsection{Case \#3: Return of the "GEDI"}

\subsubsection{Actors}

This network is characterized by the peculiar behaviour of its accounts that simultaneously share links to news stories published by GEDI ${ }^{14}$ group publications. It is made of 31 Facebook pages (see Appendix VI, case \#3). Unlike the other networks analyzed in this report, the case under scrutiny here has been surfaced by the MINE-FACTS tool during its activity. The tool dynamically discovers coordinated accounts not previously observed by looking at the sharing patterns the potentially problematic content surfaced. When this sharing pattern includes unknown Pages or groups, the new venue is added to the list of tracked accounts. In this specific case, our attention was drawn by an account of this network, which posted a misleading article regarding the alleged resignation of the Italian prime minister, Mario Draghi.

\footnotetext{
${ }^{13}$ Gianluigi Paragone is a politician and journalist openly sustaining antivaxx, anti european and conspiracy theories.

${ }^{14} \mathrm{GEDI}$ is one of the largest Italian publishing groups. It operates in all sectors of communication: daily and periodical press, radio, internet, television and advertising sales. Renewed news brands such La Repubblica and La Stampa belong to this group.
} 


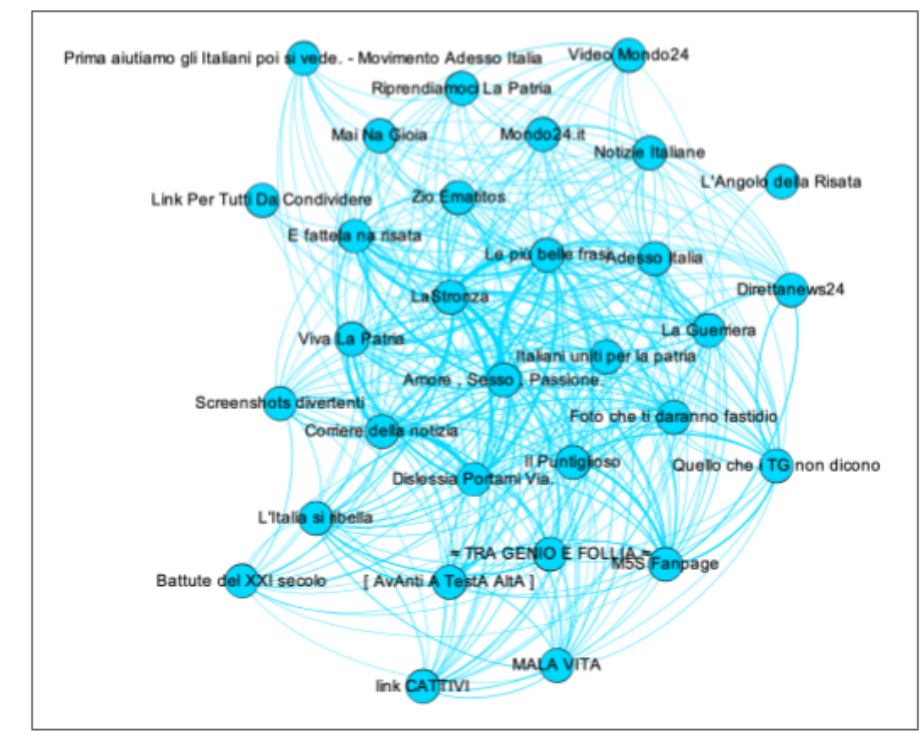

Figure 31: Network sharing "GEDI" URLs. The full list of accounts is available in Appendix VI

Between 01/01/20 and 11/30/21, the cumulative number of Page likes for this network decreased constantly from $4,828,199$ to $4,629,680$ (-4.11\%). The number of posts remained almost stable, albeit with small fluctuations, until the end of February 2021, with a significantly lower number of image posts than the link and statuses post types. At the end of February 2021, image posts also reached links and statuses levels. The posting rate surged between August and November 2021. During this time, the monthly posting rate more than doubled, from about 10,000 posts per month to about 27,000 .

The analysis of links posted pointed out that the destinations (i.e. hidden by the url shortener) that are the most widespread in the network are in particular third-level domains linked to the Italian newspaper La Repubblica ${ }^{15}$. These subdomains refer to the local versions of the newspaper itself and specifically to the various Italian provincial capitals. In addition to these subdomains, there are other destination links in the network that share with Repubblica the belonging to the GEDI publishing network, through Manzoni Advertising (A. Manzoni \& C. SpA), the exclusive advertising agency for the media of GEDI Gruppo Editoriale SpA. Among the most shared domains, tvzap.it, caffeinamagazine.it and dcommerce.it emerge, all of which are part of the Manzoni group's portfolio of publications mentioned above, as explained on this page.

In the first place, it is worth noting that several pages of the network describe themselves - in titles or information sections - in a way that differs from their prevalent activity, i.e. the sharing of links to news articles. While some of the pages ("Quello che i TG non dicono", "Il Puntiglioso", "MALA VITA", "link CATTIVI", "Direttanews24", "Notizie Italiane") declare that they have the mission of making independent information, as in some cases the name of the Pages claims, other Pages claim to be collections of funny pictures or

\footnotetext{
${ }^{15}$ Top shared domain are (sorted by most shared): www.repubblica.it, www.tvzap.it, www.adnkronos.com, roma.repubblica.it, www.caffeinamagazine.it, torino.repubblica.it, palermo.repubblica.it, milano.repubblica.it, napoli.repubblica.it, bologna.repubblica.it, firenze.repubblica.it, bari.repubblica.it, genova.repubblica.it.
} 
cartoons ("Zio Ematitos", "Foto che ti daranno fastidio", "E fattela na risata", "Battute del XXI secolo", "Screenshots divertenti", "Dislessia portami via", "L'angolo della Risata", "Mai $\mathrm{Na}$ Gioia"). In some cases ("Corriere della Notizia"), it is declared the purpose of disseminating news censored by the mainstream media.

Some pages of the network try to provide content aimed at content sharing, such as links or videos ("Link Per Tutti Da Condividere", "Video Mondo24"), phrases ("Le più belle frasi"), and feelings ("Amore, Sesso, Passione."). Other pages, like "Mondo24.it", appear to be generalist news blogs or politics pages ("Italia ribelle"). Several pages also present clear references to the theme of nationalism ("Riprendiamoci La Patria", "Italiani uniti per la patria", "Prima aiutiamo gli Italiani poi si vede. - Movimento Adesso Italia", "Viva La Patria").

The headings of the two pages "La Stronza" and "La Guerriera" share the same graphic layout, consisting of a title and a subtitle aligned in the center, as evidenced by the figure below.

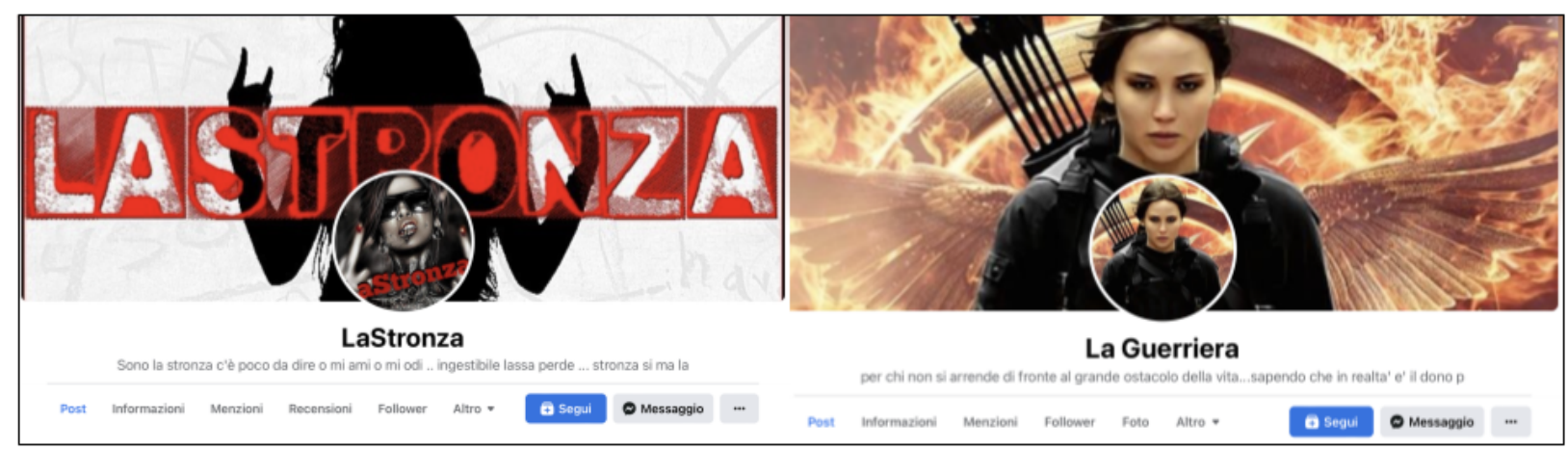

Figure 32: Headings of the pages LaStronza and La Guerriera

The page La Guerriera shows the skynew.it domain in the information section. The WHOIS data of this domain is public and the Registrant is a company based in Cyprus, called Macrosten Itd.

This company ended up at the center of a news story by the Corriere della Sera. As reported by Corriere, the company is the owner of the coronavirus.it domain, which was purchased 7 years ago and reactivated on February 24, 2020. In the cookie policy, the site indicates a name of another company, Puglia.com Srls, from whose company data the name of Andrea Denise Dinoia emerges. Dinoia, according to Corriere, denied to be the real owner of Macrosten (formally registered to the trust company Hamervate Limited) even if in some mediation procedures the name of Dinoia emerges as such. From a reverse WHOIS analysis it came up that the Cyprus holding is the owner of about 110,000 domain names.

"L'Angolo della Risata" contains in the information section a domain, gazzettadellasera.it, and a mobile phone number (320 79198 94). By retrieving the history of WHOIS records, it is possible to trace the name of the domain holder, which in 2018 (April 5) was Vincenzo Todaro. The mobile number, analyzed through the sync.me tool, returns the name Catena Umana. By carrying out a Reverse WHOIS search on the name 
Vincenzo Todaro, it is possible to go back to a list of domains in which the Catenaumana.it site appears. Catena Umana was the subject of an investigation by the debunking site bufale.net, which discovered countless Facebook pages linked to it $^{16}$. Catena Umana, according to bufale.net, aimed at spreading false, misleading or simply news entirely copied by other newspapers. Another name that emerges from one of the pages of the Catena Umana network analyzed by bufale.net is that of Vincenzo Diovisalvi. According to bufale.net, Facebook pages linked to Catena Umana, specifically called Fuori dai coglioni, appeared to advertise another domain, piovegovernoladro.eu, registered in the name of Diovisalvi himself.

Going back to our network, the pages "Italiani uniti per la patria", "Prima aiutiamo gli Italiani poi si vede. - Movimento Adesso Italia" explicitly refers to Vincenzo Diovisalvi in the information section, where he is presented as the national secretary of Ora Italia.

The pages "Screenshots divertenti", "Dislessia portami via" seem to share the same description and indicate the link CondividiQuesto.com in the information section. Looking at the footer of the site, you can see a VAT number (09313330012), as well as two other useful sites, apparently connected because they report the same VAT number in the footer. The sites indicated are notizieTG. it and autoStoreCenter.com, respectively, a news site and a car-themed site. By carrying out a search on the VAT number, it emerges that it belongs to the TOP Model Management fashion agency.

The page Mondo24.it indicates the homonymous website in the information section. Trying to reach the domain Mondo24.it, we are redirected to social24.it, which does not contain any information about the editorial staff or the people who manage it. However, the WHOIS records are public and visible and the domain is registered in the name of Rosalva della Torre, with address Via Scalenza, 06 in Piraino (ME); the WHOIS records of the mondo24.it domain instead indicate Vincenzo Alessandro Crax as registrant, with address Via Bruca, 84 in Capo D'Orlando (ME). Two geographically close localities, which suggest a link between the two registrants just mentioned.

Additionally, the network includes a set of Pages known for spreading harmful inflammatory false stories since 2017 (Giglietto et al., 2021).

In other terms, while currently posting content to legitimate news sources, the large majority of Pages in this network share questionable track-records. To attempt explaining the motivation between the current weird behaviour of these accounts we assumed a scenario in which most of these Pages are currently experiencing a reduced circulation of their content due to the active measures imposed by Facebook for violating their platform policies. Posting links to reliable sources, these Pages are trying to clean up their "criminal records" by experimenting in a scheme that we refer to as "link laundering". While explaining the current low level of engagement observed (see paragraph 3.2.3.4), the hypothesis does not explain why the network is specifically bringing traffic to news sources listed in Manzoni group's portfolio.

\footnotetext{
${ }^{16}$ See https://www.bufale.net/guida-utile-chi-ce-dietro-catena-umana-bufale-net/.
} 


\subsubsection{Behavior}

Most of the posts on the network appear to be composed in the same way, i.e. by an image-macro, with a recurring graphic template and a clickbait title, as can be seen in the figure below.

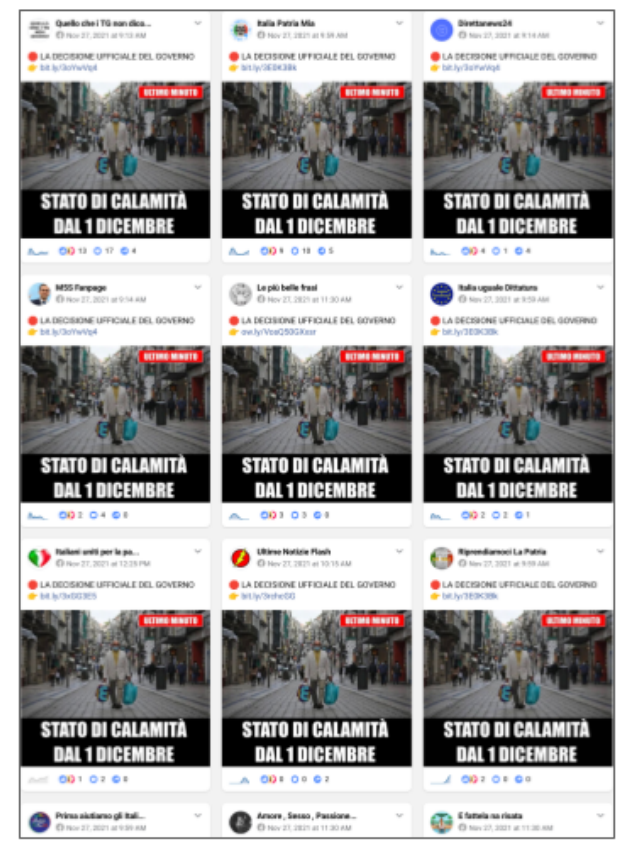

Figure 33: Example of coordinated posts by the network

A text description adds hype to the news object of the post and there is almost always a shortened link - for example, by bit.ly or ow.ly - that leads to external pages. What emerges from the analysis of external links is that, as mentioned above, the links often lead to Repubblica.it (in its second level or third level local domains), an absolutely authoritative newspaper, which suggests an attempt at link laundering. By link laundering we mean that process, adopted by the Pages belonging to the network, possibly aimed at increasing the organic reach of the pages themselves and improving the engagement values, which at this moment are still in sharp decline. This hypothesis would also be supported by the still recurring posting of memes or "self-explanatory" images ready for sharing, such as riddles, tweets, and memes.

Other recurring websites are tvzap.it or caffeinamagazine.it, which are part of the GEDI publishing group as well as the Manzoni Advertising network, as mentioned above. Therefore, it should be noted that, although Repubblica is an authoritative newspaper, other publications of the GEDI group appear in the top shared URLs, towards which most of the traffic produced by the shares of this network is directed.

In the period examined, the posts shared by the network obtained 10.5 million of total interactions. The large majority of this activity $(72.49 \%)$ occurred with photo posts without a link. These image macros, where the text is represented by inspirational quotes / sentences, gathered on average 41 interactions per post. On the other hand, posts including a link (either in the form of photo or link post) gathered 34 interactions per post on average. It is worth noting that the type of Facebook video post is the one that has obtained the highest number of interactions per post on average, i.e. 441, while the Other videos post type comes immediately after, with 256 average interactions. 


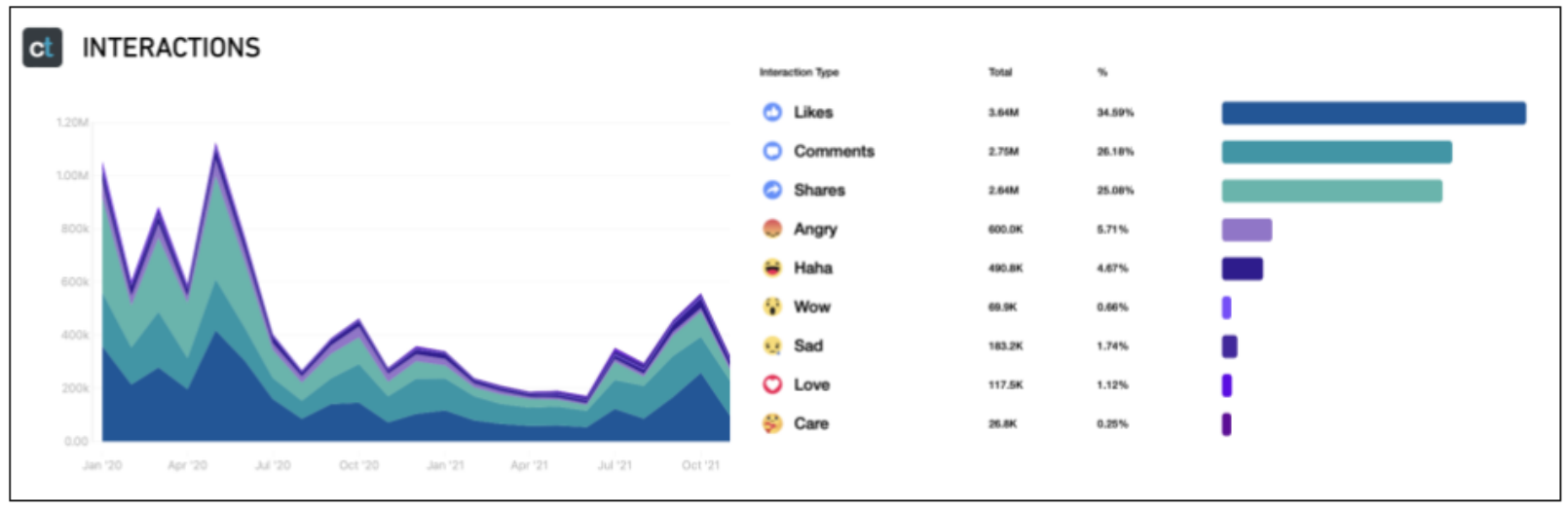

Figure 34: Interactions per type (source: CrowdTangle)

We can see that the strong presence of visual content, accompanied by captivating titles and clickbait, stimulate not only likes (34.59\% of the total) but also sharing (25.08\% of the total) and even comments ( $26.18 \%$ of the total). This structure of interaction, with an almost equal number of likes and shares, is unusual insofar as likes tend to be by far the most common type of interaction on Facebook.

The popularity and shareability of this content was most probably used to try to cumulate page followers or stimulate interactions over time. But, on the contrary, it seems that the strategy is not producing this type of result, as the followers of the network pages are constantly decreasing throughout the time frame under consideration.

The interactions seem to undergo an abrupt halt in May 2020. Analyzing the shared posts, with particular reference to the Link type, we observe the clear presence of links (not abbreviated) to the tg24-ore.com site. The domain appears to be part of a disinformation network analyzed in a previous work (Giglietto et al., 2021). Tg24-ore is indeed a news source that, according to NewsGuard, fails to meet all the basic journalistic standards, is anonymous, and publishes false news about health and partisan right-wing stories without disclosing their editorial line. The network has a long history of activity.

\subsubsection{Content}

During the following long period in which the interactions are at significantly lower levels than the previous ones (from July 2020 to June 2021), the network seems to introduce among the posted links the authoritative sources described above, such as Repubblica.it to name one. Despite this, links are posted to domains of dubious authority, such as notiziariodelweb.it, which - according to our previous investigation - is one of the most recent domains used by the Tg24-ore.com network. In fact, the pages "Foto che ti daranno fastidio", "MALA VITA", "[AvAnti A TestA AltA]", "L'Italia si ribella" has the domain notiziariodelweb.it in the Information section of the page. The latter page also indicates tg24-ore@libero.it as the email address.

The potential reach of the network is significant, with a cumulative subscriber count of almost 4.65 million users. The largest page in terms of likes ("Zio Ematitos") has 574,235 
likes, while the smallest ("Amo la Mia Italia") has about 10,000. These pages were created between 2010 and 2018 and are managed by administrators based in Italy, Spain and Dominican Republic. Between 01/01/20 and 11/30/21, the pages belonging to this network have published an average of 11,600 posts per month $(266,800$ in total between $01 / 01 / 20$ and 11/30/21). The type of content published was mainly photos and macros images (70.29\%), followed by links (27.53\%). The remaining post types used are mostly statuses ( $=4,800)$, Facebook videos $(n=705)$, Facebook Live $(n=266)$, YouTube videos $(n=76)$, other videos $(n=4)$.

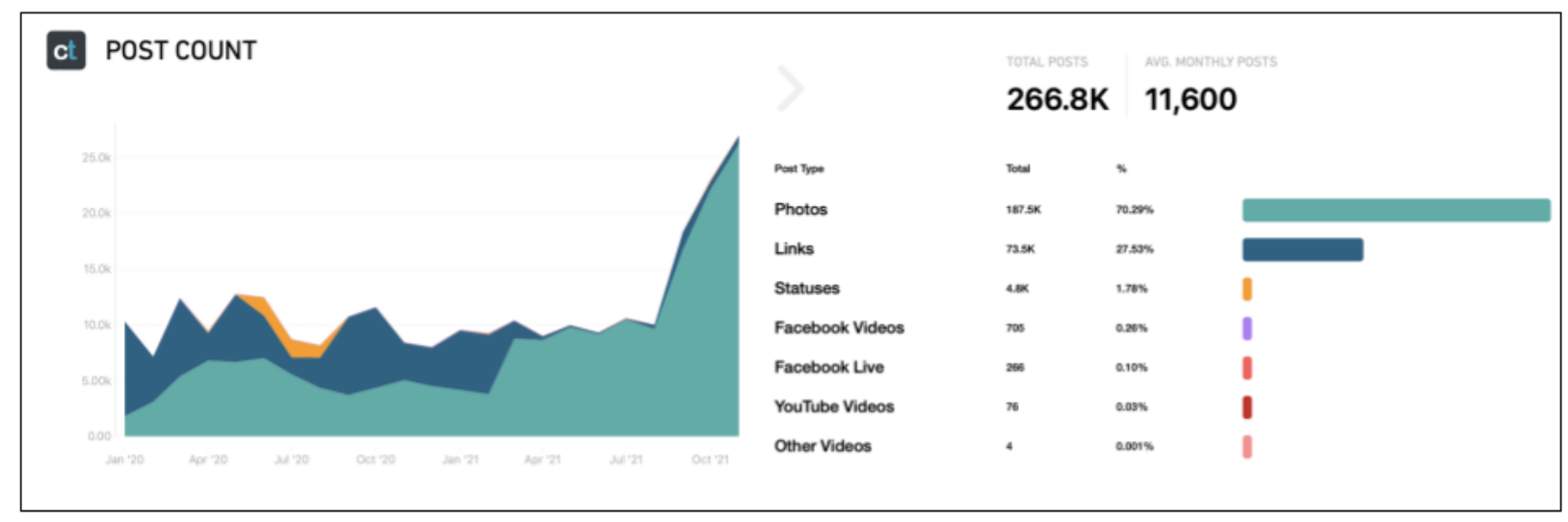

Figure 35: Posts count per type (source: CrowdTangle)

The large majority of photo type posts consists of image macros where text is superimposed or juxtaposed to a photo/background. However, a closer analysis of these posts pointed out that almost all the posts were used to land users on external websites, with the addition of an shortened link (e.g. bit.ly) in the text or in the comments (Fig. 2a and $2 b)$.

The insertion of the link in the comments or with link shortener begins following the tightening of the guidelines of the Facebook community to escape the control action by the Fact-Checkers.

Using photo type posts to link external pages is a commonly used strategy employed by pages to hide their motivations and, most probably, to exploit the better treatment in terms of circulation that photo posts receive over links by Facebook's algorithm. The link is often shortened using bit.ly or ow.ly for aesthetic reasons and/or for hiding the destination source.

The most shared contents seem to be links on issues capable of generating as much engagement as possible. A strategy that we believe can be explained by the downward trend in total network engagement. The most recurring themes concern coronavirus, politics, news and gossip, and share rather emphatic and sensationalistic tones with which they are described by the title present in the image-macros. 
In addition to the aforementioned contents, the pages of the network usually post only graphic contents (i.e. images without links) and specifically memes, tweets, quotes, and riddles that are well suited to sharing or being commented on. In some cases, there are in fact calls-to-action, which urge users to intervene with a reaction, a share or a comment.

\subsubsection{Case \#4: Attack of the clones}

\subsubsection{Actors}

The core of this network is currently composed of 7 Facebook pages (see Appendix VI, case \#4).

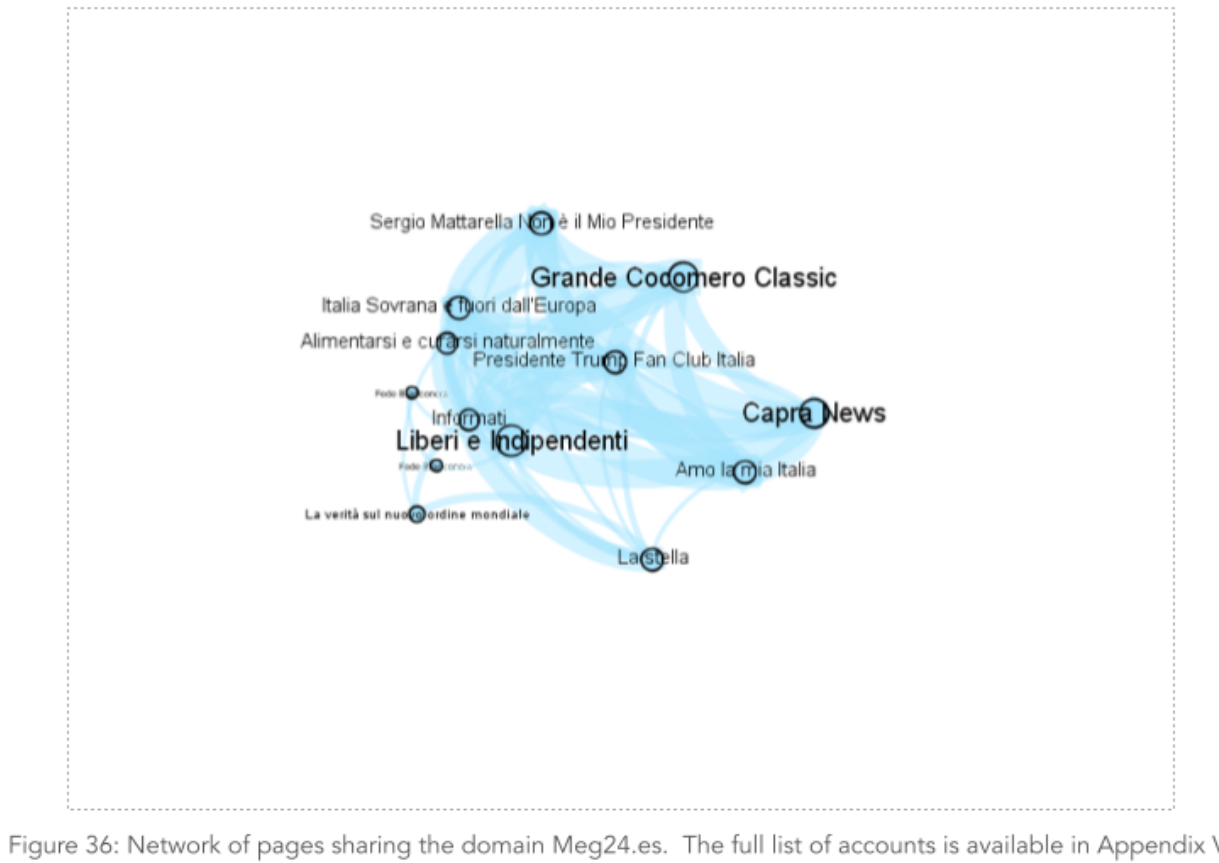

The Pages were created between 2014 and 2020 and are managed by administrators mainly based in Italy and Spain. The potential reach of the network is significant, with a cumulative subscriber count of almost 550,000 users. The largest page in terms of likes (Grande Cocomero Classic) has 307,000 likes, while the smallest (Amo la Mia Italia) has about 10,000. Between 01/01/20 and 11/30/21, the cumulative number of Page likes increased by $7.23 \%$ from 541,094 to 580,212 . The number of likes has suffered a slight decline in the period between January 2020 and August 2020, when it experienced a significant increase $(21,292$ likes). The increase remained almost constant in the remainder of the period. Posts published by this network have been often surfaced by MINE-FACTS tool during the test period of November 2021.

The majority of posts of this network include links pointing to the domain mag24.es, an anonymous web news magazine that publishes hyperpartisan news and is often copied in part or in whole by other newspapers. Mag24 is repeatedly cited in the chronicles as a source that produces problematic information $(1, \underline{2}, \underline{3})$. The WHOIS data provided by the Spanish NIC registry shows that the domain is registered to Francesco Soro. 


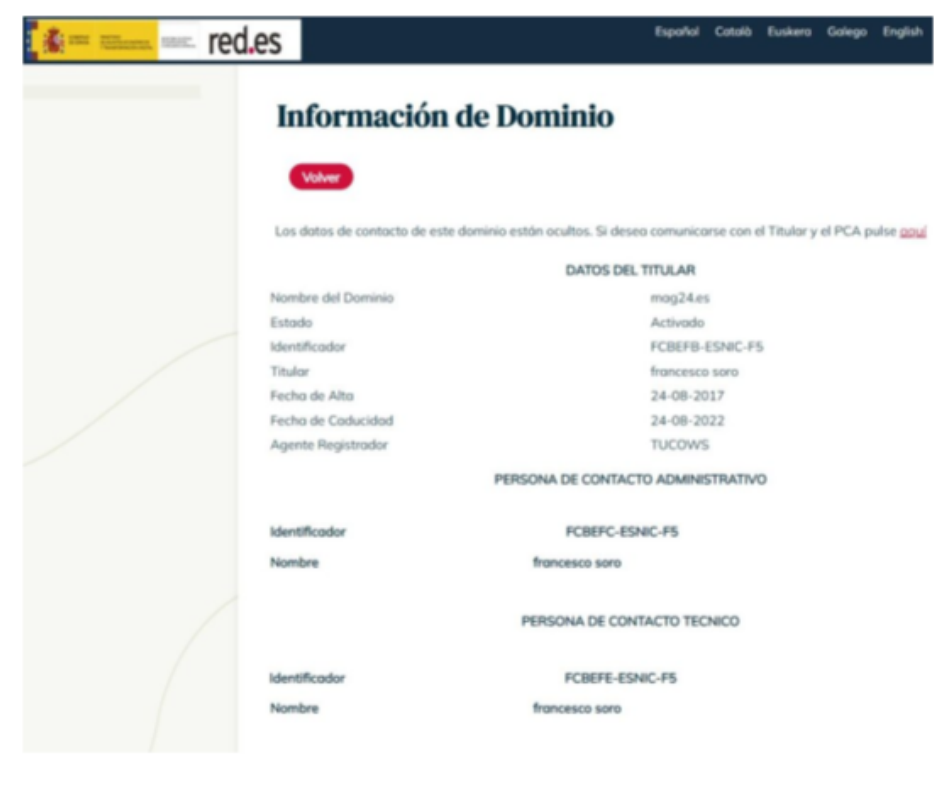

Figure 37: WHOIS data for mag24.es

Thanks to the snapshots of the site archived by WayBackMachine, we also went back to Pachi Solutions, a company based in Spain founded by Francesco Soro (which was liquidated in 2018) to which Mag24 referred.

The network has a history that dates back to at least 2014 when it shared links to articles hosted on a site with similar characteristics to Mag24, whose domain name was grandecocomero.com (as one of the pages is named).

Mag24.es shared the AdSense code (Google's advertising system) with gigimoncalvo.com. Francesco (sometimes called Chicco) Soro successfully competed in the 2009 municipal election of Novi Ligure as a candidate to city councilor with the "Leghisti di Novi" party, in support of Gigi Moncalvo (who lost the election but will later become the director of La Padania, the official newspaper of the League). According to these press articles (1, 2), Francesco Soro was arrested for dealing in marijuana in 2013. In particular in the article published by II Novese, there is a photo dating back to the time of the arrest that shows remarkable similarities with Francesco Soro's Facebook profile pictures; there is also a Youtube video, entitled Leghisti di Novi for Moncalvo Mayor and uploaded 12 years ago, where Soro appears as a candidate for Moncalvo (see figure below). 


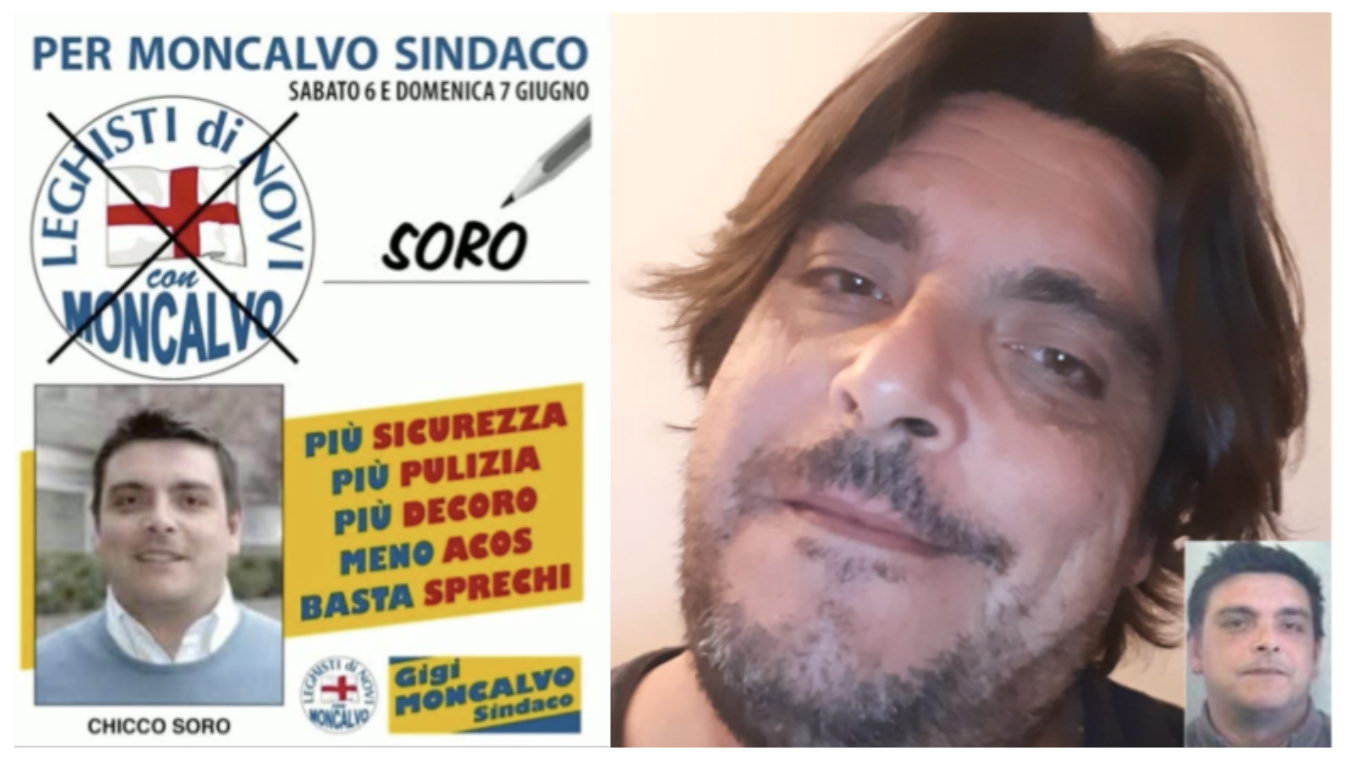

Figure 38: Soro as a candidate for Gigi Moncalvo on the left; Soro's Facebook profile picture on the right; bottom right, II Novese's photo

A few months ago, Soro himself opened a new YouTube channel (the first videos date back to 6 months ago) in which he spread conspiracy theories and skepticism about Covid. Mag24.es homepage lists political news, gossip, advice on wellness, travel and sports. Mag24.es has had its own Facebook page since 2019, but at the time of our analysis the page is not anymore available.

In the seven pages analyzed so far, the presence of Mag.24 is constant and not only displayed in the links of the posts, but also in some metadata of the pages such as the information space of the page: "Grande Cocomero Classic", "Italia Sovrana and Fuori dall'Europa" contain in the "website" section the full link of Mag.24. "Liberi e Indipendenti" Page includes the Mag24.es site and www.grandecocomero.info/ in its links and shares the exact same page description with "Grande Cocomero Classic" Page, highlighting its connection. Wayback Machine shows that until the beginning of 2018 the site had a similar layout to Mag24. In the capture of June 3, 2017 (the oldest available on Wayback Machine), some interesting things can be identified: the caption "PACHI SOLUTIONS | Designed by somstudio "on the footer and, next to it, a link to an Instagram profile, Living Lanzarote, which will be discussed in more detail later. Starting from the capture of 13 October 2017, grandecocomero.info redirects to a new domain: www.grandecocomero.com.

By performing a reverse Google Analytics ID search of Mag24.es (UA-51183173), in May 2021 two domains seemed to be related, www.capra.news and www.robedamaschi.it, as shown in the picture below. 


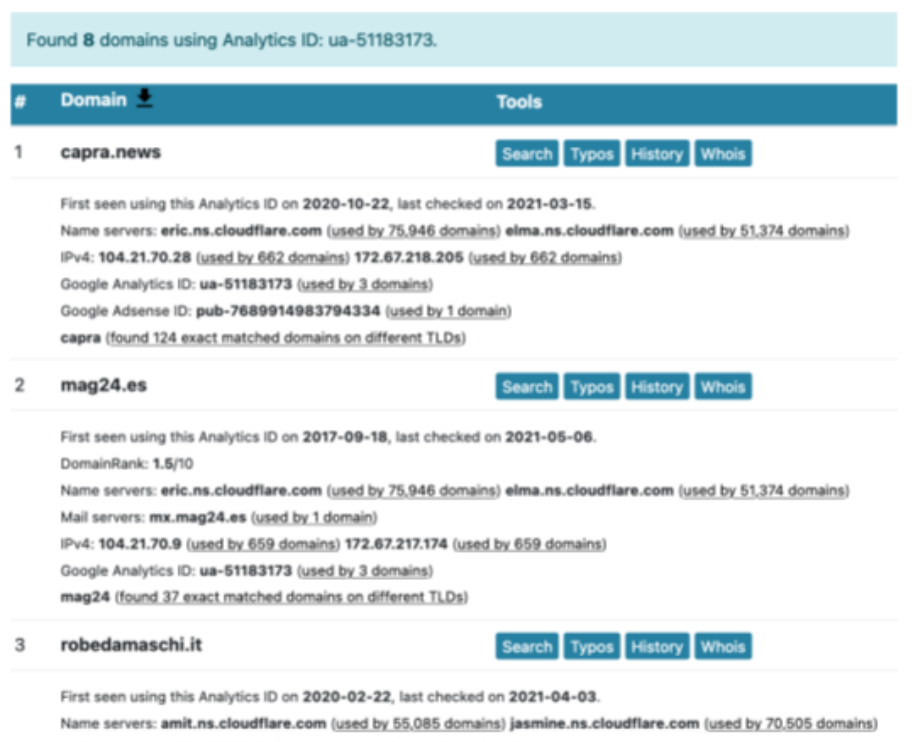

Figure 39: capra.news, mag24.es and robedamaschi.it sharing the same Google Adsense UA code in May 2021

Today, www.mag24.es appears to share its UA code (UA-51183173) with www.grandecocomero.com. Moreover, www.grandecocomero.com seems to have shared its Google AdSense code pub-7689914983794334 to two other domains: gigimoncalvo.it and medicbunker-la-verita.blogspot.com.

\subsubsection{Behavior}

Most of the posts on the network appear to be composed in the same way, i.e. by an image-macro, with a recurring graphic template and a clickbait title, as can be seen in the figure below.
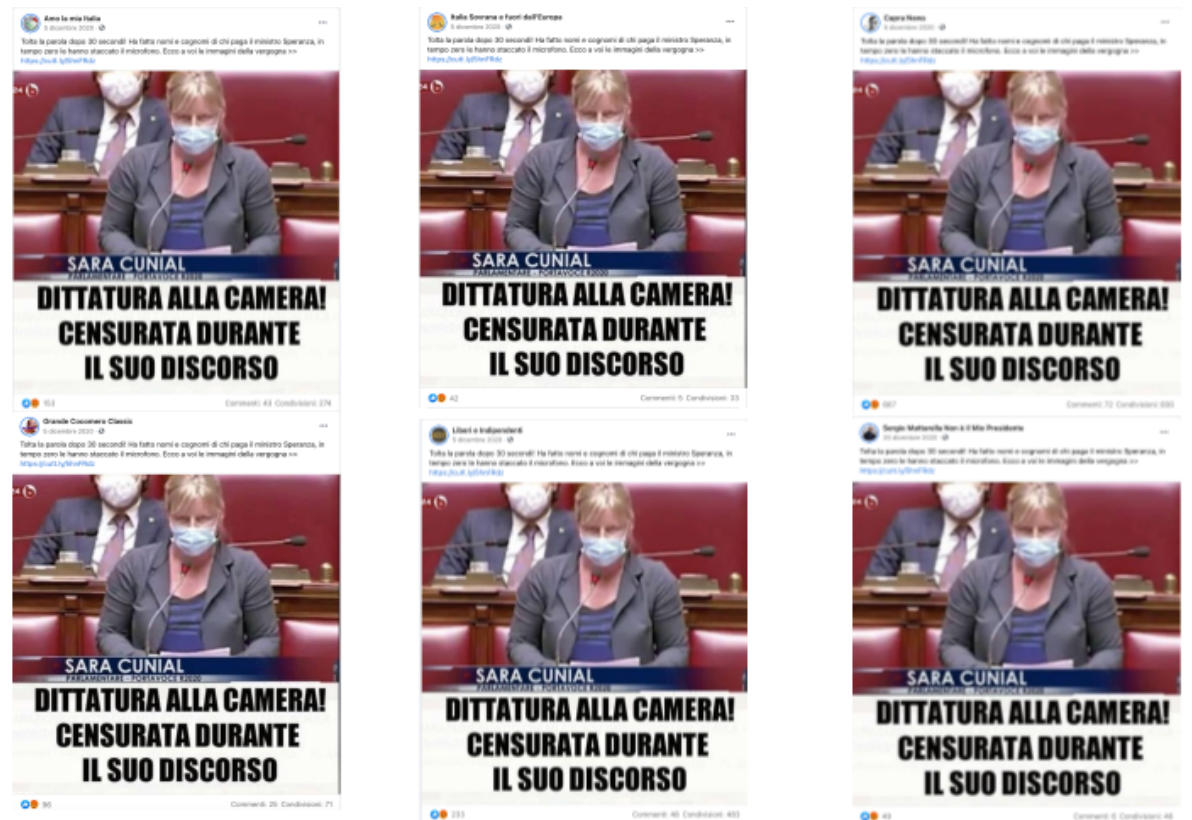

Figure 40: Example of network posts 
A text description adds hype to the news object of the post, while the invitation to click on the link is almost constant, which is systematically placed in the first comment. These links, which are usually not abbreviated by a url shortener, lead almost every time to mag24.es.

The issues addressed by the network are those relating to an alleged state of health dictatorship in Italy, with news regarding Covid-19 and the fact that the mainstream media would operate a form of censorship and control of the narrative regarding the pandemic. With respect to politics, the network seems to take a tendentially anti-government stance.

\subsubsection{Content}

The large majority of photo type posts consists of image macros where text is superimposed or juxtaposed to a photo/background. However, a closer analysis of these posts pointed out that almost all the posts were used to land users on external websites, with the addition of an abbreviated link (e.g. bit.ly) in the text or in the comments (Fig. 2a and $2 b$ ).

The insertion of the link in the comments or with link shortener begins following the tightening of the guidelines of the Facebook community to escape the control action by the Fact-Checkers.

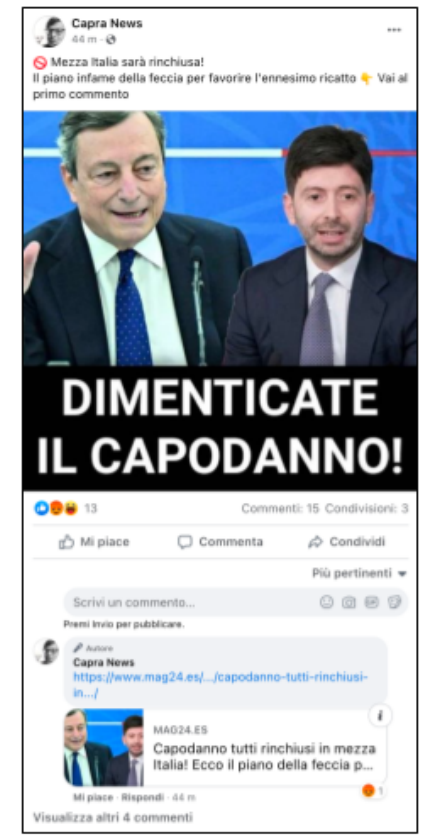

Figure 41: Example of post with link in the first comment

Using photo type posts to link external pages is a commonly used strategy employed by pages to hide their motivations and, most probably, to exploit the better treatment in terms of circulation that photo posts receive over links by Facebook's algorithm. The link is often shortened using bit.ly for aesthetic reasons and/or for hiding the destination source.

The posting rate fluctuated over the entire period (01/01/2020 - 11/30/2021), with May 2021 as the most prolific month (8,970 posts) and June 2020 as the most unproductive month (1,928 posts). Over the entire period the pages belonging to this network have published an average of 5,447 posts per month (125,300 in total between 01/01/20 and $11 / 30 / 21)$. The type of content published was mainly photos and macros images $(95.08 \%)$, 
followed by links (2.85\%). The remaining post types used are mostly Facebook videos ( $n=$ 805), statuses $(n=802)$ and Facebook Live $(n=943)$.

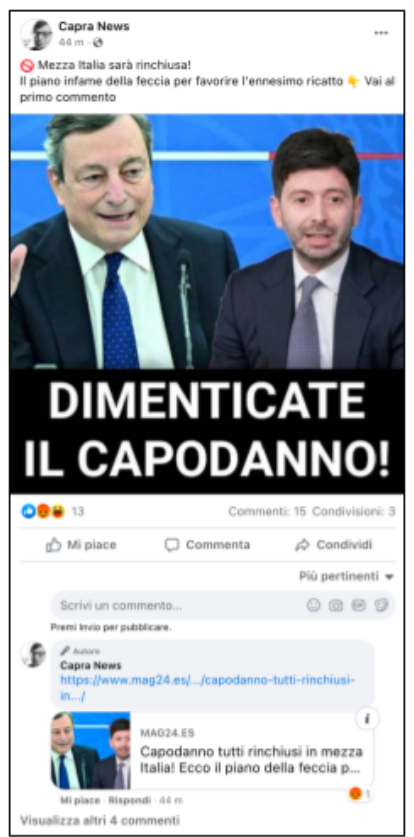

Figure 41: Example of post with link in the first comment

During the same 23 months, the Facebook posts shared by this network gathered $6,863,119$ total interactions. However, the large majority of this activity (92.63\%) happened on photo posts without a link. These image macros where the text is represented by inspirational quotes/sentences gathered on average 53 interactions per post. On the other hand, posts including a link (either in a form of photo or link post) gathered on average 38 interactions per post on average.

The most interesting data is perhaps the average of the interactions for the post type statuses, which reaches 314 per single post. Followed by Facebook Videos, which reach 104 average interactions per post. Despite this, links and statuses represent only $0.64 \%$ and $0.64 \%$ of the total posts produced by the network. This explains rather low overall interaction values. 


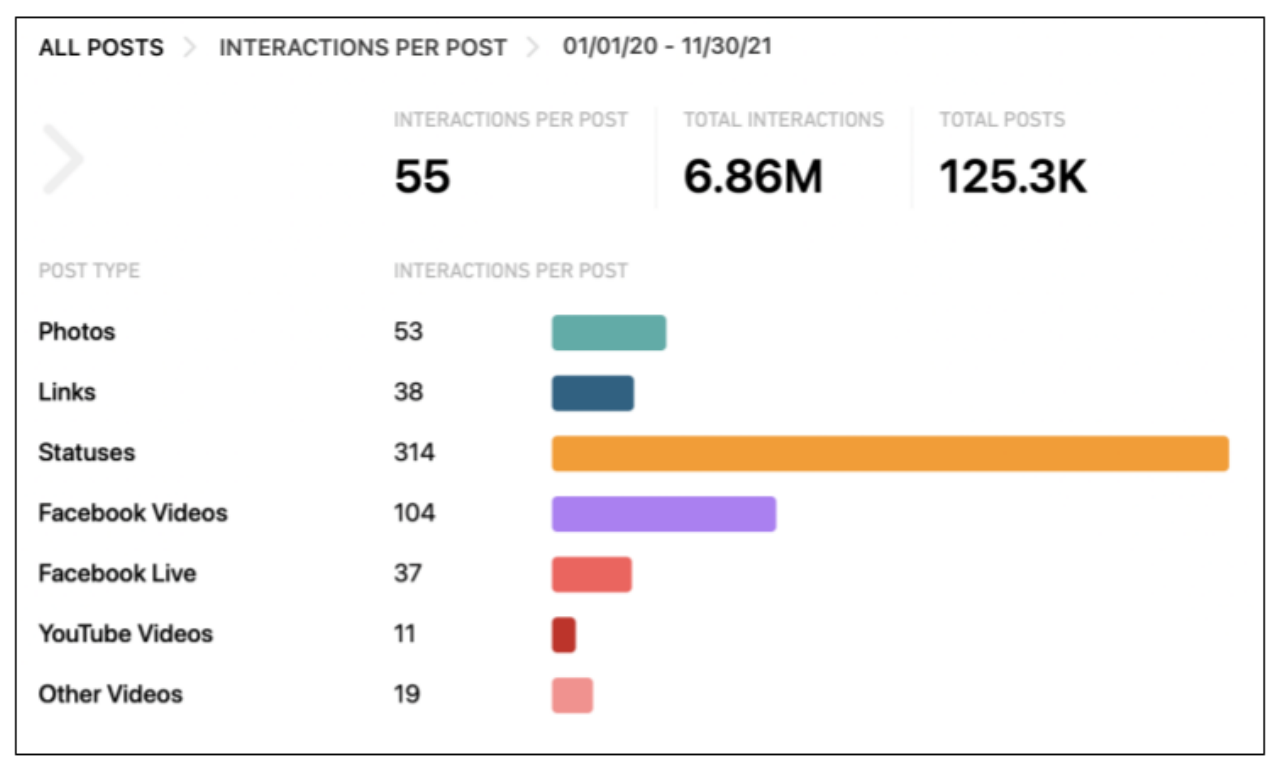

Figure 42: Type of interactions per post (source: CrowdTangle)

The prevalence of image macros as the main driver of engagement, also explains the peculiarities of the structure of interaction observed. By analysing each Facebook metric during the same lapse of time, we found that the majority of interactions are likes $135.8 \%$ of the total amount of interactions, $\mathrm{N}=2.45 \mathrm{M})$ and shares $(27.8 \%$ of the total amount of interactions, $N=1.91 \mathrm{M})$, while the total amount of comments is only a little lower $(22.6 \%$ of the total amount of interactions, $\mathrm{N}=1.55 \mathrm{M}$ ).

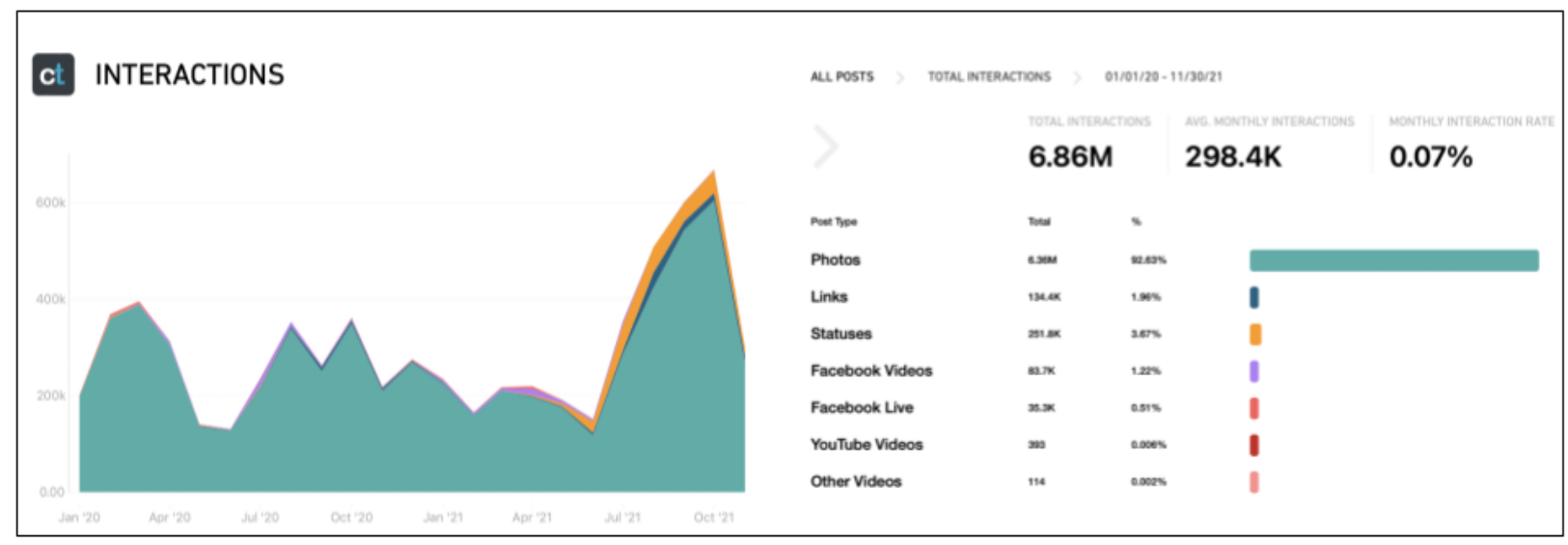

Figure 43: Interactions per post type (source: CrowdTangle)

This structure of interaction, with an almost equal number of likes, shares and comments is unusual insofar as likes tend to be by far the most common type of interaction on Facebook. While the volume of shares is most probably inflated by the repost strategy within the network, the prevalence of shares and comments is also explained by the peculiarities of the image macros posted. The text displayed (or the combination of text 
and image), is often shared by users as a way to communicate their mood to their friends and sometimes to address a specific individual in their Facebook audience. Also, the juxtaposed text on image macros is often quite sensational and this can lead to a significant number of comments.

The total number of interactions underwent heavy fluctuations throughout the analyzed period, going from more than 450,000 monthly interactions to about 150,000 . We also note a surge around the end of June 2021, which leads the network to reach a peak of total monthly interactions of about 670,000 in October 2021, and then suffer a further and equal decline, still ongoing. 


\subsection{Micro}

At the micro level we observe cases of problematic news shared by the accounts included in the identified networks. As already said in the Introduction of this report, the news has been surfaced by the tool developed for this project and categorized by the fact-checking group Facta.news (see Appendix II for further information about the classification's criteria). For this part, we identified three exemplary cases of two posts and one link deemed overall as problematic (Jack, 2017).

\subsubsection{Third dose}

The Facebook page Presidente Trump Fan Page Italia is part of the network of Mag24.es (see paragraph 2.2.4.). The page has 14,072 followers and is updated more than once a day. Posts are usually made by a short caption and a photograph or an image with a text. In the first comment of almost every post there is a link to a related article by Mag24.es. The Facebook page, which is labeled as "Politician", describes itself as "Page dedicated to the fans of the President of the United States of America Donald Trump". The page was created with the same name on the 2nd of February of 2017 and is currently administered by four different people, 3 of whom are located in Spain and one in Italy. The status of the page is "not verified".

The image below (Figure 44) shows a post of the page that was published on the 1st of November early in the morning. At the moment of the collection of the data - at 8:44 am of the same day - the post had received 136 total interactions, performing more than three times better with respect to the standard of the page. The post is made by a photograph of a woman who is getting vaccinated by a doctor, with a text which says "Third dose? It's useless, like the first two". The caption of the post says "What happened yesterday in the province of Padua it's the demonstration. Go to the first comment".

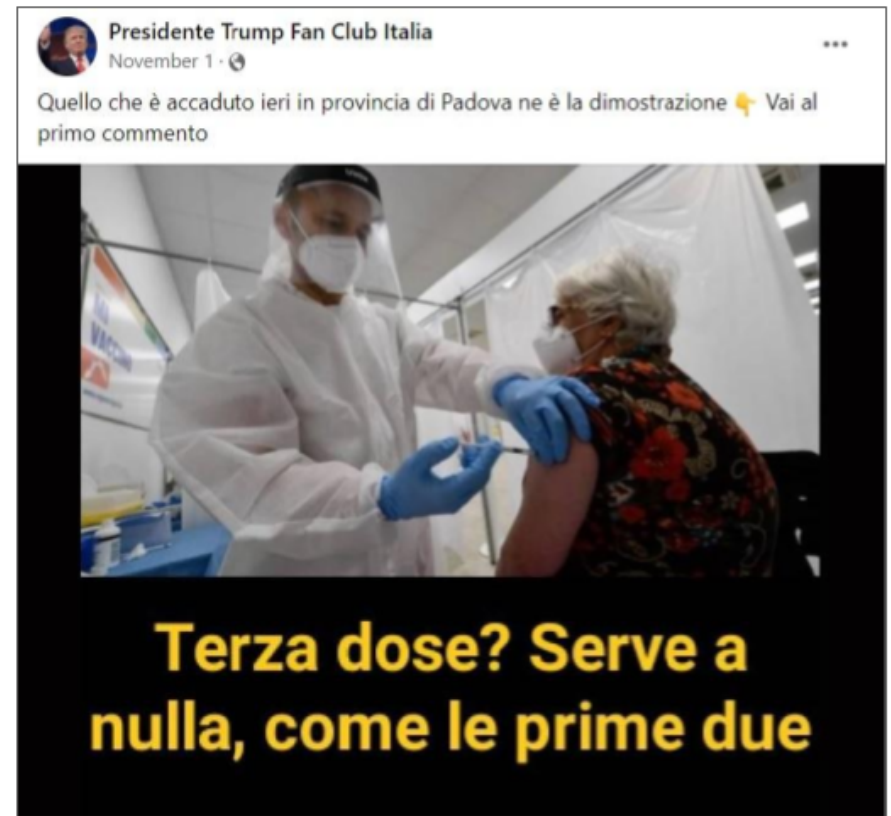

Figure 44: Screenshot of a post of the Facebook page Presidente Trump Fan Club Italia 
Through a search by keywords on CrowdTangle, we found the same post shared by several Facebook pages of the same network on the same day in two periods of time - at about $8: 30$ am or 8 pm. Figure 45 below shows the results given by CrowdTangle.

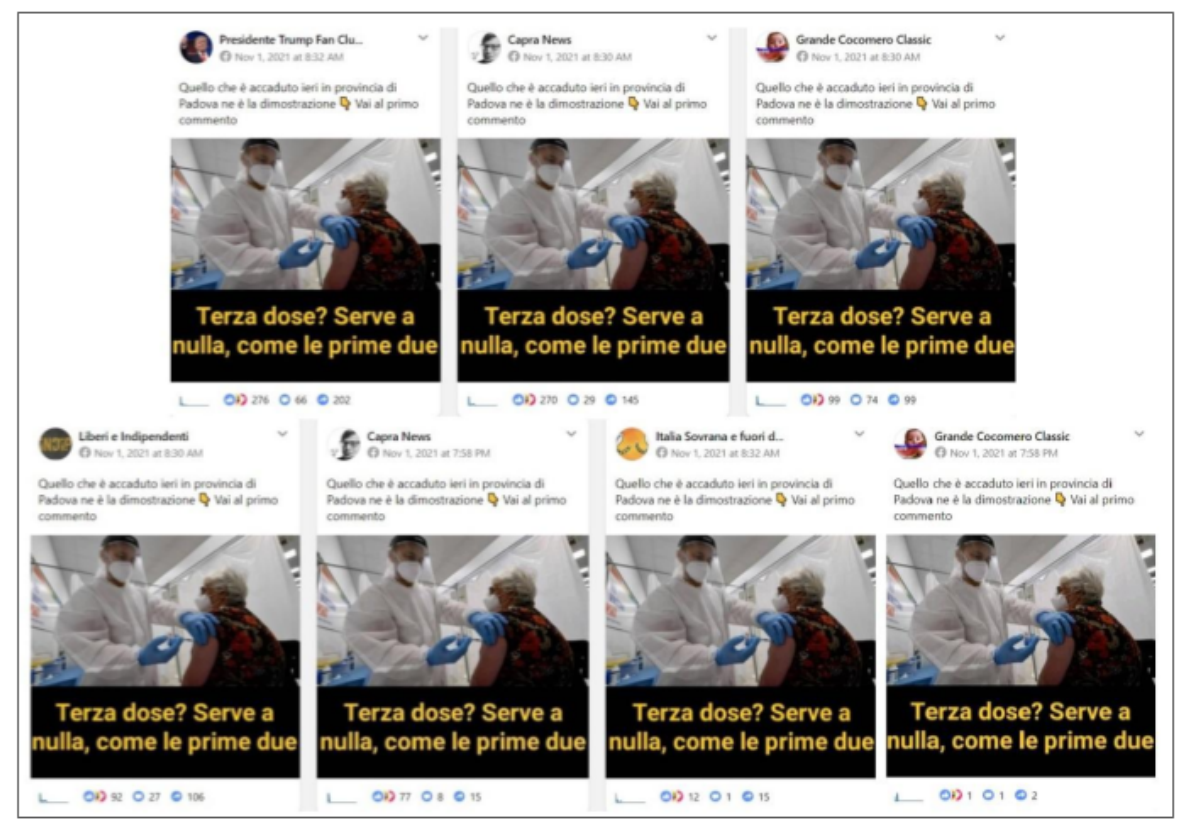

Figure 45: Screenshot of the post of Facebook page Presidente Trump Fan Club Italia published by several pages of the same network

In the first comment of the post, the page Presidente Trump Fan Page Italia - as well as the pages in Figure 46 above that published the same post - provides the link to an article of Mag24.es. The preview of the piece is shown in Figure 46 below.

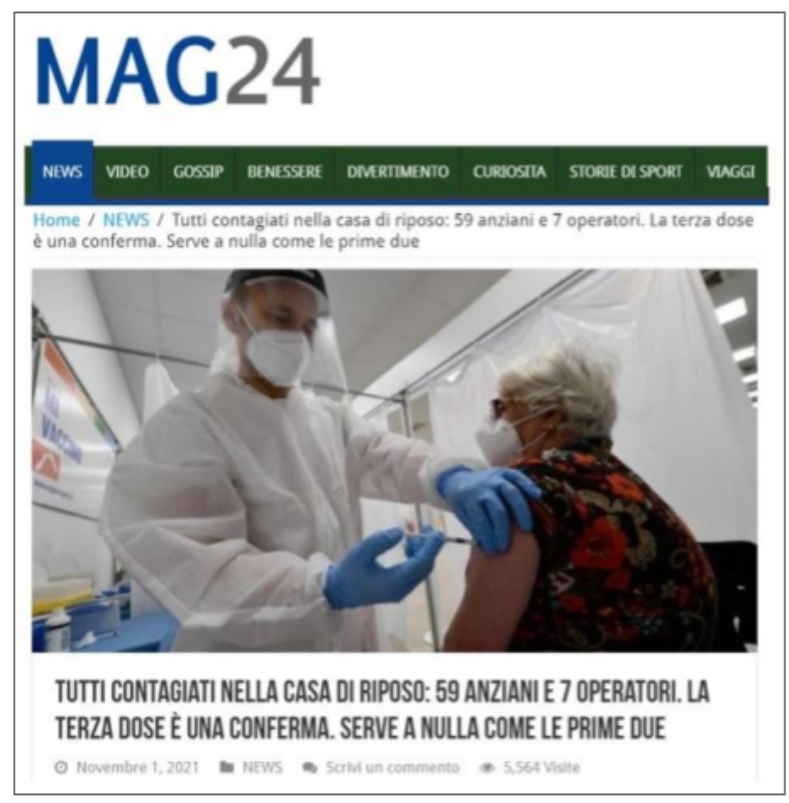

Figure 46: Screenshot of the article by Mag24.es linked in the first comment of the post by Presidente Trump Fan Club Italia

The title of the article is "Everyone was infected in the retirement home: 59 elderly people and 7 operators. The third dose is a confirmation. It's as useless as the first two". The article 
claims that in a retirement home in Conselve, in the province of Padua, several hosts and workers got infected by coronavirus, although everyone of them had already received even the third dose of the Covid-19 vaccine. Hence, the author of the article states that vaccines are useless and that this episode confirms this hypothesis. More cases of Covid-19 positive tests in the area of Padua are presented, but there is no source for any of them.

The article, which according to Mag24.es website received more than five thousand views, was labeled by Facta.news as "false news". Vaccines' efficacy has indeed been confirmed by several studies developed worldwide.

\subsubsection{Shocking declaration of a doctor}

The next case comes from the Facebook page Associazione Nazionale Papaboys, an account which publishes mostly religious content. The page has 307,186 followers and it's labeled as a News \& media website. The verification status of the page is "not verified". On the homepage many information about the organization are provided, as well as contacts of the people responsible for the page: the confirmed page owner is Daniele Venturi and the 5 admins are all located in Italy. The Facebook page was created on the 8th of February of 2011 as "Associazione Nazionale Papaboys", but on the 6th of April of 2019 the page name changed to "Beautiful Life". As can be seen in Figure 48 below in the screenshot taken from CrowdTangle, from the end of January 2019 to the end of April of the same year the page was totally inactive. The name "Associazione Nazionale Papaboys" was restored a few months later, on the 15th of November of 2019.

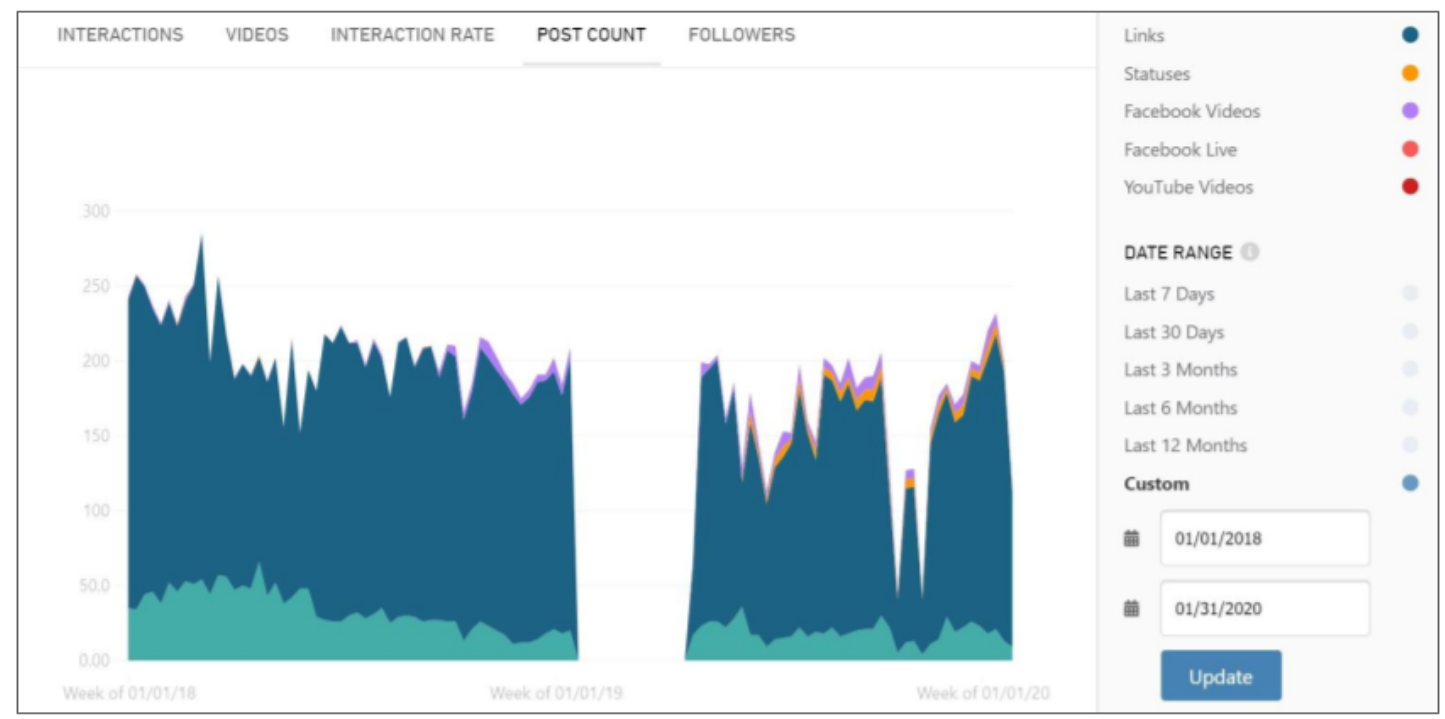

Figure 47: Activity of the Facebook page Associazione Nazionale Papaboys from 2018 to 2020 (source: CrowdTangle)

The image below (Figure 49) is the screenshot of a post published by the page on the 22nd of November. In the preview we see an article by the organization's website titled "An American scientist declares: Prayer has the power to cure illnesses", with a photograph of a man with a lab coat. The caption in Italian says "'Prayer has the power to cure illnesses', Shocking declaration of a doctor". A few hours after the publication, at $1 \mathrm{pm}$ of the same 
day, the post received 292 total interactions and was performing 5.5 times better than the usual content published on the page.

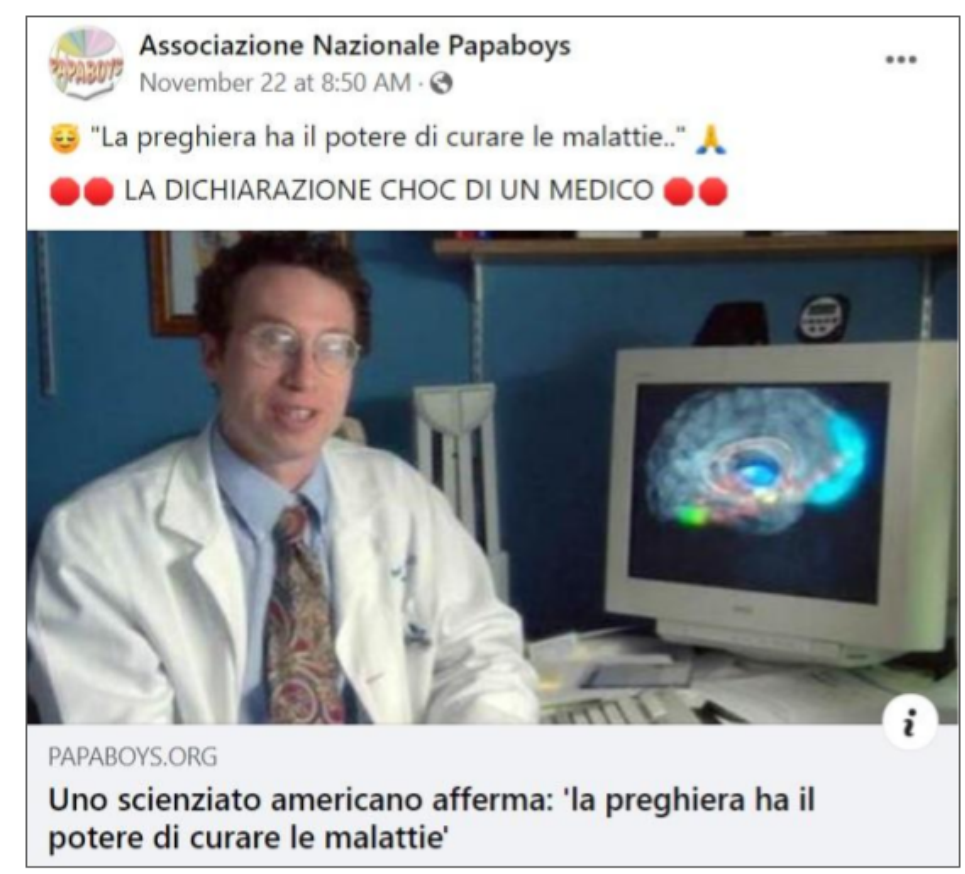

Figure 48: Screenshot of a post on Associazione Nazionale Papaboys page

The article linked in the post is from the news website Papaboys.org of the same religious organization (preview in Figure 50 below).

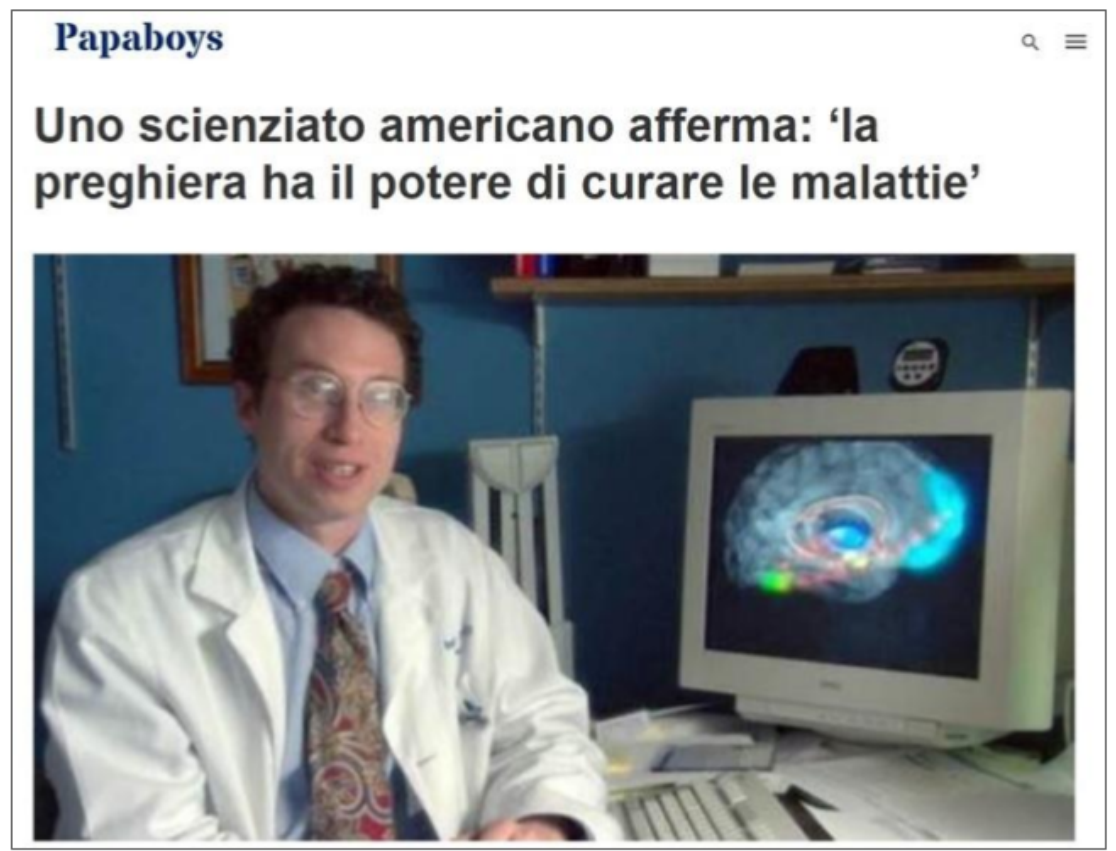

Figure 49: Screenshot of an article of Associazione Nazionale Papaboys website

Both the Facebook post and the article show a photograph of Doctor Andrew Newberg, an American neuroscientist whose research is focused on the effects of religion on the human 
brain. In the article on Papaboys' website it's claimed that from Newberg's work and from other investigations - not further described - there was evidence of the power of prayers to cure illnesses. Some details of Doctor Newberg's research are briefly mentioned, as well as the book in which he presented them, titled "How God changes the brain".

At the end of the article on Papaboy's website a source is provided, with a link to an old article in Italian published on the religious news website Aleteia. The short piece is from November 2016 and it's said to have been translated from Portuguese, but no source of the original version is provided. The article, with the same claims about the power of prayers to cure illnesses, was almost entirely copied by Associazione Nazionale Papaboy's website. In both cases, there is no reference to non-Italian websites or organizations about those claims.

The same article had already been published in the previous years and had been shared by several religious Facebook pages. In Figure 51 below there is a screenshot of a chart which shows all the publications of the article of Papaboys.org on Facebook pages from 2019 to November 2021; after it, Figure 52 shows a detailed version of the publications observed in 2021. The highest is the amount of followers of the page, the biggest is the circle.

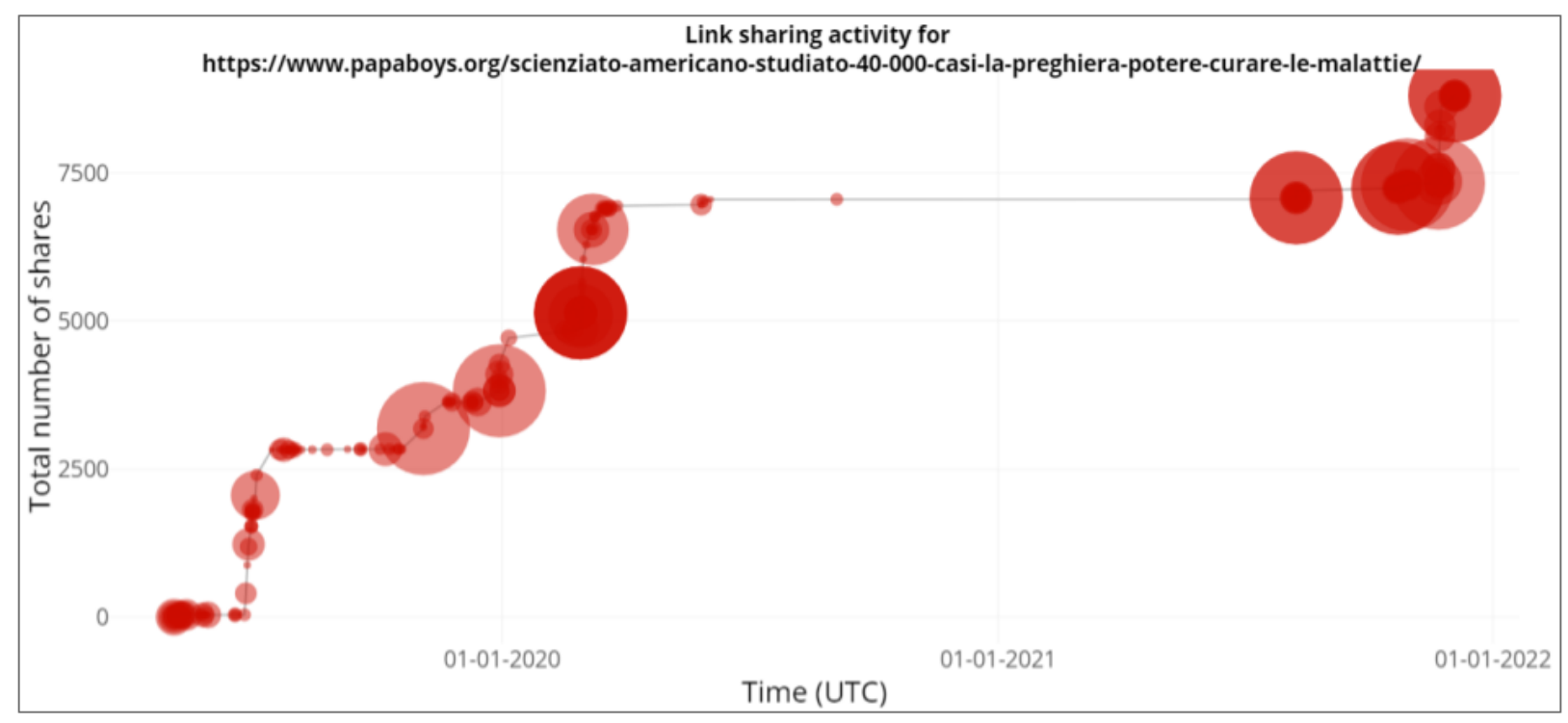

Figure 50: Screenshot of the graphic of the shares of the article of Associazione Nazionale Papaboys website 


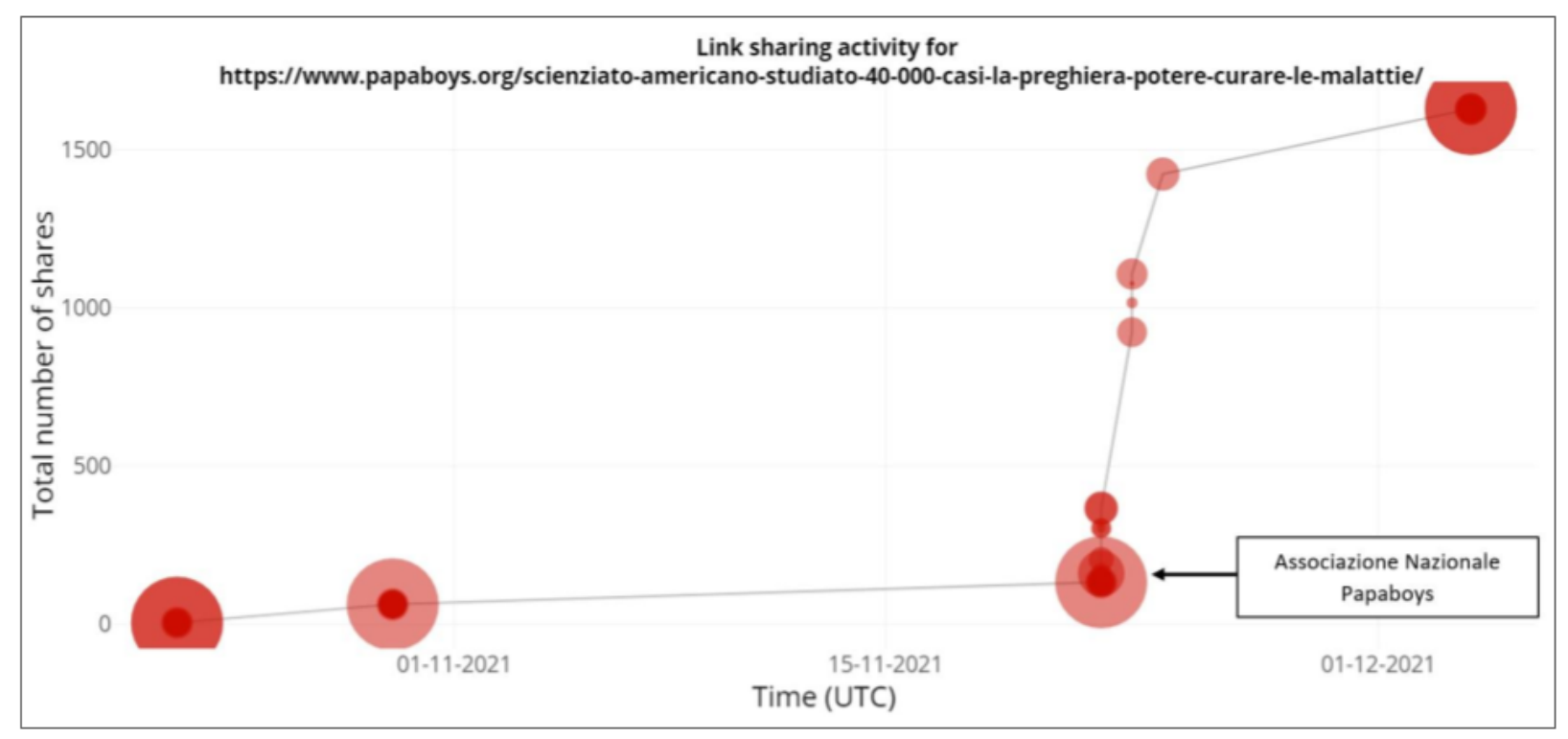

Figure 51: Screenshot of the graphic of the shares of the article of Associazione Nazionale Papaboys website during 2021

Facta.news identified the news published on Papaboys.org as "out of context". Doctor's Newberg's research was indeed mentioned by several American websites, but in those articles there is no proof of the power of prayers to cure illnesses, whereas the news shared by Papaboys' organization claims that Newberg's research took to this conclusion. The case also exemplifies the strategy of re-circulating old content at the right time (e.g. a coronavirus resurgence) without specifying the original publishing date at the risk of misleading the reader to believe that the article concerns current events.

\subsubsection{Thrombosis due to inoculation}

The last case that we report for the micro analysis is taken from the website Naturamorevole news, which is included in the Blogspot network (see chapter 2.2.1 of this report). 


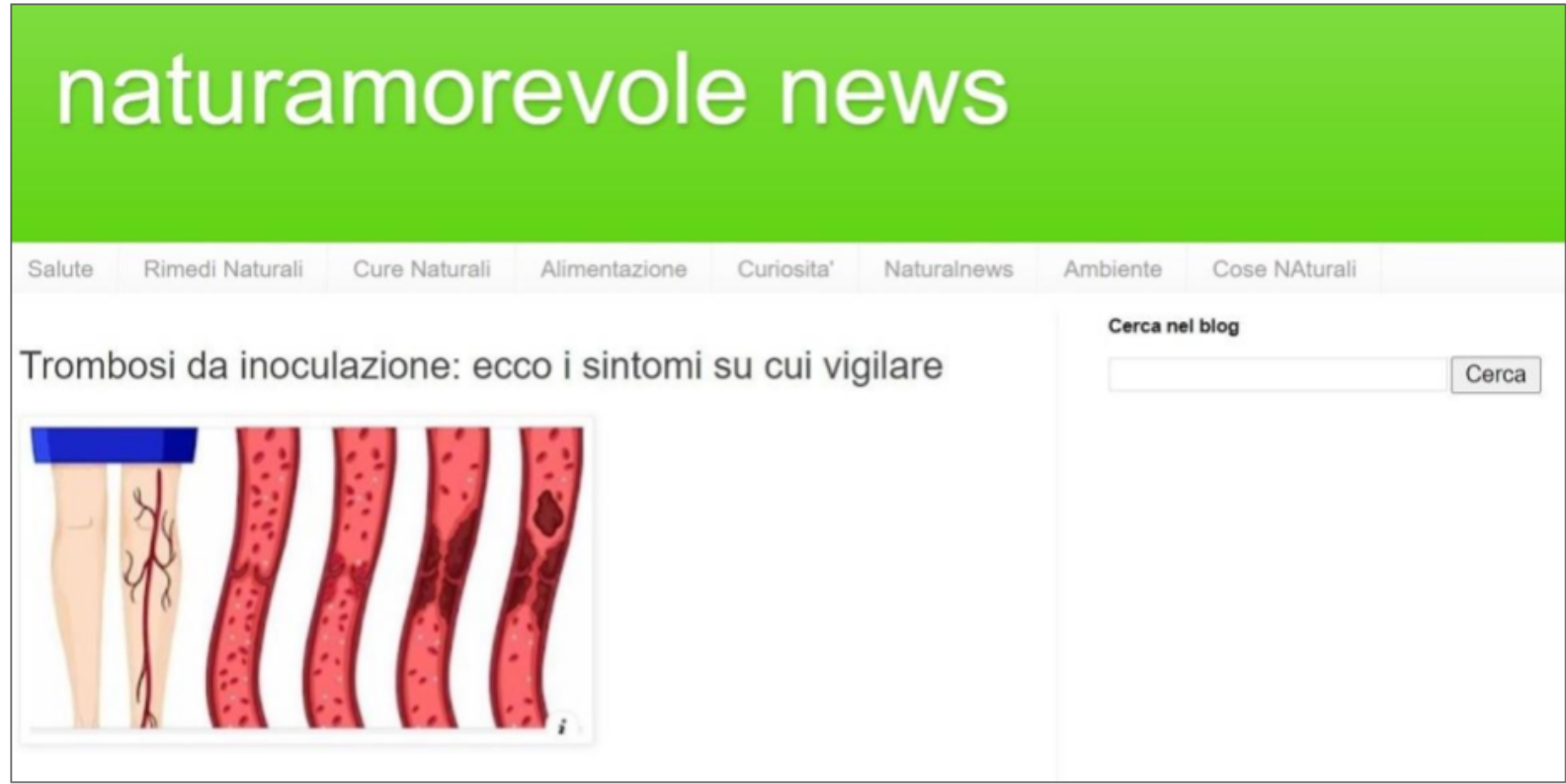

Figure 52: Screenshot of an article on Naturamorevole news website

Figure 52 above shows the preview of an article published on the 19th of June - that circulated again in November - titled "Thrombosis due to inoculation: there are the symptoms to which pay attention". The article had already been published many times in the previous months on several Facebook pages of the same network. The following picture (Figure 54) shows a graphic in which it's possible to observe when and by which pages the article was posted on Facebook. As for the graphics presented for case \#2, the highest is the amount of followers of the page, the biggest is the circle. The last circle on the right indicates the shares of the month of November, with the names of the pages that published the piece. As can be seen, the publications happened at the same time.

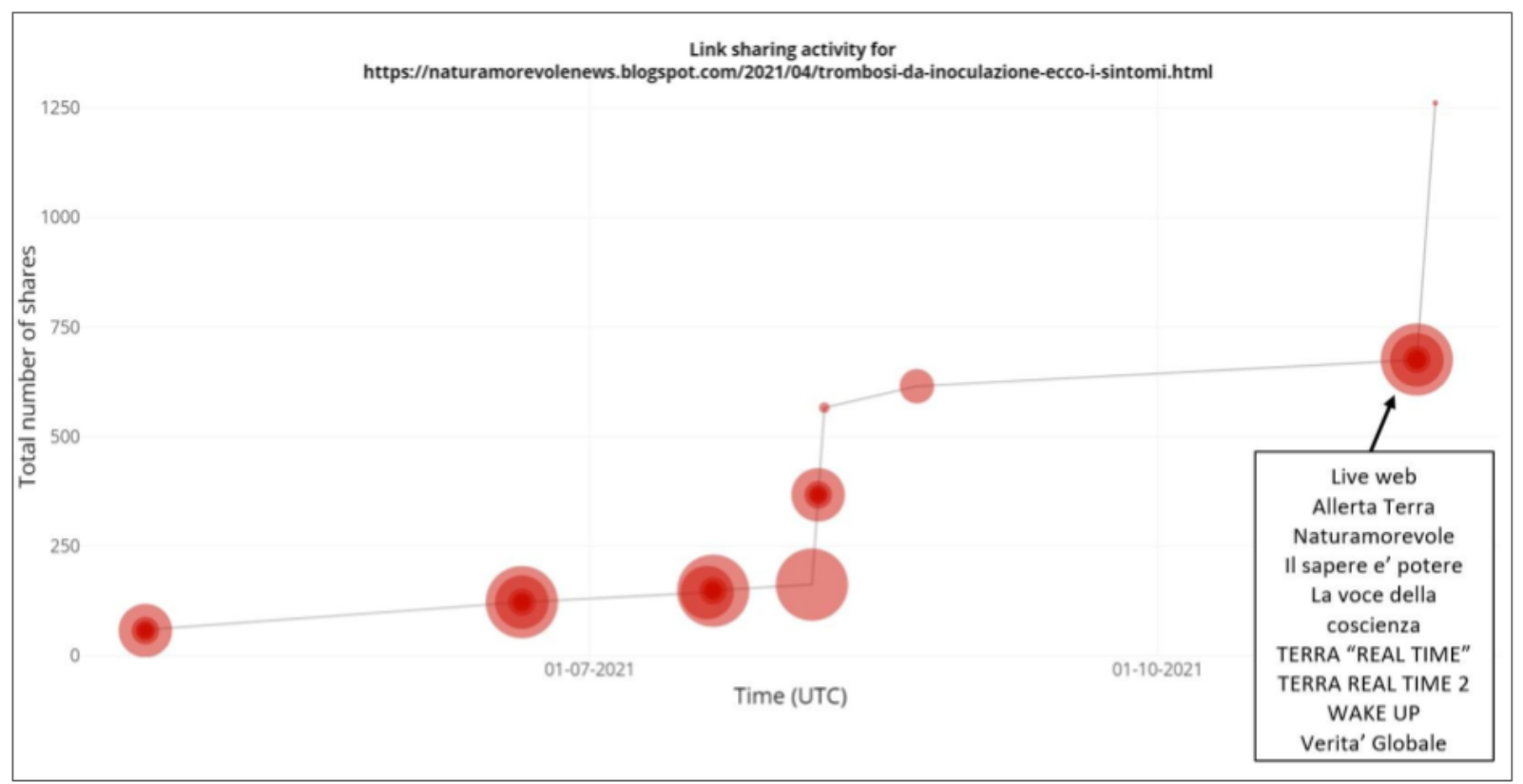

Figure 53: Screenshot of the graphic that shows the shares of the article by Naturamorevole news by pages of the same network 
The focus of the article by Naturamorevole news is on the symptoms of thrombosis due to Covid-19 vaccination, in particular, Johnson\&Johnson and AstraZeneca vaccines. The piece provides a list of side effects that can appear shortly after the inoculation of Covid-19 vaccine, claiming that everyone should pay great attention to thrombosis' symptoms in the first 14 days after the vaccination. No official or scientific source is provided for these claims. The article got an engagement of 459, with 8 coordinated shares detected in our analysis until November. At the end of the text there are two external links - one of which is presented as a video, but it's not - that lead to the same piece of the news website Grandeinganno.it (in English, Great Deceit). The article on Naturamorevole news' website is the exact copy of the one by Grandeinganno.it, which is older by a few months (April 2021).

The news has been categorized by Facta.news as "out of context". This label is due to the fact that the piece by Naturamorevole news (as well as the one by Grandeinganno.it) is a partial copy of an article published by the news website $\Perp$ Giorno, in which it's specified that the cases of death or serious injuries developed after receiving the Covid-19 vaccination are only a few and that there is no proof of the correlation between thrombosis and vaccines. 


\section{Design and test of the MINE-FACTS prototype}

In this Chapter we describe the method and a quantitative overview of the performance of the prototype tool. The tool employs a content-agnostic approach for detecting potentially problematic links and posts. By content-agnostic we mean that the tool does not analyze the content itself to draw its conclusions. The focus is instead on the behaviour of the social media actors that circulated the content. This methodology is based on an automated script that leverages several functionalities already implemented in the R library CooRnet. The script is executed four times per day which has been chosen as a time frame to select four different daily periods uniformly distributed with a time span of 6 hours: the first execution occurs at 2 AM while the remaining respectively at 8 AM, 2 PM and 8 PM. In the next Section, a brief description of the design of this automated script is presented.

During the November 2021 test phase, the tool surfaced a total of 360 posts and 71 links that have been subsequently rated by a team from Facta.news using a set of categories derived from the rating options available for Facebook's third-party fact-checkers initiative. The codebook used is described in detail in Appendix II.

\subsection{Design and development}

The starting point of the prototype system is the initial list of Facebook Pages, public groups, and verified public profiles selected through multiple CooRnet iterations started with a list of knowingly Italian false news stories, as described in the introduction of Chapter 3. Using the post/search endpoint of the Crowdtangle API, the automated script extracts the list of up to 100 top performing posts ${ }^{17}$ recently created by the accounts in these lists. Posts are sorted by a combination of the measures. The first is the overperforming score ${ }^{18}$ which is defined as the ratio between the expected interaction value and the actual value of a specific post. In this sense, this score determines whether a Facebook page, a public group or an account publishes a post whose performance is higher than expected by a benchmark model. The second measure is the following comments/shares ratio (Giglietto, Valeriani, et al., 2019):

$$
\frac{C_{i}-S_{i}}{C_{i}+S_{i}}
$$

where $C$ is the number of comments for each single link/post $i$ while $S$ is the number of shares. This ratio detects the asymmetry between the sharing and commenting activities related to a single link/post: if the cumulative interactions are composed only by shares, the value of the ratio would be equal to -1 . Conversely, if the interactions are represented only by comments, its value would be 1 . The combination between the overperforming score and the comments/shares ratio is finally provided by multiplying their values.

\footnotetext{
${ }^{17}$ Only posts with at least 100 interactions and published by an account with at least 500 followers/subscribers are taken into account.

18 See

https://help.crowdtangle.com/en/articles/2013937-how-do-you-calculate-overperforming-scores.
} 


\subsubsection{Posts}

Each run of the prototype retrieves the first three posts with the most negative value of the combined value of overperforming score and comments/shares ratio. The choice of selecting these specific values is grounded in our previous experiences that pointed out the asymmetry of these two types of interactions as a useful signal of massive activity by partisan communities (Giglietto, Valeriani, et al., 2019). These posts are finally chronologically stored in the list of posts which is subsequently analyzed by Facta.news. The final list under analysis consists of 360 posts.

An overview of the final percentage of posts along with the corresponding absolute number is present in Figure 54.

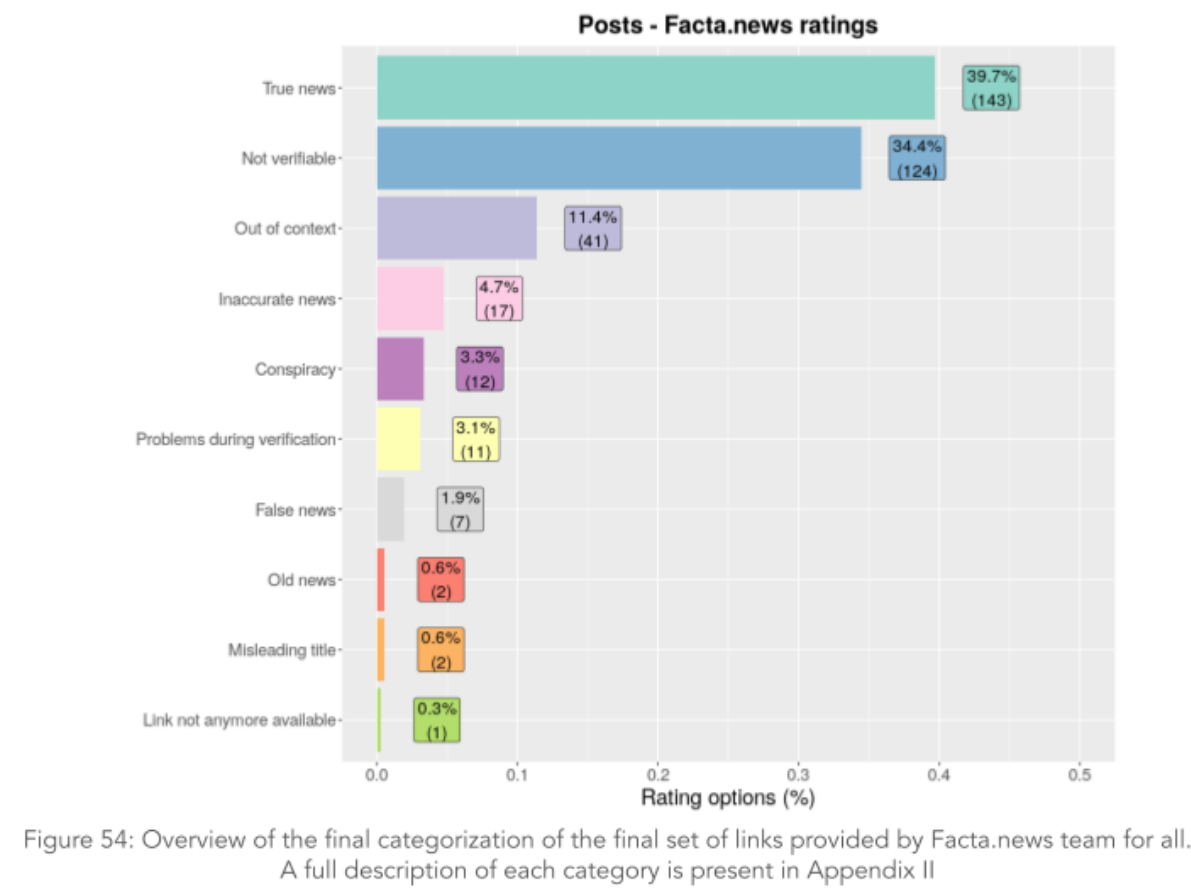

\subsubsection{Links}

In order to select a list of links associated with the starting lists of Facebook accounts, the prototype system extracts an initial list of URLs from the first 100 posts with the greatest performance according to the combined measure defined above. From this initial list, all links without at least two shares are removed in order to avoid considering posts which cannot be shared in a coordinated manner. After retrieving the URLs information through Crowdtangle, the R library CooRnet is employed to determine whether a Coordinated Link Sharing strategy is observed for a specific link. The first three links having the most negative values of the aforementioned comments/shares ratio are finally stored in the final lists of links.

After each run of the prototype system, it is worth noting that the list of Facebook accounts is updated in order to include in the following runs all the accounts which have been observed to participate in the coordinated activities. The final list under analysis consists of 71 links. This number is significantly lower than the total number of posts since not all runs succeeded in retrieving coordinated links and because multiple posts may point to the same link. The fact-checking activity of links performed by Facta.news follows the 
same rules as for posts. An overview of the final percentage of links along with the corresponding absolute number is present in Figure 55.

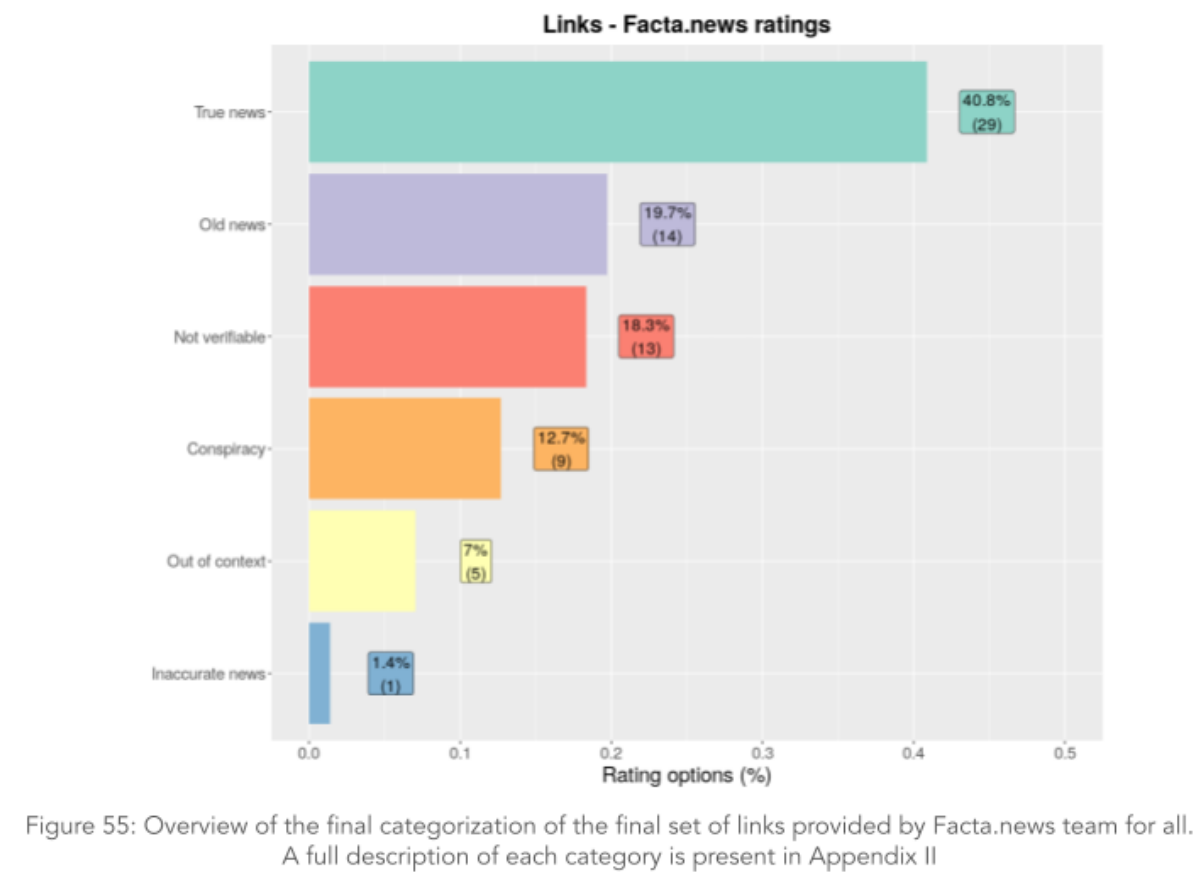

\subsection{Outcomes of the testing phase}

To provide a term of comparison to the rating's distribution obtained by posts and links surfaced by MINE-FACTS tool, we relied one again on Meta's URL Shares Dataset. Beside the user-centered interactions gathered by a URL, the dataset also provides additional information on the rating eventually obtained by the URL when analyzed by Facebook's third-party fact-checkers. Given the fact that the only active partner for Italy during the period of time covered by the dataset (January 2017, February 2021) is Pagella Politica/Facta.news ${ }^{19}$, we can compare the amount of content rated as problematic among the content detected by the MINE-FACTS tool with those surfaced by the dashboard that Meta makes available to their third-party fact-checkers.

Meta's dataset includes 2,504 Italian URLs rated by Pagella Politica/Facta.news. The large majority of these URLs under scrutiny have been rated as true $(72.4 \%$ or 1,812$)$. The other non problematic rating options were opinion $(6.3 \%$ or 158$)$, and satire (4\% or 102$)$. Not eligible, accounted for $6 \%$ (142) of the rated URLs while $1.6 \%$ (39) were "not rated". On the side of that we can deem as problematic information we have instead "fact checked as false" (6.2\% or 155), "fact checked as mixture or false headline" (3.6\% or 91), "prank generator" ( $0.1 \%$ or 3$)$, and "factchecked as missing context" $(0.1 \%$ or 2$)$. In other terms, the $82.7 \%$ (or 2,072 ) of URLs rated by the Italian TPFC were non problematic, $10 \%$ (251) problematic and $7.2 \%$ (181) non eligible or not rated.

Using the same summarized categories of problematic, non problematic and non eligible/rated, MINE-FACTS tool detected an higher percentage of problematic content

${ }^{19}$ Both Pagella Politica and Facta.news.news are projects made by The Fact-Checking Factory (TFCF) Srl. The latter brand was launched in April 2020. 
(21.9\% for posts and 21.1 for links) and a lower percentage of non problematic content (40.8\% for posts and $39.7 \%$ for links).

The prototype system can also be tested by analyzing the distribution of peculiar quantities related to the retrieved links/posts by the system itself. The distinction between news according to the categories provided by Facta.news has been simplified in order to compare only three summarized categories: "ineligible or not rated", "non problematic" and "problematic information" which comprise conspiracy, false news, out-of-context news, inaccurate news and news with a misleading title. Our next analysis is focused on two measures which have been already employed on the extraction phase: the comments/shares ratio and the overperforming score. While the former have been computed for both links and posts, the latter is provided by the Crowdtangle platform only for posts.

The comments/shares ratio distributions of posts for the selected categories are shown in Figure 56. The distribution patterns related to three categories show a diversification in correspondence of the most negative values of the ratio. In fact, the distribution corresponding to the problematic information values presents a significantly higher peak with respect to not verifiable and true news. This intuition is also confirmed by performing a Kruskal Wallis test which presents a highly statistically significant $p$-value (Kruskal-Wallis $\left.\chi^{2}(2, N=360)=20.941, p<.001\right)$ against the null hypothesis of samples generated by the same distribution. Moreover, a pairwise comparison using the Wilcoxon rank sum test shows that the difference of the problematic information trend and the other two categories is statistically significant. This is an important quantitative result in support of the goodness of the prototype system: the problematic information posts can be distinguished from the not verifiable and true news due to their significantly higher values of comments/shares ratio. This result shows how shares are prevalent over comments when it comes to low-quality media contents.

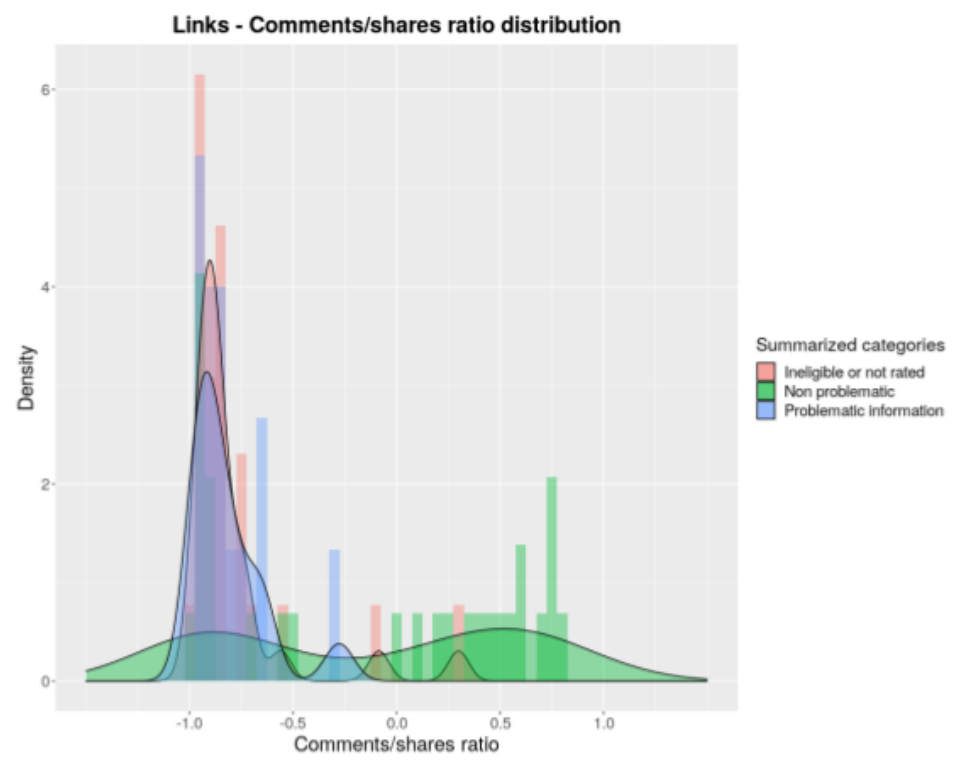

Figure 56: Distribution patterns of comments over shares ratio for "problematic" and "true" links. The distinction between "problematic" and "true" is defined according to "Pagella Politica" fact-checking activity 
Similarly, the distributions of the comments/shares ratio have been compared also for links. In Figure 57, it is shown that both problematic information and not verifiable news present a significantly higher peak with respect to true news, as proved by a Kruskal-Wallis test (Kruskal-Wallis $\left.\chi^{2}(2, N=71)=6.8717, p<.05\right)$. Again, the Wilcoxon rank sum test confirms that problematic information and true news have different trends. It is worth noting that a small peak of positive values towards the value equal to 1 is only present in the true news distribution. This is another indication that links are properly distinguished by quantities which can be easily retrieved by our prototype system.

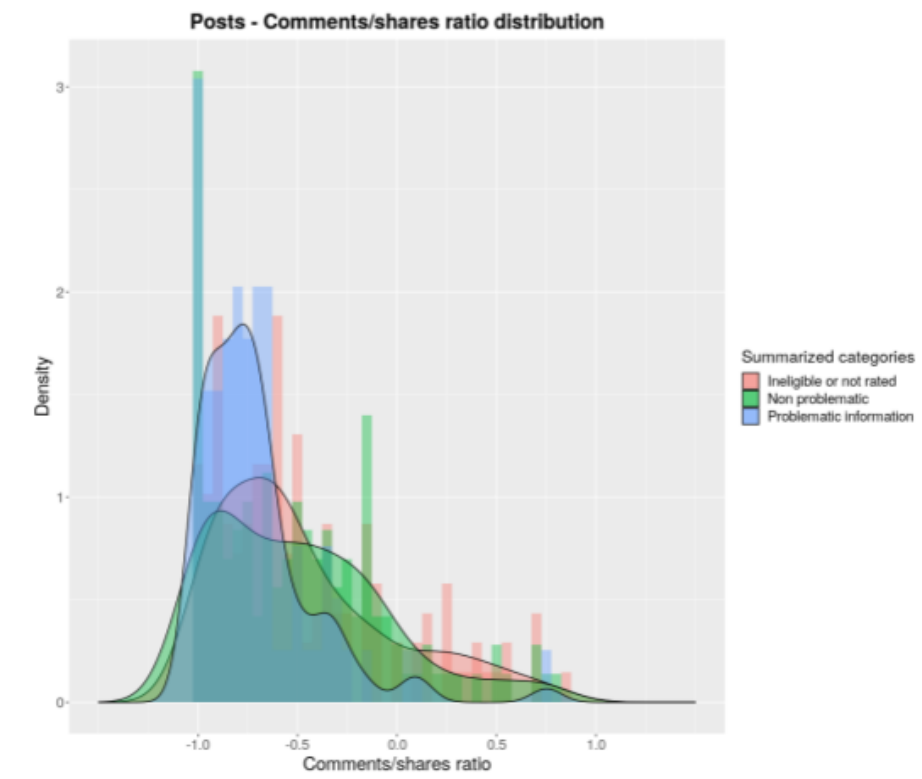

Figure 57: Distribution patterns of comments over shares ratio for "problematic" and "true" posts. The distinction between "problematic" and "true" is defined according to FACTA methodology described in Appendix II

Conversely, as shown in Figure 58, the overperforming scores of posts have a similar trend peaking towards lower values and then slightly decreasing. To our research aim, the slight difference between peak values are not significantly relevant to support evidence of different behaviors between these distributions. Even though the overperforming score could be a potential candidate to detect problematic information, it is not enough to reveal low-quality media contents. Instead, these results return a relevant hint of how nefarious Facebook accounts have adopted consistent strategies of posting activities emerging when the commenting and sharing patterns are compared. 


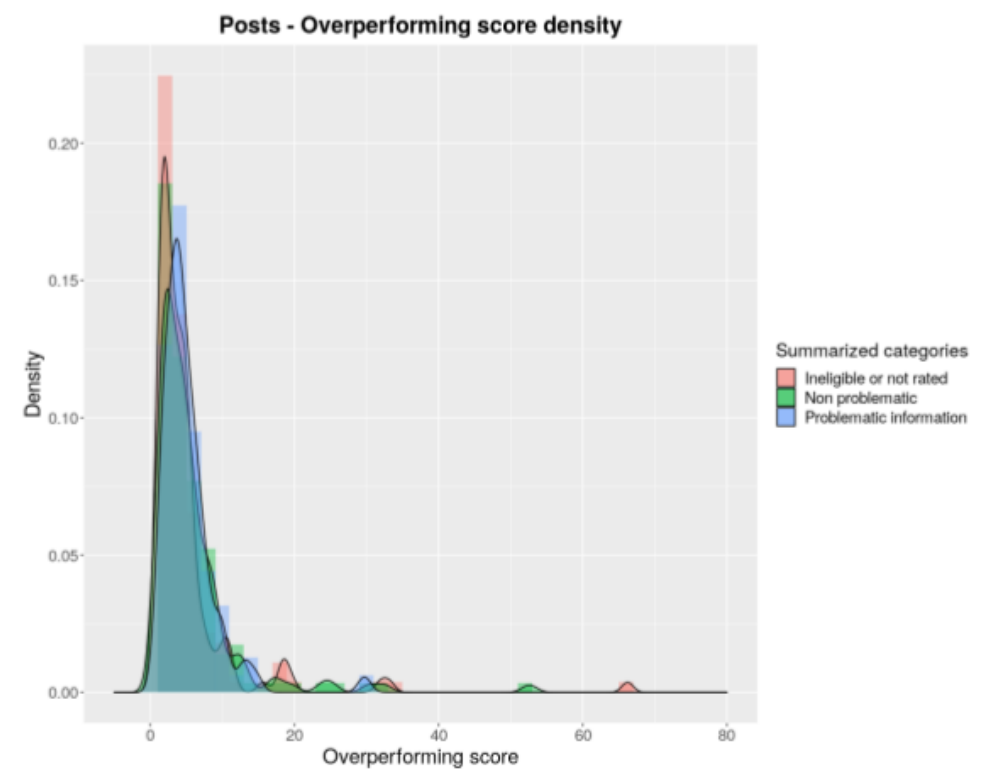

Figure 58: Distribution patterns of overperforming score for "problematic" and "true" posts. The distinction between "problematic" and "true" is defined according to Facta.news methodology described in Appendix II 


\section{References}

Allport, G. W., \& Postman, L. (1946). AN ANALYSIS OF RUMOR. Public Opinion Quarterly, 10(4), $501-517$.

Cresci, S. (2020). A decade of social bot detection. Communications of the ACM, 63(10), 72-83.

CrowdTangle Team. (2019). CrowdTangle API. CrowdTangle Help.

https://help.crowdtangle.com/en/articles/1189612-crowdtangle-api

European Commission. (2020). Tackling COVID-19 disinformation - Getting the facts right.

Europa.eu.

https://ec.europa.eu/info/sites/info/files/communication-tackling-covid-19-disinformation-gettin g-facts-right_en.pdf

François, C. (2020). Actors, Behaviors, Content: A Disinformation ABC. Algorithms.

https://cdn.annenbergpublicpolicycenter.org/wp-content/uploads/2020/05/ABC_Framework_T

WG_Francois_Sept_2019.pdf

Giglietto, F., Marino, G., Terenzi, M., Righetti, N., \& Rossi, L. (2021). Coordinated Hateful

Disinformation on Italian Politics and Social Issues, since 2017.

https://papers.ssrn.com/sol3/papers.cfm?abstract_id=3777263

Giglietto, F., Righetti, N., \& Marino, G. (2019). Understanding Coordinated and Inauthentic Link Sharing Behavior on Facebook in the Run-up to 2018 General Election and 2019 European Election in Italy. https://doi.org/10.31235/osf.io/3jteh

Giglietto, F., Righetti, N., \& Rossi, L. (2020). CooRnet. Detect coordinated link sharing behavior on social media (Version 1.0.0) [\#rstat]. Github. https://github.com/fabiogiglietto/CooRnet

Giglietto, F., Righetti, N., Rossi, L., \& Marino, G. (2020a). It takes a village to manipulate the media: coordinated link sharing behavior during 2018 and 2019 Italian elections. Information, Communication and Society, 1-25.

Giglietto, F., Righetti, N., Rossi, L., \& Marino, G. (2020b). Coordinated Link Sharing Behavior as a Signal to Surface Sources of Problematic Information on Facebook. International Conference on Social Media and Society, 85-91.

Giglietto, F., Terenzi, M., Marino, G., Righetti, N., \& Rossi, L. (2020a). An Italian Network of Memes, 
News, Spam Pages, and Dietary Supplements. https://doi.org/10.2139/ssrn.3743531

Giglietto, F., Terenzi, M., Marino, G., Righetti, N., \& Rossi, L. (2020b). Adapting to Mitigation Efforts: Evolving Strategies of Coordinated Link Sharing on Facebook. https://papers.ssrn.com/abstract $=3775469$

Giglietto, F., Valeriani, A., Righetti, N., \& Marino, G. (2019). Diverging patterns of interaction around news on social media: insularity and partisanship during the 2018 Italian election campaign. Information, Communication and Society, 22(11), 1610-1629.

Golebiewski, M., \& Boyd, D. (2018). Data voids: Where missing data can easily be exploited. Data \& Society, 29.

lannelli, L., Splendore, S., Valeriani, A., \& Marino, G. (2020). Studiare la polarizzazione politica nello "shockdown mediale." Mediascapes journal, O(15), 189-202.

Ilardi, E. (2020). L'impero della burocrazia. Una riflessione su istituzioni, emergenza e formazione a partire dall'epidemia di COVID-19. Mediascapes journal, O(15), 108-117.

Jack, C. (2017). Lexicon of Lies: Terms for Problematic Information. Data \& Society. https://datasociety.net/output/lexicon-of-lies/

Lovari, A. (2020). Spreading (dis)trust: Covid-19 misinformation and government intervention in Italy. Media and Communication, 8(2), 458-461.

Lovari, A., \& Righetti, N. (2020). La comunicazione pubblica della salute tra infodemia e fake news: il ruolo della pagina Facebook del Ministero della Salute nella sfida social al Covid-19. Mediascapes journal, O(15), 156-173. 


\section{Appendix l: Methodology}

The MINE-FACTS tool supports the work of fact-checkers and debunkers by surfacing potentially problematic information with a content-agnostic approach. The tool is based on CooRnet (https://coornet.org/), a library developed in $\mathrm{R}^{20}$ - a statistical programming language - that given a set of links detects coordinated link sharing behavior (CLSB) and outputs the network of entities that performed such behavior.

CLSB refers to a specific coordinated activity performed by a network of Facebook pages, groups and verified public profiles (Facebook public entities) that repeatedly share the same news articles in a very short time from each other.

To identify such networks, CooRnet's authors designed, implemented and tested an algorithm that detects sets of Facebook public entities which performed CLSB by (1) estimating a time threshold that identifies URLs shares performed by multiple distinguished entities within an unusually short period of time (as compared to the entire dataset), and (2) grouping the entities that repeatedly shared the same news story within this coordination interval. The rationale is that, while it may be common that several entities share the same URLs, it is unlikely, unless a consistent coordination exists, that this occurs within the time threshold and repeatedly.

The MINE-FACTS tool tracks the posts published by lists of accounts that performed CLSB. The top performing posts of these lists are periodically analyzed to surface problematic posts and links. To sort posts, the tool employs a combination of signals that weighs the CrowdTangle's overperming score of the post with a measure of asymmetry between the sharing and commenting activities related. Backed by the results of previous studies (Giglietto, Valeriani, et al., 2019), this measure ranges from -1 to 1: if the cumulative interactions are composed only by shares, the value of the ratio would be equal to -1 .

Conversely, if the interactions are represented only by comments, its value would be 1 . The combination between the overperforming score and the comments/shares ratio is finally provided by multiplying their values. This sorted list of posts is then sent to the fact-checker (during the testing phase we sent the top 3 ) and performed this process every six hours.

A list of links are then extracted by these overperforming posts and used for a real-time CooRnet interaction. A CooRnet iteration is the process of using the links posted by a set of accounts that performed CLSB to start a new cycle of detection. Iterations may be used to keep a list of coordinated accounts updated over time or to study in depth one specific network. In the latter case only the links posted by a subset of the coordinated accounts initially detected (e.g. one specific cluster) are employed. This process can be repeated until CooRnet outputs a network of coordinated accounts composed of only one component and one cluster ${ }^{21}$.

MINE-FACTS tool thus launches a CooRnet iteration on the links extracted by the top performing posts. If the process detects CLSB on one or more of these links, the list of links are sent to the fact-checker. Additionally, MINE-FACTS tool analyzes the list of coordinated accounts resulting for this iteration and automatically adds newly found

\footnotetext{
${ }^{20}$ CooRnet was ported to python (https://pypi.org/project/pycoornet/) in the context of the Social Media Behaviour project (https://upb-ss1.github.io/) of Universidad Pontificia Bolivariana.

${ }^{21}$ In this report this process has been employed to isolate the four exemplary coordinated networks described in chapter 3.2.
} 
accounts (those not present in the original lists) to the pool of tracked coordinated accounts. In other terms, thanks to this feature, the list of coordinated accounts is dynamically updated over time ${ }^{22}$.

${ }^{22}$ The network described in paragraph 3.2.3. has been detected using this feature. 


\section{Appendix II: Categories of the coding protocol adopted by}

\section{Facta.news}

This appendix briefly describes the categories adopted by Facta.news to classify the posts and links surfaced by the tool during the testing phases. The coding categories and protocol used are in-line to those adopted by Facta.news in their role as Facebook's third-party fact-checkers for Italy ${ }^{23}$. Besides these original categories, the report also employed the following summarized categories: problematic information, non problematic, ineligible or not rated.

\begin{tabular}{|c|c|c|}
\hline Category & Description & Summarized Category \\
\hline True news & $\begin{array}{l}\text { The category includes content that faithfully and } \\
\text { accurately reports the news. }\end{array}$ & Non problematic \\
\hline False news & $\begin{array}{l}\text { The category includes contents that report one } \\
\text { or more false information. }\end{array}$ & Problematic information \\
\hline Inaccurate news & $\begin{array}{l}\text { The category includes content that contains } \\
\text { information in which there is a detail that does } \\
\text { not correspond to the truth. This category } \\
\text { includes contents that do not fully faithfully } \\
\text { report the news given by newspapers and/or } \\
\text { television services (example: lack of } \\
\text { geographical precision, numbers rounded up to } \\
\text { emphasize the narrative, allusion to hypothetical } \\
\text { future events with respect to ongoing } \\
\text { investigations). }\end{array}$ & Problematic information \\
\hline Old news & $\begin{array}{l}\text { The category includes content published before } \\
\text { the project examination period (November } \\
2021 \text { ). The content published in the period prior } \\
\text { to November } 2021 \text { are therefore classified as } \\
\text { "Old news" and are accompanied by an } \\
\text { evaluation that provides information on the } \\
\text { veracity of the contents. }\end{array}$ & Ineligible or not rated \\
\hline Out of context & $\begin{array}{l}\text { The category includes content that has been } \\
\text { taken out of context. The checks that fall into } \\
\text { this category are images and / or videos } \\
\text { extrapolated from their original context; } \\
\text { newspaper articles reported in a way that is not }\end{array}$ & Problematic information \\
\hline
\end{tabular}

${ }^{23}$ See rating options for Facebook's third-party fact-checkers at https://www.facebook.com/business/help/341102040382165?id=673052479947730. 


\begin{tabular}{|c|c|c|}
\hline & $\begin{array}{l}\text { faithful to the original with the addition and / or } \\
\text { removal of entire paragraphs or individual } \\
\text { details; interviews and statements extrapolated } \\
\text { to the original context and inserted in different } \\
\text { narratives than the original. }\end{array}$ & \\
\hline Conspiracy & $\begin{array}{l}\text { The category includes conspiracy-minded } \\
\text { content by themes and / or tones used: that is } \\
\text { news in various ways false or incorrect but } \\
\text { whose main characteristic is to adhere to a } \\
\text { conspiracy-based and conspiracy-based vision } \\
\text { of events. Most of the tests that fall into this } \\
\text { category concern topics such as the pandemic, } \\
\text { the vaccination campaign, } 5 G \text { technology and } \\
\text { conspiracy theories such as the "Big Reset". }\end{array}$ & Problematic information \\
\hline Misleading title & $\begin{array}{l}\text { The category includes journalistic content } \\
\text { whose title is misleading, while reporting exact } \\
\text { information and / or not in line with the tone } \\
\text { used in the title. The so-called "click-catcher" or } \\
\text { "click-bait" content fall into this category. }\end{array}$ & Problematic information \\
\hline Not verifiable & $\begin{array}{l}\text { The category includes content that cannot be } \\
\text { verified by independent fact-checkers. The } \\
\text { checks that fall into this category are the } \\
\text { contents that share and / or report an opinion, } \\
\text { for example politics; interviews (or individual } \\
\text { parts of them) containing information that } \\
\text { cannot be verified on the basis of facts or data; } \\
\text { press reviews made by other journalists or } \\
\text { Facebook pages; Facebook posts and / or } \\
\text { opinion articles; religious content. Sports } \\
\text { content (cheering for a team, success of } \\
\text { individual players, comments during or after a } \\
\text { sporting event) also fall into the category. }\end{array}$ & Ineligible or not rated \\
\hline $\begin{array}{l}\text { Problems } \\
\text { during } \\
\text { verification }\end{array}$ & $\begin{array}{l}\text { The category includes content which, although } \\
\text { verifiable, have not been examined by } \\
\text { Facta.news This category includes contents } \\
\text { whose verification required the opinion of an } \\
\text { expert and / or a body which, when contacted } \\
\text { by the editorial staff of Facta.news.news, did not } \\
\text { provide an answer. }\end{array}$ & Ineligible or not rated \\
\hline $\begin{array}{l}\text { Link not } \\
\text { anymore } \\
\text { available }\end{array}$ & $\begin{array}{l}\text { The category includes contents whose link was } \\
\text { found to be no longer valid at the time of } \\
\text { verification. The single case (as of November 19) } \\
\text { that falls into this category is a Facebook post, } \\
\text { probably removed by its author. }\end{array}$ & Ineligible or not rated \\
\hline
\end{tabular}




\section{Appendix III: IFCN lists of coordinated account and links shared}

IFCN list

\begin{tabular}{|c|c|c|c|}
\hline Accounts & Accounts Type & $\begin{array}{c}\text { Coordinated } \\
\text { Shares }\end{array}$ & $\begin{array}{c}\text { Avg. } \\
\text { Subscriber } \\
\text { Count }\end{array}$ \\
\hline https://www.facebook.com/993133494135040 & Facebook Page & 2 & 111,966 \\
\hline https://www.facebook.com/groups/1546292368988979 & Facebook Group & 5 & 63,369 \\
\hline https://www.facebook.com/groups/671333500080601 & Facebook Group & 5 & 31,798 \\
\hline https://www.facebook.com/groups/2199849466894317 & Facebook Group & 2 & 28,508 \\
\hline https://www.facebook.com/groups/1135510726801903 & Facebook Group & 3 & 21,969 \\
\hline https://www.facebook.com/156506994850085 & Facebook Group & 42 & 21,895 \\
\hline https://www.facebook.com/groups/767223116737784 & Facebook Group & 43 & 16,638 \\
\hline https://www.facebook.com/groups/395864810462818 & Facebook Group & 2 & 16,198 \\
\hline https://www.facebook.com/233694076653209 & Facebook Page & 2 & 15,693 \\
\hline https://www.facebook.com/302677638342 & Facebook Group & 7 & 14,464 \\
\hline https://www.facebook.com/groups/226662881718020 & Facebook Group & 2 & 13,699 \\
\hline https://www.facebook.com/226936397765735 & Facebook Group & 4 & 11,861 \\
\hline https://www.facebook.com/groups/246346472737293 & Facebook Group & 2 & 10,915 \\
\hline https://www.facebook.com/groups/314108895965762 & Facebook Group & 3 & 10,625 \\
\hline https://www.facebook.com/groups/546739728715996 & Facebook Group & 2 & 10,505 \\
\hline https://www.facebook.com/groups/901301826930098 & Facebook Group & 24 & 9,847 \\
\hline https://www.facebook.com/groups/496970383741557 & Facebook Group & 2 & 8,066 \\
\hline https://www.facebook.com/245528502789756 & Facebook Page & 2 & 7,847 \\
\hline https://www.facebook.com/332913046822812 & Facebook Group & 9 & 7,024 \\
\hline https://www.facebook.com/855164184556054 & Facebook Group & 5 & 6,021 \\
\hline https://www.facebook.com/groups/1403647343203313 & Facebook Group & 4 & 5,907 \\
\hline https://www.facebook.com/groups/468589553170287 & Facebook Group & 5 & 5,806 \\
\hline https://www.facebook.com/groups/205676692886588 & Facebook Group & 3 & 5,433 \\
\hline https://www.facebook.com/groups/229249995511 & Facebook Group & 7 & 5,290 \\
\hline https://www.facebook.com/groups/274356496387357 & Facebook Group & 10 & 4,542 \\
\hline https://www.facebook.com/groups/162097880588421 & Facebook Group & 2 & 4,528 \\
\hline https://www.facebook.com/groups/473414249357438 & Facebook Group & 3 & 4,355 \\
\hline https://www.facebook.com/groups/256075332219902 & Facebook Group & 3 & 4,286 \\
\hline https://www.facebook.com/groups/187913741257671 & Facebook Group & 3 & 4,032 \\
\hline https://www.facebook.com/groups/191997130953557 & Facebook Group & 2 & 3,947 \\
\hline
\end{tabular}




\begin{tabular}{|c|c|c|c|}
\hline https://www.facebook.com/groups/282038159324113 & Facebook Group & 2 & 3,862 \\
\hline https://www.facebook.com/groups/488816355274725 & Facebook Group & 2 & 3,512 \\
\hline https://www.facebook.com/groups/283170365202989 & Facebook Group & 2 & 3,475 \\
\hline https://www.facebook.com/groups/527052101559173 & Facebook Group & 2 & 3,095 \\
\hline https://www.facebook.com/groups/124273754251082 & Facebook Group & 3 & 2,834 \\
\hline https://www.facebook.com/groups/881942715204999 & Facebook Group & 6 & 2,792 \\
\hline https://www.facebook.com/groups/250209462807083 & Facebook Group & 7 & 2,718 \\
\hline https://www.facebook.com/571071613344159 & Facebook Group & 13 & 2,631 \\
\hline https://www.facebook.com/348077323923 & Facebook Group & 2 & 2,431 \\
\hline https://www.facebook.com/groups/643054759595697 & Facebook Group & 5 & 2,346 \\
\hline https://www.facebook.com/groups/1626481714331741 & Facebook Group & 2 & 2,198 \\
\hline https://www.facebook.com/117987608214936 & Facebook Group & 2 & 2,190 \\
\hline https://www.facebook.com/groups/854710055000883 & Facebook Group & 2 & 2,184 \\
\hline https://www.facebook.com/101378948011127 & Facebook Page & 2 & 2,137 \\
\hline https://www.facebook.com/groups/229185368228515 & Facebook Group & 8 & 2,089 \\
\hline https://www.facebook.com/groups/234456273898172 & Facebook Group & 2 & 2,010 \\
\hline https://www.facebook.com/groups/188825571175561 & Facebook Group & 2 & 1,972 \\
\hline https://www.facebook.com/groups/1987840154873800 & Facebook Group & 3 & 1,907 \\
\hline https://www.facebook.com/groups/2619348368336202 & Facebook Group & 3 & 1,792 \\
\hline https://www.facebook.com/groups/593809637892001 & Facebook Group & 2 & 1,745 \\
\hline https://www.facebook.com/groups/176080219181436 & Facebook Group & 2 & 1,665 \\
\hline https://www.facebook.com/groups/302273864082316 & Facebook Group & 4 & 1,659 \\
\hline https://www.facebook.com/groups/230274708022639 & Facebook Group & 2 & 1,650 \\
\hline https://www.facebook.com/groups/325390044539695 & Facebook Group & 5 & 1,645 \\
\hline https://www.facebook.com/groups/1409197145804486 & Facebook Group & 4 & 1,563 \\
\hline https://www.facebook.com/121885154590522 & Facebook Group & 2 & 1,552 \\
\hline https://www.facebook.com/groups/185989632435 & Facebook Group & 2 & 1,515 \\
\hline https://www.facebook.com/groups/225992555249084 & Facebook Group & 2 & 1,460 \\
\hline https://www.facebook.com/groups/213620363056991 & Facebook Group & 3 & 1,444 \\
\hline https://www.facebook.com/groups/1148447221846304 & Facebook Group & 3 & 1,298 \\
\hline https://www.facebook.com/groups/1355881671266003 & Facebook Group & 2 & 1,058 \\
\hline https://www.facebook.com/groups/664340773598517 & Facebook Group & 3 & 1,031 \\
\hline https://www.facebook.com/groups/153730921414079 & Facebook Group & 2 & 895 \\
\hline https://www.facebook.com/230678423944319 & Facebook Group & 2 & 690 \\
\hline https://www.facebook.com/262573854236609 & Facebook Group & 4 & 681 \\
\hline
\end{tabular}




\begin{tabular}{|l|l|l|l|}
\hline$\underline{\text { https://www.facebook.com/groups/1707575499460072 }}$ & Facebook Group & 2 & 643 \\
\hline$\underline{\text { https://www.facebook.com/groups/1442694492639611 }}$ & Facebook Group & 2 & 554 \\
\hline$\underline{\text { https://www.facebook.com/groups/1210296982321058 }}$ & Facebook Group & 3 & 351 \\
\hline
\end{tabular}

Top coordinated URLs

\begin{tabular}{|c|c|c|}
\hline URL & $\begin{array}{c}\text { Total } \\
\text { Interactions }\end{array}$ & $\begin{array}{c}\text { Coordinated } \\
\text { Shares }\end{array}$ \\
\hline$\frac{\text { https://www.affaritaliani.it/blog/cose-nostre/covid-19-le-autopsie-non-vanno-fatt }}{\underline{\text { e-ordine-del-ministero-della-salute-671347.html }}}$ & 43,300 & 189 \\
\hline https://www.youtube.com/watch?v=JXW2BNFzAtO & 18,434 & 142 \\
\hline$\frac{\text { https://gazzettadimantova.gelocal.it/mantova/cronaca/2020/05/06/news/scomp }}{\text { arsi-i-profili-facebook-dello-pneumologo-de-donno-1.38811099 }}$ & 42,373 & 134 \\
\hline https://www.youtube.com/watch?v=-ieATrlU4Oo & 6,357 & 98 \\
\hline https://www.youtube.com/watch?v=gROBKBJTk1s & 2,221 & 59 \\
\hline $\begin{array}{l}\text { https://www.lastampa.it/esteri/2020/05/04/news/test-sul-sanque-effettuati-in-gia } \\
\text { ppone-rivela-la-mortalita-da-coronavirus-e-di-gran-lunga-inferiore-all-influenza-1. } \\
\underline{38801430}\end{array}$ & 10,719 & 56 \\
\hline $\begin{array}{l}\text { https://quifinanza.it/soldi/video/dl-rilancio-emendamento-rincari-bollette-codaco } \\
\qquad \underline{\text { ns/390337 }}\end{array}$ & 64,102 & 53 \\
\hline$\frac{\text { https://www.noicontrump.com/dr-fauci-conferma-al-congresso-come-il-vaccino-a }}{\underline{\text { imenta-la-pericolosita-del-coronavirus.html }}}$ & 5,027 & 41 \\
\hline$\frac{\text { https://childrenshealthdefense.org/news/vaccine-trial-catastrophe-moderna-vacc }}{\text { ine-has-20-serious-injury-rate-in-high-dose-group }}$ & 30,342 & 24 \\
\hline$\frac{\text { https://www.tgcom24.mediaset.it/2020/video/paolo-liquori-questo-virus-nasce-i }}{\text { n-un-laboratorio 13934963.shtml }}$ & 7,776 & 20 \\
\hline
\end{tabular}




\section{Appendix VI: Lists of coordinated accounts in the networks analyzed}

This appendix includes five tables that lists some metadata related to all the coordinated accounts included in the cases described in chapter

Meso Level: Case \#1

\begin{tabular}{|c|c|c|}
\hline Accounts & Account Type & $\begin{array}{c}\text { Avg. Subscriber } \\
\text { Count }\end{array}$ \\
\hline$\underline{\text { I sapere e' potere }}$ no dittocrazia & Facebook Page & 56,976 \\
\hline$\underline{\text { TERRA REAL TIME 2 }}$ & Facebook Group & 28,848 \\
\hline$\underline{\text { WAKE UP }}$ & Facebook Page & 14,560 \\
\hline$\underline{\text { Allerta Terra }}$ & Facebook Page & 7,104 \\
\hline$\underline{\text { La Cruna dell'Ago }}$ & Facebook Page & 5,470 \\
\hline$\underline{\text { Lo Strillone Social }}$ & Facebook Group & 4,031 \\
\hline$\underline{\text { Evoluchannel group. Attivisti }}$ & Facebook Group & 3,400 \\
\hline$\underline{\text { La voce della coscienza }}$ & Facebook Group & 3,334 \\
\hline$\underline{\text { Protesta contro il green pass e vaccino e sopra l'aumento di tutto }}$ & Facebook Group & 2,866 \\
\hline$\underline{\text { L'Antibavaglio }}$ & Facebook Group & 2,299 \\
\hline$\underline{\text { Verita' Globale }}$ & Facebook Page & 1,845 \\
\hline$\underline{\text { Covid19 Emergenza Democratica }}$ & Facebook Group & 1,790 \\
\hline
\end{tabular}

Meso Level: Case \#2

\begin{tabular}{|c|c|c|}
\hline Accounts & Account Type & $\begin{array}{c}\text { Avg. } \\
\text { Subscriber } \\
\text { Count }\end{array}$ \\
\hline$\leq 3<3$ Lord Jesus Christ is our Savior $<3<3$ & Facebook Group & 313,706 \\
\hline Carlo Acutis QGruppo di preghiera per i nostri figli e tutti i giovani & Facebook Group & 90,133 \\
\hline Nostra Signora di Lourdes & Facebook Group & 73,987 \\
\hline Maria che scioglie i nodi & Facebook Group & 73,334 \\
\hline$\underline{\text { Ave Maria }}$ & Facebook Group & 72,755 \\
\hline Le parole di Papa Francesco & Facebook Group & 69,386 \\
\hline$\underline{\text { SANTA RITA }}$ & Facebook Group & 58,929 \\
\hline Madonna di Lourdes & Facebook Group & 36,578 \\
\hline MA CHI SONO GLI ANGELI? - GRUPPO CATTOLICO & Facebook Group & 34,029 \\
\hline confido in te & Facebook Group & 23,894 \\
\hline PADRE PIO & Facebook Group & 22,104 \\
\hline
\end{tabular}




\begin{tabular}{|c|c|c|}
\hline Grazie a Dio per la salvezza & Facebook Group & 20,939 \\
\hline LO SPIRITO SANTO - GRUPPO CATTOLICO & Facebook Group & 20,558 \\
\hline MADONNA DI FATIMA & Facebook Group & 19,939 \\
\hline Katolikong Pilipino & Facebook Group & 19,569 \\
\hline LA SPIRITUALITA' DI SAN FRANCESCO - GRUPPO CATTOLICO & Facebook Group & 17,875 \\
\hline Madre Speranza di COLEVALENZA & Facebook Group & 17,463 \\
\hline Amicizia vera e sincera & Facebook Group & 16,122 \\
\hline Grazie a Dio per la salvezza & Facebook Group & 13,609 \\
\hline Figli Spirituali di Papa Francesco & Facebook Group & 11,953 \\
\hline INNAMORATI DI GESÜ E MARIA (FOREVER) & Facebook Group & 11,920 \\
\hline SAN FRANCESCO D'ASSISI & Facebook Group & 11,047 \\
\hline Madonna di Loreto & Facebook Group & 10,514 \\
\hline Gli Amici di San Gerardo Maiella e di San Giovanni Paolo II & Facebook Group & 10,059 \\
\hline A GESÜ PER MARIA & Facebook Group & 8,699 \\
\hline$\underline{\text { II Signore è Dio Stesso }}$ & Facebook Group & 8,380 \\
\hline GRUPPO GOSPA MEDJUGORJE & Facebook Group & 8,320 \\
\hline GRUPPO GUARIGIONE & Facebook Group & 7,961 \\
\hline 9.2.abbraccio di Gesù e Maria & Facebook Group & 7,863 \\
\hline PREGHIERE & Facebook Group & 7,563 \\
\hline Gesù & Facebook Group & 7,153 \\
\hline vergine maria & Facebook Group & 7,049 \\
\hline Gruppo di Padre Michele Vassallo (non ufficiale) & Facebook Group & 6,755 \\
\hline LA REGINA DEL SANTO ROSARIO DI POMPEI & Facebook Group & 6,655 \\
\hline io amo Gesù & Facebook Group & 6,405 \\
\hline Vangelo della vita eterna & Facebook Group & 6,025 \\
\hline Madonna di Medjugorje(Primo gruppo di movimento Facebook) & Facebook Group & 5,757 \\
\hline$\underline{\text { La Cruna dell'Ago }}$ & Facebook Group & 4,036 \\
\hline Dio è l'unica salvezza. & Facebook Group & 3,900 \\
\hline La speciale devozione di Padre Pio per San Michele Arcangelo & Facebook Group & 3,698 \\
\hline II Vangelo di Dio & Facebook Group & 3,414 \\
\hline Devoti Madonna di Fatima & Facebook Group & 3,359 \\
\hline Devoti di S. Michele & Facebook Group & 2,932 \\
\hline$\underline{\text { San Francesco di Paola }}$ & Facebook Group & 2,321 \\
\hline SIGNORE, AIUTAMI A PREGARE & Facebook Group & 2,186 \\
\hline Gruppo di Preghiera & Facebook Group & 2,156 \\
\hline
\end{tabular}




\begin{tabular}{|c|c|c|}
\hline$\underline{\text { Santa Teresa del Bambino Gesù e Volto Santo. }}$ & Facebook Group & 2,140 \\
\hline GESÙ È AMORE A\% & Facebook Group & 1,842 \\
\hline$\underline{\text { IL VERO AMORE DI DIO }}$ & Facebook Group & 1,744 \\
\hline Medjugorie e la Civiltà dell'AMORE & Facebook Group & 1,731 \\
\hline Madonna del Santo Rosario & Facebook Group & 1,617 \\
\hline Liberaci Gesù da ogni male Preghiera di liberazione e guarigione $\bullet$ & Facebook Group & 1,575 \\
\hline Adorazione perpetua & Facebook Group & 1,494 \\
\hline IL SUO NOME E' GESU' & Facebook Group & 1,492 \\
\hline La Perla Preziosa & Facebook Group & 1,492 \\
\hline$\underline{\text { Una preghiera al Padre per le mani di Gesù e di Maria }}$ & Facebook Group & 1,283 \\
\hline Gruppo di preghiera Amici di Padre Pio & Facebook Group & 1,211 \\
\hline Gruppo di preghiera contro il Corona virus & Facebook Group & 880 \\
\hline$\underline{\text { lo sono Gesù il nazareno }}$ & Facebook Group & 766 \\
\hline Medjugorje aspettando... & Facebook Group & 741 \\
\hline$\underline{\text { Viaggio nei ricordi di Padre Pio }}$ & Facebook Group & 719 \\
\hline$\underline{\text { Padre Pio ieri oggi sempre }}$ & Facebook Group & 566 \\
\hline
\end{tabular}

\begin{tabular}{|c|c|c|}
\hline Account & Account Type & $\begin{array}{c}\text { Avg. } \\
\text { Subscriber } \\
\text { Count }\end{array}$ \\
\hline Associazione Nazionale Papaboys & Facebook Page & 307,211 \\
\hline$\underline{\| \text { Vangelo del giorno - a cura dei Papaboys }}$ & Facebook Page & 26,936 \\
\hline$\underline{\text { San Francesco D'Assisi Prega Per Noi }}$ & Facebook Page & 24,942 \\
\hline$\underline{\text { Santa Rita da Cascia prega per noi }}$ & Facebook Page & 24,697 \\
\hline$\underline{\text { W L'italia }}$ & Facebook Page & 14,501 \\
\hline$\underline{\text { Papabovs 3.0 }}$ & Facebook Page & 12,960 \\
\hline
\end{tabular}

Meso Level: Case \#3

\begin{tabular}{|c|c|c|}
\hline Account & Account type & $\begin{array}{c}\text { Avg. } \\
\text { subscriber } \\
\text { count }\end{array}$ \\
\hline Zio Ematitos & Facebook Page & 574,235 \\
\hline Foto che ti daranno fastidio & Facebook Page & 492,104 \\
\hline$\underline{\text { Quello che i TG non dicono }}$ & Facebook Page & 404,669 \\
\hline$\underline{\text { Le più belle frasi }}$ & Facebook Page & 379,089 \\
\hline
\end{tabular}




\begin{tabular}{|c|c|c|}
\hline E fattela na risata & Facebook Page & 320,434 \\
\hline Link Per Tutti Da Condividere & Facebook Page & 283,546 \\
\hline$\approx$ TRA GENIO E FOLLIA $\approx$ & Facebook Page & 226,154 \\
\hline$\underline{\text { link CATTIVI }}$ & Facebook Page & 225,324 \\
\hline Amore, Sesso, Passione. & Facebook Page & 212,945 \\
\hline MALA VITA & Facebook Page & 212,579 \\
\hline Mondo24.it & Facebook Page & 158,226 \\
\hline [AvAnti A TestA AltA ] & Facebook Page & 140,459 \\
\hline$\underline{\text { L'Italia si ribella }}$ & Facebook Page & 132,207 \\
\hline Direttanews24 & Facebook Page & 125,061 \\
\hline$\underline{\text { Italiani uniti per la patria }}$ & Facebook Page & 95,762 \\
\hline Battute deI XXI secolo & Facebook Page & 77,784 \\
\hline$\underline{\text { Video Mondo24 }}$ & Facebook Page & 75,087 \\
\hline Prima aiutiamo gli Italiani poi si vede. - Movimento Adesso Italia & Facebook Page & 59,325 \\
\hline$\underline{\text { L'Angolo della Risata }}$ & Facebook Page & 58,241 \\
\hline Mai Na Gioia & Facebook Page & 55,607 \\
\hline Notizie Italiane & Facebook Page & 53,982 \\
\hline$\underline{\text { M5S Fanpage }}$ & Facebook Page & 42,646 \\
\hline$\underline{\text { LaStronza }}$ & Facebook Page & 38,979 \\
\hline La Guerriera & Facebook Page & 36,255 \\
\hline$\underline{\text { Corriere della notizia }}$ & Facebook Page & 32,808 \\
\hline$\underline{\| \text { Puntiglioso }}$ & Facebook Page & 32,695 \\
\hline$\underline{\text { Riprendiamoci La Patria }}$ & Facebook Page & 32,519 \\
\hline Adesso Italia & Facebook Page & 25,793 \\
\hline$\underline{\text { Viva La Patria }}$ & Facebook Page & 21,383 \\
\hline Dislessia Portami Via. & Facebook Page & 15,850 \\
\hline$\underline{\text { Screenshots divertenti }}$ & Facebook Page & 12,854 \\
\hline
\end{tabular}

Meso Level: Case \#4

\begin{tabular}{|c|c|c|}
\hline Account & Account Type & $\begin{array}{c}\text { Avg. } \\
\text { Subscriber } \\
\text { Count }\end{array}$ \\
\hline Grande Cocomero Classic & Facebook Page & 309.641 \\
\hline Liberi e Indipendenti & Facebook Page & 121.202 \\
\hline
\end{tabular}




\begin{tabular}{|c|c|c|}
\hline Sergio Mattarella Non è il Mio Presidente & Facebook Page & 33.434 \\
\hline$\underline{\text { Italia Sovrana e fuori dall'Europa }}$ & Facebook Page & 28.472 \\
\hline$\underline{\text { Capra News }}$ & Facebook Page & 25.984 \\
\hline$\underline{\text { Presidente Trump Fan Club Italia }}$ & Facebook Page & 11.464 \\
\hline Amo la mia Italia & Facebook Page & 9.813 \\
\hline
\end{tabular}




\section{Appendix V: Most popular Italian news stories on Facebook (Feb/June 2020)}

Meta's URL Shares Dataset employs differential privacy. We thus report the max and min value for each metric intended as the upper and lower bound of a $95 \%$ confidence interval. In other terms we are $95 \%$ sure that the URL has been viewed/clicked/etc by a number of users included in the interval. In other terms, for each link we could say with $95 \%$ confidence that the number reported is within the interval.

Views

\begin{tabular}{|c|c|c|c|c|c|}
\hline & URL & Tpfc Rating & Views & Max & Min \\
\hline$\# 1$ & $\begin{array}{l}\text { Coronavirus, l'esperto americano di } \\
\text { bioterrorismo: "Creato in laboratorio, è un'arma } \\
\text { da querra biologica" - Tgcom24 }\end{array}$ & opinion & $15,383,307$ & $15,428,054$ & $15,338,560$ \\
\hline$\# 2$ & $\begin{array}{l}\text { Patente, revisione, collaudo: il decreto Cura Italia } \\
\text { e le altre novità per l'auto - Quattroruote.it }\end{array}$ & NA & $14,203,243$ & $14,243,266$ & $14,163,220$ \\
\hline \#3 & $\begin{array}{l}\text { Togliere le scarpe in casa tiene fuori } 400 \text { mila } \\
\text { batteri (meningite, polmonite) }\end{array}$ & NA & $13,575,884$ & $13,620,631$ & $13,531,137$ \\
\hline \#4 & Coronavirus, dentro il reparto di terapia intensiva & NA & $13,368,081$ & $13,408,104$ & $13,328,058$ \\
\hline \#5 & $\begin{array}{l}\| \text { rianimatore: "Se stessimo tutti a casa il } \\
\text { Coronavirus si fermerebbe in } 15 \text { giorni" } \\
\text { Globalist }\end{array}$ & NA & $12,589,439$ & $12,629,462$ & $12,549,416$ \\
\hline \#6 & $\begin{array}{l}\text { Reti } 5 G \text { e salute, la paura ferma lo sviluppo in } \\
\text { Svizzera | TechRadar }\end{array}$ & NA & $12,178,705$ & $12,223,452$ & $12,133,958$ \\
\hline \#7 & $\begin{array}{l}\text { Sull'ambulanza a Bergamo con Marco e Roberto: } \\
\text { "Dopo } 8 \text { notti la paura del buio" | L'HuffPost }\end{array}$ & NA & $12,163,331$ & $12,191,632$ & $12,135,030$ \\
\hline \#8 & $\begin{array}{l}\text { Diodato - Fai Rumore (Video Ufficiale) [Sanremo } \\
\underline{2020]}\end{array}$ & NA & $12,153,232$ & $12,197,979$ & $12,108,485$ \\
\hline \#9 & 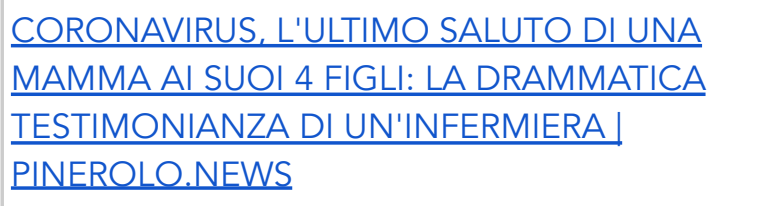 & NA & $11,787,882$ & $11,827,905$ & $11,747,859$ \\
\hline \#10 & $\begin{array}{l}\text { Francesco Gabbani - Viceversa (Official Music } \\
\text { Video) - Sanremo } 2020\end{array}$ & NA & $11,717,433$ & $11,762,180$ & $11,672,686$ \\
\hline
\end{tabular}

Clicks

\begin{tabular}{|c|c|c|c|c|c|}
\hline & URL & Tpfc Rating & Views & Max & Min \\
\hline$\# 1$ & $\begin{array}{l}\text { Coronavirus, dentro il reparto di terapia } \\
\text { intensiva }\end{array}$ & NA & $3,169,093$ & $3,169,812$ & $3,168,374$ \\
\hline$\# 2$ & $\begin{array}{l}\text { Coronavirus, l'esperto americano di } \\
\underline{\text { bioterrorismo: "Creato in laboratorio, è }} \\
\text { un'arma da guerra biologica" - Tgcom24 }\end{array}$ & opinion & $2,898,334$ & $2,899,137$ & $2,897,531$ \\
\hline
\end{tabular}




\begin{tabular}{|c|c|c|c|c|c|}
\hline \#3 & $\begin{array}{l}\text { CORONAVIRUS, L'ULTIMO SALUTO DI UNA } \\
\text { MAMMA AI SUOI } 4 \text { FIGLI: LA DRAMMATICA } \\
\text { TESTIMONIANZA DI UN'INFERMIERA } \\
\text { PINEROLO.NEWS }\end{array}$ & NA & $1,930,360$ & $1,931,079$ & $1,929,641$ \\
\hline$\# 4$ & $\begin{array}{l}\text { https://www.youtube.com/watch?v=4cX7PJbV } \\
\underline{4 \mathrm{qs}}\end{array}$ & NA & $1,614,928$ & $1,615,550$ & $1,614,306$ \\
\hline \#5 & $\begin{array}{l}\text { Coronavirus, bollette sospese per } 2 \text { mesi. Stop } \\
\text { anche al canone Rai - II Sole } 24 \text { ORE }\end{array}$ & NA & $1,526,933$ & $1,527,736$ & $1,526,130$ \\
\hline \#6 & $\begin{array}{l}\text { La bozza del nuovo decreto: misure restrittive } \\
\text { prorogabili fino al } 31 \text { luglio }\end{array}$ & NA & $1,493,954$ & $1,494,673$ & $1,493,235$ \\
\hline \#7 & 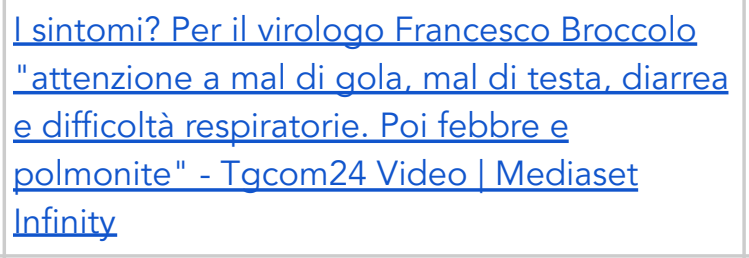 & NA & $1,388,869$ & $1,389,588$ & $1,388,150$ \\
\hline$\# 8$ & $\begin{array}{l}\text { L'ultimo messaggio del } 18 \text { enne Mattia prima } \\
\text { di essere intubato: "Non ti lascio, lotterò per } \\
\text { te" - ilGiornale.it }\end{array}$ & NA & $1,387,945$ & $1,388,664$ & $1,387,226$ \\
\hline \#9 & $\begin{array}{l}\text { Coronavirus, direttrice laboratorio Sacco: } \\
\text { Stiamo scambiando un'influenza per una } \\
\text { pandemia globale }\end{array}$ & $\begin{array}{l}\text { fact } \\
\text { checked as } \\
\text { true }\end{array}$ & $1,383,605$ & $1,384,408$ & $1,382,802$ \\
\hline$\# 10$ & $\begin{array}{l}\text { Coronavirus: "Sappiamo guarirlo", annuncio } \\
\text { del virologo francese }\end{array}$ & NA & $1,382,905$ & $1,383,624$ & $1,382,186$ \\
\hline
\end{tabular}

Shares

\begin{tabular}{|c|c|c|c|c|c|}
\hline & URL & Tpfc Rating & Views & Max & Min \\
\hline \#1 & $\begin{array}{l}\| \text { rianimatore: "Se stessimo tutti a casa il } \\
\text { Coronavirus si fermerebbe in } 15 \text { giorni" } \\
\text { Globalist }\end{array}$ & NA & 236,245 & 236,496 & 235,994 \\
\hline$\# 2$ & $\begin{array}{l}\text { Coronavirus, dentro il reparto di terapia } \\
\text { intensiva }\end{array}$ & NA & 187,088 & 187,339 & 186,837 \\
\hline \#3 & $\begin{array}{l}\text { https://www.youtube.com/watch?v=JXW2BNF } \\
\underline{\text { zAtO }}\end{array}$ & NA & 183,798 & 184,016 & 183,580 \\
\hline$\# 4$ & $\begin{array}{l}\text { "Condividete l'appello per ritrovare il mio } \\
\text { cane Otto" - Rieti Life }\end{array}$ & NA & 176,753 & 176,971 & 176,535 \\
\hline$\# 5$ & $\begin{array}{l}\text { https://www.youtube.com/watch?v=D5DhJS5h } \\
\text { GWc }\end{array}$ & $\begin{array}{l}\text { fact } \\
\text { checked as } \\
\text { true }\end{array}$ & 167,798 & 168,049 & 167,547 \\
\hline \#6 & $\begin{array}{l}\text { Reti } 5 \mathrm{G} \text { e salute, la paura ferma lo sviluppo in } \\
\text { Svizzera | TechRadar }\end{array}$ & NA & 165,595 & 165,876 & 165,314 \\
\hline \#7 & $\begin{array}{l}\text { Diodato - Fai Rumore (Video Ufficiale) } \\
\text { [Sanremo 2020] }\end{array}$ & NA & 143,473 & 143,754 & 143,192 \\
\hline
\end{tabular}




\begin{tabular}{|c|c|c|c|c|c|}
\hline \#8 & $\begin{array}{l}\text { "Bambini e anziani non devono uscire, stiamo } \\
\text { vedendo i primi risultati. Rischio di vanificare } \\
\text { gli sforzi" - Libertà Piacenza }\end{array}$ & NA & 143,319 & 143,570 & 143,068 \\
\hline \#9 & $\begin{array}{l}\text { Coronavirus, l'esperto americano di } \\
\text { bioterrorismo: "Creato in laboratorio, è } \\
\text { un'arma da guerra biologica" - Tgcom24 }\end{array}$ & opinion & 138,150 & 138,431 & 137,869 \\
\hline \#10 & $\begin{array}{l}\text { https://www.torinotoday.it/politica/referendum } \\
\text {-taglio-parlamentari-29-marzo-2020.html }\end{array}$ & NA & 132,743 & 133,024 & 132,462 \\
\hline
\end{tabular}

Shares without clicks

\begin{tabular}{|c|c|c|c|c|c|}
\hline & URL & Tpfc Rating & Views & Max & Min \\
\hline \#1 & $\begin{array}{l}\frac{\text { https://www.qlobalist.it/science/2020/03/09/il-r }}{\text { ianimatore-se-stessimo-tutti-a-casa-il-coronavir }} \\
\text { us-si-fermerebbe-in-15-giorni-2054212.html }\end{array}$ & NA & 183,261 & 183,441 & 183,081 \\
\hline \#2 & $\begin{array}{l}\text { http://www.rietilife.com/2020/04/30/condividet } \\
\text { e-lappello-per-ritrovare-il-mio-cane-otto/ }\end{array}$ & NA & 147,056 & 147,212 & 146,900 \\
\hline \#3 & $\begin{array}{l}\text { https://global.techradar.com/it-it/news/la-svizze } \\
\text { ra-blocca-le-nuove-antenne-5g-per-rischi-di-sal } \\
\underline{\text { ute }}\end{array}$ & NA & 142,089 & 142,290 & 141,888 \\
\hline \#4 & $\begin{array}{l}\text { https://www.youtube.com/watch?v=D5DhJS5h } \\
\underline{\text { GWc }}\end{array}$ & $\begin{array}{l}\text { fact } \\
\text { checked as } \\
\text { true }\end{array}$ & 129,778 & 129,958 & 129,598 \\
\hline \#5 & $\begin{array}{l}\text { https://www.torinotoday.it/politica/referendum- } \\
\text { taglio-parlamentari-29-marzo-2020.html }\end{array}$ & NA & 116,081 & 116,282 & 115,880 \\
\hline \#6 & $\begin{array}{l}\text { https://www.youtube.com/watch?v=tPv9ZPXm } \\
\text { FWU }\end{array}$ & NA & 112,293 & 112,494 & 112,092 \\
\hline \#7 & $\begin{array}{l}\text { https://www.liberta.it/breaking-news/2020/03/3 } \\
\text { 1/biasucci-bambini-e-anziani-non-devono-uscir } \\
\text { e-stiamo-vedendo-i-primi-risultati-rischio-di-van } \\
\text { ificare-gli-sforzi/ }\end{array}$ & NA & 101,806 & 101,986 & 101,626 \\
\hline$\# 8$ & $\begin{array}{l}\text { https://www.fanpage.it/attualita/arrivano-in-itali } \\
\frac{\text { a-medici-cinesi-esperti-nella-lotta-al-coronaviru }}{\text { s-vi-aiuteremo-a-combatterlo/ }}\end{array}$ & NA & 97,487 & 97,667 & 97,307 \\
\hline \#9 & $\begin{array}{l}\text { https://www.youtube.com/watch?v=cNoylMSX } \\
\text { YCE }\end{array}$ & NA & 96,121 & 96,322 & 95,920 \\
\hline \#10 & $\begin{array}{l}\text { https://www.oltre.tv/togliere-le-scarpe-casa-bat } \\
\text { teri-meningite/ }\end{array}$ & NA & 95,590 & 95,791 & 95,389 \\
\hline
\end{tabular}

\section{Comments}

\begin{tabular}{|c|c|c|c|c|c|}
\hline & URL & Tpfc Rating & Views & Max & Min \\
\hline \multirow{2}{*}{$\# 1$} & https://www.liberoquotidiano.it/sondaggi/polit & fact & 236,088 & 236,244 & 235,932 \\
\hline
\end{tabular}




\begin{tabular}{|c|c|c|c|c|c|}
\hline & $\begin{array}{l}\text { ica/22309241/giuseppe conte voi andreste p } \\
\text { iazza manifestare.html }\end{array}$ & $\begin{array}{l}\text { checked as } \\
\text { true }\end{array}$ & & & \\
\hline \#2 & $\begin{array}{l}\text { https://www.youtube.com/watch?v=JXW2BNF } \\
\text { zAtQ }\end{array}$ & NA & 133,348 & 133,504 & 133,192 \\
\hline \#3 & $\begin{array}{l}\text { https://www.repubblica.it/esteri/2020/03/13/n } \\
\text { ews/coronavirus una_scusa_per_ali_italiani_pe } \\
\text { r non fare niente il commento infelice di u } \\
\text { n presentatore britannico-251192061/ }\end{array}$ & NA & 130,287 & 130,467 & 130,107 \\
\hline \#4 & $\begin{array}{l}\text { https://www.rassegnastampa.eu/politica/sond } \\
\text { aggio-favorevole-o-contrario-a-uscire-dalleuro/ }\end{array}$ & NA & 126,575 & 126,755 & 126,395 \\
\hline \#5 & $\begin{array}{l}\text { https://www.notizie.it/esteri/2020/02/13/don-b } \\
\text { ucci-polemica/ }\end{array}$ & NA & 117,797 & 117,998 & 117,596 \\
\hline \#6 & $\begin{array}{l}\frac{\text { https://www.adnkronos.com/fatti/politica/2020 }}{\text { /03/21/coronavirus-zingaretti-senza-europa-no }} \\
\text { n-avremmo-mai-fatta_jaYYd25Q7UdhNRzTJa } \\
\underline{\text { QwRM.html }}\end{array}$ & NA & 113,674 & 113,854 & 113,494 \\
\hline \#7 & $\begin{array}{l}\frac{\mathrm{https}: / / \text { www. }}{\text { ws/31229manista.eu/football-please/ne }} \\
\text { e-i-calciatori-si-potrebbe-giocare-a-maggio- }\end{array}$ & NA & 112,856 & 113,036 & 112,676 \\
\hline \#8 & $\frac{\text { http://www.ansa.it/sito/videogallery/italia/202 }}{\frac{\text { o/03/07/coronavirus-i-milanesi-affollano-i-navi }}{\text { gli-non-possono-impedirci-di-stare-a-casa_84a }}}$ & NA & 108,270 & 108,450 & 108,090 \\
\hline \#9 & $\begin{array}{l}\text { https://www.corriere.it/spettacoli/20_maqgio } \\
\text { 15/morto-ezio-bosso-pianista-che-sapeva-com } \\
\text { muovere-aveva-48-anni-bc5dc824-967b-11ea- } \\
\text { a66c-1f6181297d24.shtml }\end{array}$ & NA & 107,757 & 107,884 & 107,630 \\
\hline \#10 & $\begin{array}{l}\text { https://video.repubblica.it/dossier/coronavirus } \\
\text {-wuhan-2020/coronavirus-milano-folla-ai-navial } \\
\begin{array}{l}\text { i-all-ora-dell-aperitivo-e-poche-mascherine/35 } \\
9851 / 360404\end{array}\end{array}$ & NA & 105,478 & 105,605 & 105,351 \\
\hline
\end{tabular}

